\title{
Entrepreneurial initiatives at public liberal arts and general baccalaureate colleges
}

Jack R. Kirby

West Virginia University

Follow this and additional works at: https://researchrepository.wvu.edu/etd

\section{Recommended Citation}

Kirby, Jack R., "Entrepreneurial initiatives at public liberal arts and general baccalaureate colleges" (2005). Graduate Theses, Dissertations, and Problem Reports. 2649.

https://researchrepository.wvu.edu/etd/2649

This Dissertation is protected by copyright and/or related rights. It has been brought to you by the The Research Repository @ WVU with permission from the rights-holder(s). You are free to use this Dissertation in any way that is permitted by the copyright and related rights legislation that applies to your use. For other uses you must obtain permission from the rights-holder(s) directly, unless additional rights are indicated by a Creative Commons license in the record and/ or on the work itself. This Dissertation has been accepted for inclusion in WVU Graduate Theses, Dissertations, and Problem Reports collection by an authorized administrator of The Research Repository @ WVU.

For more information, please contact researchrepository@mail.wvu.edu. 
Entrepreneurial Initiatives

At Public Liberal Arts and General Baccalaureate Colleges

Jack R. Kirby

Dissertation submitted to the

College of Human Resources and Education

at West Virginia University

in partial fulfillment of the requirements

for the degree of

Doctor of Education

In

Educational Leadership Studies

Ernest Goeres, Ph.D., Chair

Randyl Elkin, Ph.D.

Richard Hartnett, Ed.D.

Jon Reed, J.D.

Rebecca Schaupp, Ed.D.

Department of Advanced Educational Studies

Morgantown, West Virginia

2005

Key Words: entrepreneurship, public liberal arts, general baccalaureate, president, higher education, state appropriations

Copyright 2005 Jack R. Kirby 


\begin{abstract}
Entrepreneurial Initiatives

At Public Liberal Arts and General Baccalaureate Colleges
\end{abstract}

Jack R. Kirby

Until recent years, the concept of entrepreneurship has been the subject of study and application primarily in the private sector business community. However, in the wake of decreasing traditional sources of funding, higher operating costs, increasing government intervention, and institutional initiatives, entrepreneurship has gained increasing attention in public higher education (Elford \& Hemstreet, 1996; Keast, 1995; Kozeracki, 1998).

This study examined the current patterns of entrepreneurial activities in public liberal arts and general baccalaureate colleges as defined by the Carnegie Classification of Institutions of Higher Education (The Carnegie Foundation for the Advancement of Teaching, 2000). A survey instrument was prepared to determine what kinds of entrepreneurial initiatives were being used by these institutions and what level of success was being experienced. The study further examined the relationships between the level of entrepreneurial activity, the success of the entrepreneurial initiatives, and numerous institutional variables. The survey instrument was mailed to the institution's president. The entire population of seventy-five public higher education institutions was surveyed with a response rate of 37 percent.

This study provided much needed data regarding the types of traditional and entrepreneurial initiatives being used at four-year colleges and universities and which ones are proving successful. The respondent institutions reported increasing tuition and fees, using college/university foundations, and distance-learning within the existing organizational structure as having the highest levels of success, with over eighty percent of the institutions using these three initiatives to generate revenue. Of equal importance is the finding that the least successful initiatives were technology transfer centers, spinoff companies, distance-learning programs in partnership with private sector enterprise, and distance-learning programs as for-profit subsidiaries, with only 3.6 percent of the respondent institutions using these initiatives.

Significant relationships were found between the level of entrepreneurial activity and the level of success of the entrepreneurial initiatives with the number of full-time faculty, changes in state appropriations, and changes in the purpose and/or mission of the institution to encourage entrepreneurial endeavors.

The study also includes recommendations for practice and recommendations for further study. 


\section{ACKNOWLEDGEMENTS}

I wish to acknowledge and express my deepest gratitude to all of my friends, colleagues, associates, and family members who gave me unending encouragement and support throughout the entire process of completing my doctorate.

First, I want to thank the members of my doctoral committee. I extend my deepest and most heartfelt thanks to my committee chair, Dr. Ernest Goeres. He guided me through the process with constant encouragement, unending patience, meticulous review and a professional expertise that can only come from years of experience and remarkable intellect.

Dr. Randyl Elkin, who represented my minor area of study, has been a professor and mentor to me throughout my graduate education. He never gave up on me through all the years and I cannot thank him enough for his continued encouragement and support.

Dr. Richard Hartnett has always had my greatest admiration and respect as one of the best professors I was privileged to study under in class. I was extremely fortunate to have him on my committee and benefit from his immense knowledge and insight.

Dr. Jon Reed has my deepest appreciation for agreeing to participate on my committee and his eye for detail sharpened the focus of my study.

Dr. Larry Stead has my unending gratitude for agreeing, at the last minute, to assist in the final examination of my study.

There is simply no way to adequately express my appreciation to Dr. Rebecca Schaupp. Her friendship, guidance and encouragement sustained my confidence. I found energy through her enthusiasm and strength through her steadfast support. 
Next, I to extend my deepest thanks to Dr. Craig White, Dr. Mohamad Khalil, and Dr. Clarence Rohrbaugh for all of their professional expertise and assistance with the statistical analysis.

I would also like to extend my appreciation to Michael Oliverio for his hard work and diligence assisting me in gathering secondary data for the study.

I dedicate this dissertation to my loving wife for her unwavering support and confidence in me. She unselfishly offered her encouragement, even when it meant enduring many evenings and weekends of my absence as I worked in my office.

Finally, I thank God for being with me every step of the way. Let Him receive all the praise and glory. 


\section{TABLE OF CONTENTS}

Chapter

Page

I. INTRODUCTION ............................................................. 1

Background and Rationale........................................... 1

Decreases in Traditional Funding Sources ........................ 1

State Support................................................. 3

Federal Support ............................................. 6

Societal and Economic Influences .................................. 7

Global Influences ....................................................... 11

Market-Driven Demands on Higher Education .................. 12

Defining Entrepreneurship in Higher Education ................ 14

Types of Entrepreneurial Responses................................ 16

Purpose of the Study ................................................ 20

Significance of the Study ........................................... 24

Definition of Terms.................................................... 26

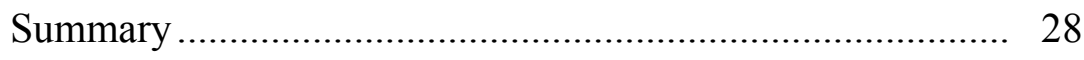

II. REVIEW OF THE LITERATURE ............................................ 29

Entrepreneurial Issues in Higher Education ..................... 29

Declining Traditional Support ...................................... 29

Defining Entrepreneurship......................................... 38

Describing Entrepreneurs........................................... 39

The Entrepreneurial Process ......................................... 42 
Organizational Forms................................................. 44

Entrepreneurial Responses in Higher Education ................. 47

III. RESEARCH DESIGN ................................................... 59

Methodology ............................................................. 59

Population ........................................................ 59

Data Collection ............................................... 59

Survey Instrument........................................... 60

Response Rate ................................................... 61

Analysis of Data.................................................. 62

Limitations of the Study..................................... 69

Proposed Time Lines ............................................ 69

Background of the Researcher ............................... 69

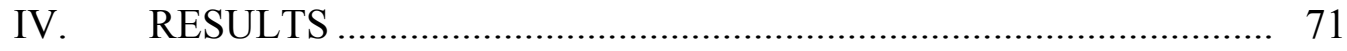

Introduction............................................................. 71

Survey Response and Data Collection .............................. 71

Data Analysis .......................................................... 72

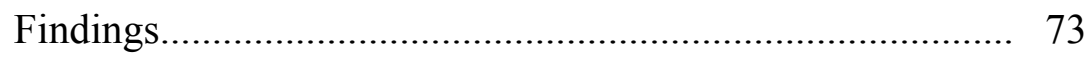

Research Question 1: To what extent do these institutions generate revenue through entrepreneurial initiatives?.................................... 73

Research Question 2: Is there a relationship between the number of entrepreneurial initiatives and the following factors:

The number of years the president/chancellor has been in current position? 
The field of study or discipline of the president/chancellor?

The business/industry experience of the institution's president/chancellor?

The institution's enrollment?

An increase or decrease in enrollment from the previous year?

The institution's tuition, both in-state and out-of-state?

An increase or decrease in tuition from previous year?

The number of faculty, both full-time and part-time?

The number of tenure track and non-tenure track faculty? 106

An increase or decrease in full-time faculty, both tenure track and non-tenure track, from the previous year?

An increase or decrease in full-time tenure track faculty from the previous year?

An increase or decrease in part-time faculty from the previous year?

The highest degree offered at the institution?

The addition or elimination or programs for teaching, research, and service since the previous year?

An increase or decrease in state appropriations from the previous year? 116

Whether the governing board encourages or discourages entrepreneurial activities to generate revenue? 
The number of programs supported by generating their own revenue?

Administrative and/or organizational changes

during the president's/chancellor's tenure?

Whether faculty are formally encouraged to pursue innovative and entrepreneurial activities?

Whether merit pay or other reward systems are used to encourage faculty to pursue innovative and entrepreneurial activities?

Whether the institution's purpose and/or mission has been changed to reflect greater emphasis on entrepreneurial activities?

Whether faculty or staff ate represented by a union?

Question 2 Summary....

Research Question 3: What entrepreneurial institutional initiatives are proving successful in terms of generating revenue for these institutions? ... 135

Research Question 4: Is there a relationship Between the number of successful entrepreneurial Initiatives and the following factors:

The number of years the president/chancellor has been in current position?

The field of study or discipline of the president/chancellor?

The business/industry experience of the institution's president/chancellor?

The institution's enrollment?

An increase or decrease in enrollment from the previous year? 
The institution's tuition, both in-state and out-of-state?

An increase or decrease in tuition from previous year?

The number of faculty, both full-time and part-time?

The number of tenure track and non-tenure track faculty?

An increase or decrease in full-time faculty, both tenure track and non-tenure track, from the previous year?

An increase or decrease in full-time tenure track faculty from the previous year?

An increase or decrease in part-time faculty from the previous year?

The highest degree offered at the institution?...... 164

The addition or elimination or programs for teaching, research, and service since the previous year?

An increase or decrease in state appropriations from the previous year?

Whether the governing board encourages or discourages entrepreneurial activities to generate revenue?

The number of programs supported by generating their own revenue?

Administrative and/or organizational changes during the president's/chancellor's tenure?

Whether faculty are formally encouraged to pursue innovative and entrepreneurial activities? 
Whether merit pay or other reward systems are used to encourage faculty to pursue innovative and entrepreneurial activities?

Whether the institution's purpose and/or mission has been changed to reflect greater emphasis on entrepreneurial activities?

Whether faculty or staff are represented by a union?

Question 4 Summary.....

Research Question 5: What impact have entrepreneurial initiatives had on institutional mission, purpose and academic integrity?

Research Question 6: Does the institution's governing board/body encourage or discourage entrepreneurial initiatives to generate revenue?

Comparison of Institutional Data for the Population with Institutional Data for the Respondent Institutions

Enrollment Data ................................................ 182

Tuition Data ..................................................... 183

Faculty Data .................................................... 185

Highest Degree Offered Data................................ 187

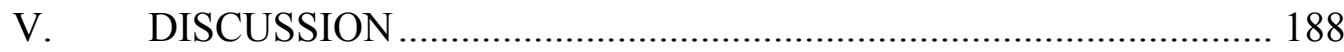

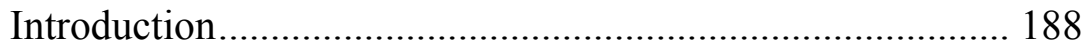

Interpretation of Findings ................................................... 188

Questions $1 \&$ 3: To what extent do these institutions generate revenue through entrepreneurial initiatives and what entrepreneurial institutional initiatives are proving successful in terms of generating revenue for these institutions? 
Questions 2 \& 4: Is there a relationship between the number of entrepreneurial initiatives and the number of successful entrepreneurial initiatives and the following factors:

The number of years the president/chancellor has been in current position?

The field of study or discipline of the president/chancellor?

The business/industry experience of the institution's president/chancellor?

The institution's enrollment?

An increase or decrease in enrollment from the previous year?

The institution's tuition, both in-state and out-of-state?

An increase or decrease in tuition from previous year?

The number of faculty, both full-time and part-time?

The number of tenure track and non-tenure track faculty?

An increase or decrease in full-time faculty, both tenure track and non-tenure track, from the previous year?

An increase or decrease in full-time tenure track faculty from the previous year?

An increase or decrease in part-time faculty from the previous year?

The highest degree offered at the institution?...... 202

The addition or elimination or programs for teaching, research, and service since the previous year? 
An increase or decrease in state appropriations from the previous year?

Whether the governing board encourages or discourages entrepreneurial activities to generate revenue?

The number of programs supported by generating their own revenue?

Administrative and/or organizational changes during the president's/chancellor's tenure?

Whether faculty are formally encouraged to pursue innovative and entrepreneurial activities?

Whether merit pay or other reward systems are used to encourage faculty to pursue innovative and entrepreneurial activities?

Whether the institution's purpose and/or mission has been changed to reflect greater emphasis on entrepreneurial activities?

Whether faculty or staff ate represented by a union?

Research Question 5: What impact have entrepreneurial initiatives had on institutional mission, purpose and academic integrity?

Research Question 6: Does the institution's governing board/body encourage or discourage entrepreneurial initiatives to generate revenue?

Recommendations for Practice

Recommendations for Further Study

APPENDIX A: Carnegie Classification of Institutions

Of Higher Education 
APPENDIX B: Entrepreneurial Initiatives Survey ........................ 238

APPENDIX C: Initial Letter........................................................... 241

APPENDIX D: Cover Letter for Survey Instrument ...................... 242

APPENDIX E: Follow-up Letter ............................................... 243

APPENDIX F: Contact Information for Survey Recipients ............. 244 


\section{LIST OF TABLES}

Table 1, Data Analysis Plan ......................................................................... 63

Table 2, Entrepreneurial Initiatives Level of Use .......................................... 73

Table 3, Rank Order Listing of Number of Institutions Currently Using Each Entrepreneurial Initiative ........................................................... 78

Table 4, Number of New Initiatives Used by Respondent Institutions ................. 81

Table 5, Number of Traditionally Used Initiatives Reported by Respondent Institutions

Table 6, Distribution of Initiatives Planned for the Future Reported by Respondent Institutions..................................................... 84

Table 7, Entrepreneurial Scores .............................................................. 86

Table 8, Cross Tabulation of High and Low Entrepreneurial Scores with President's/Chancellor's Length of Time in Current Position................. 88

Table 9, Field of Study or Discipline of the President/Chancellor ....................... 91

Table 10, Enrollments for Full-Time and Part-time Undergraduate Students and Full-Time and Part-Time Graduate Students for Respondent Institutions ......

Table 11, In-State and Out-of-State Tuition Reported by Respondent Institutions. 97

Table 12, Changes in In-State and Out-of-State Tuition ..................................... 100

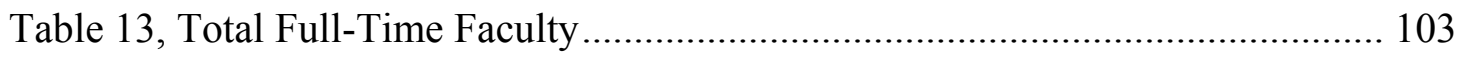

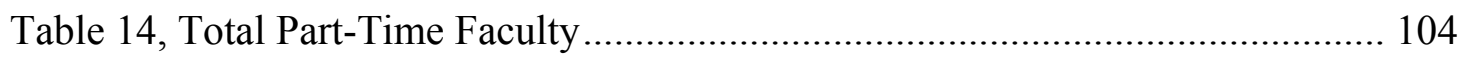

Table 15, Total Full-Time Tenure Track Faculty …............................................ 107 
Table 16. Total Full-Time Non-Tenure Track Faculty ......................................... 108

Table 17. Program Additions and Eliminations...................................................... 114

Table 18. State Appropriations ..................................................................... 116

Table 19. Cross Tabulation of High and Low Entrepreneurial

Scores and State Appropriations ..................................................... 117

Table 20. Governing Board Support for Entrepreneurial Activities........................ 118

Table 21. Programs Generating Own Revenue................................................. 119

Table 22. Types of Programs Identified as Generating

a Portion of Their Own Revenue ......................................................... 120

Table 23. Administrative and/or Organizational Changes................................... 121

Table 24. Level of Institutional Support for Faculty Entrepreneurship................... 125

Table 25. Reward Systems Used to Encourage Faculty

Entrepreneurial Activities ................................................................ 126

Table 26. Change in Institution's Purpose or Mission.......................................... 129

Table 27. Are Faculty Represented by a Union? ............................................... 131

Table 28. Are Staff Represented by a Union? .................................................. 132

Table 29. Relationship between the Number of Entrepreneurial Initiatives

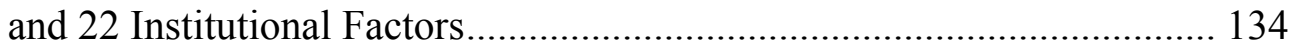

Table 30. Level of Success for New Initiatives and Traditionally

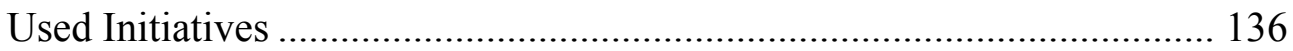

Table 31 Rank Ordered Success Scores for Each Entrepreneurial Initiative............ 141

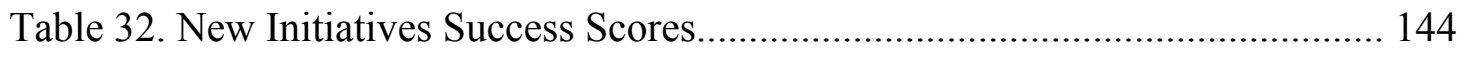

Table 33. Traditionally Used Initiatives Success Scores .................................... 146 


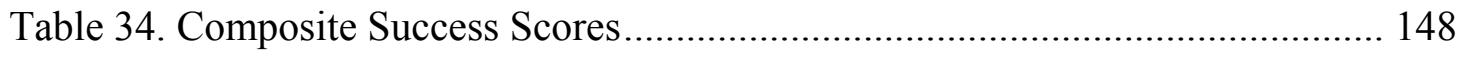

Table 35. Relationship between the Number of Successful Entrepreneurial Initiatives and 22 Institutional Factors............................................ 177

Table 36. Downsides to Entrepreneurial Programs or Activities ........................... 180

Table 37. Enrollment for Full-Time and Part-Time Undergraduate Students and Full-Time and Part-Time Graduate Students for Population ............. 182

Table 38. In-State and Out-of-State Tuition for Population ................................. 184

Table 39. Total Full-Time Faculty for the Population......................................... 185

Table 40. Total Part-Time Faculty for Population............................................... 185

Table 41. Total Full-Time Tenure Track Faculty for Population .......................... 186

Table 42. Total Full-Time Non-Tenure Track Faculty for Population..................... 187 


\section{TABLE OF FIGURES}

Figure 1. Distribution of New Initiatives Used by the Respondent

Institutions Compared to the Normal Distribution

Figure 2. Distribution of Traditionally Used Initiatives Reported

by Respondent Institutions Compared to the Normal Distribution

Figure 3. Distribution of Initiatives Planned for the Future as Reported

by Respondent Institutions Compared to the Normal Distribution

Figure 4. Distribution of Entrepreneurial Scores Compared to the Normal Distribution

Figure 5. Distribution of President's/Chancellor's Length of Service Compared to the Normal Distribution

Figure 6. Significant Difference in Number of New Initiatives

Between 5 or Fewer Years in Current Position Group and 11 to 15 Years in Current Position Group. 90

Figure 7. Distribution of Total Full-Time Faculty Compared

To the Normal Distribution. 103

Figure 8. Distribution of Total Part-Time Faculty Compared

To the Normal Distribution. 104

Figure 9. Distribution Total Full-Time Tenure Track Faculty Compared

To the Normal Distribution. 107

Figure 10. Distribution of Total Full-Time Non-Tenure Track Faculty

Compared to the Normal Distribution ..... 108 
Figure 11. Significant Difference in Entrepreneurial Score Based on Whether Or Not there was a Change in the Institution's Purpose or Mission To Reflect a Greater Emphasis on Entrepreneurial Activities................... 130

Figure 12. Distribution of the New Initiatives Success Scores Compared To the Normal Distribution. 145

Figure 13. Distribution of the Traditionally Used Initiatives Success Scores Compared to the Normal Distribution 147

Figure 14. Distribution of the Composite Success Scores Compared to the Normal Distribution 149

Figure 15. Box Plot Comparing New Initiatives Success Score with the Level Of State Appropriations

Figure 16. Box Plot Comparing Composite Success Score with the Level Of Institutional Support for Faculty Entrepreneurial Activities 


\section{CHAPTER I \\ INTRODUCTION}

\section{Background and Rationale}

Until recent years, the concept of entrepreneurship has been the subject of study and application primarily in the private sector business community. However, in the wake of decreasing traditional sources of funding, higher operating costs, increasing government intervention, and institutional initiatives, entrepreneurship has gained increasing attention in public higher education (Elford \& Hemstreet, 1996; Keast, 1995; Kozeracki, 1998). The implications for policy decisions, institutional planning, and institutional principles could be immense, possibly resulting in conflict between the values and culture of institutions of higher learning and those of market-driven enterprise (Keast, 1995).

\section{Decreases in Traditional Sources of Funding}

According to Brawer (1998b), "decreasing finances present the most salient reason for the involvement of higher educational institutions in commercial endeavors" (p. 1). Levine (1997) reports, “during the 1980s and 1990s, government support for higher education declined, both financially and politically" (para. 1). Levine presents two explanations offered by college leaders:

The first is that these are bad times for government; officials simply have less money to give away. The second is that government priorities have changed, particularly in the states. Colleges have given way in importance to prisons, health care, and highways, and, even within education, schools now get preference over colleges. (para. 1) 
Breneman (2002), speaking about the current recession (2002-2003), further indicates that "state budget cuts for higher education appear to be running higher than in previous downturns, while tuition increases at some public institutions are truly exceptional: 15 to 30 percent or more" (p. 2). As institutions of higher education raise tuition to offset decreasing state support, the federal government is poised to initiate some kind of institutional accountability for tuition increases as Congress drafts legislation to renew the Higher Education Act, the law that governs most federal student-aid programs (Burd, 2003). Burd points to a news release (Tuesday, July 22, 2003), issued by Reps. John A. Boehner of Ohio and Howard P. McKeon of California, indicating, "curbing tuition increases would be among their top priorities..." (para. 2). Such legislation appears to have public support. Crawford (2003) reported "Americans overwhelmingly approve of the current state of higher education, according to a study released on Wednesday [June 19, 2003] by Educational Testing Service, except for one thing: the cost" (para. 1). Crawford continues, stating "almost three-fourths of those surveyed also said that the federal government should place limits on college tuition in order to keep increases in line with inflation" (para. 5).

Other traditional areas of support appear to be diminishing as well. Marcy (2003) reports that, while endowment losses continue, several foundations have announced plans to substantially reduce their grants to higher education. 


\section{State Support}

According to Breneman (2002), state support for higher education has actually been declining for several years:

The states' share of public higher-education revenues peaked nationally in 1979 at 62 percent and has declined steadily ever since, in response to new needs pressed on the states by changing demographics, particularly the aging population. Leaders of public higher education sought more private support, raised tuition whenever possible, and generally diversified their revenue sources. (p. 2)

Supporting these observations, Yudof (2002) indicates that the proportion of family households with children has declined from almost one-half to one-third over the last 40 years. Yudof continues:

The country's aging population appears more interested in issues like health care and public safety than higher education. While higher education's share of average state spending fell 14 percent from 1986 to 1996, Medicaid's share nearly doubled. The funds allocated to correctional facilities grew by more than 25 percent. (para. 6) Exacerbating the problem, higher education is now facing an enrollment surge (Breneman, 2002). According to a 1999 report published by the Western Interstate Commission for Higher Education and the College Board (as cited in Breneman, 2002):

The number of high-school graduates began to increase in the 1990s and will continue through 2008, when the nation will graduate the largest public high-school class in its history -3.2 million students - exceeding 
the class of 1979 , the peak year of the baby boom, by more than 60,000 graduates. (p. 3)

State funding concerns have clearly continued into the new decade. Citing a survey conducted by the Center for the Study of Education Policy at Illinois State University for the 2001-2 fiscal year, Schmidt (2002) reports:

...aggregate appropriations for higher education rose by a total of 4.6 percent, the smallest such increase in five years.

In 13 states, higher education was not appropriated enough new money to stay ahead of inflation. Five of those states - Florida, Iowa, Massachusetts, Mississippi, and Nebraska - adopted budgets that called for reductions in higher education spending. (p.1)

Schmidt further pointed out that this did not include mid-year rescissions. As of the date of Schmidt's writing (January 18, 2002), 18 states, responding to shortfalls in their budgets for fiscal year 2001-2, had mid-year rescissions ranging from 1 percent in Colorado to 10 percent in Illinois. Schmidt also indicated that five other states were considering budget cuts in response to the continued deterioration of their economies.

Trombley (2003) reports that, for the fiscal year 2002-3, "state support for higher education, measured in current dollars, increased only 1.2 percent, a sharp decline from last year's 3.5 percent and the smallest increase in a decade" (p. 1). Trombley further indicates that appropriations dropped in 14 states, with the largest drop in Oregon, with an 11 percent decline.

McGuinness (1999) reflects that the remainder of the 1990s and into the next decade will be one of the most troubling times in the history of our nation's higher 
education system. McGuinness (pp. 183-184) predicts that state government and higher education relations are likely to be strained because of five broad trends:

1. Escalating demands - driven not only by numbers, but by higher expectations for an increasingly diverse population.

2. Severe economic constraints - contributing factors will be the federal deficit, competing priorities for public funds, discontent with rising student costs, and competition for limited corporate and philanthropic funds.

3. The academy's inherent resistance to change - the slow, incremental process of change will cause public frustration and governmental intervention.

4. Negative climate of public opinion - public sentiment that higher education is disconnected from major societal priorities and mismanaged in ways that will make it increasingly inaccessible in terms of cost.

5. Instability of state political leaders - as each state legislative session begins, the proportion of new members increases, and the memory of higher education policies by long-term legislative members is lost.

Declining state support has forced higher education to find ways to cut costs, operate more efficiently, and find alternative sources of revenue. It has also resulted in restructuring in higher education (Slaughter and Leslie, 1997). Slaughter and Leslie indicated that, "restructuring often put increased resources at the disposal of units and 
departments close to the market; that is, those relatively able to generate external grants and contracts or other sources of revenue" (p. 8). This amounts to academic entrepreneurism, which Slaughter and Leslie prefer to call "academic capitalism" (p. 8).

\section{Federal Support}

The federal government has supported higher education to serve a variety of national purposes, from sponsoring the land-grant colleges in the nineteenth century to underwriting student loans and university-based research in the twentieth century (Gladieux \& King, 1999). Smith (as cited in Campbell and Slaughter, 1999) report that, "in the 1940s the federal government began awarding grants and contracts for significant amounts of money to academic researchers who pursued paths of national as well as scholarly interest" (p. 1). Ekzkowitz and Stevens (as cited in Anderson, 2001) relate that, "early in this century, many institutions rejected federal funds, viewing them as "tainted" (p. 5). However, during the post-World War II years federally sponsored research became a source of prestige and autonomy in higher education (Campbell \& Slaughter, 1999).

Campbell and Slaughter indicate that by the mid-1970s the federal share of academic research funding began to decline while, at the same time, business leaders began to voice concerns that government regulation and restrictions were impeding their ability to compete in the global marketplace.

This led to a changed response by the federal government in the 1980s that encouraged federally sponsored academic research and facilitated university-industry collaboration. Bok (2003) identifies critical government initiatives that encouraged entrepreneurial activities within higher education: 
In 1980, Congress passed the Bayh-Dole Act, which made it easier for universities to own and license patents on discoveries made through research paid for with public funds. Federal and state legislation offered subsidies for a variety of university-business cooperative ventures to help translate the fruits of academic science into new products and processes. Tax breaks encouraged industry to invest more in university-based research. (pp. 11-12)

Etzkowitz and Webster (as cited in Anderson, 2001) refer to this as "the translation of research findings into intellectual property, a marketable commodity, and economic development" (p. 5). Bok reports that, "within a decade, two hundred universities had established offices to seek out commercially promising discoveries and patent them for licensing to companies" (p. 12). Bok goes on to say, "by the year 2000, universities had increased the volume of their patenting more than 10 -fold and were earning more than $\$ 1$ billion per year in royalties and license fees" (p. 12).

According to Gladieux and King (1999), "the federal government provides less than 15 percent of all college and university revenues" (p. 151). However, they further report that federal expenditures far exceed those of state government, industry, and other donors in the areas of direct aid to students and funds for research and development.

\section{Societal and Economic Influences}

Levine (1997) points out that, "even if budgets improve for the federal government and for states, officials still must respond to demands for spending on health care, prisons, and repair of deteriorating infrastructure such as highways - all of which many citizens value at least as much as higher education" (pp. 2-3). These growing 
demands for government funds create a market-like environment, where higher education must compete with many other public programs. Furthermore, higher education is becoming seen as a "mature industry," where continued expansion will be slow, concentrating more on stability rather than growth, and questions of accountability will be asked regarding cost, efficiency, productivity, and effectiveness (Berdahl, Altbach, and Gumport, 1999; Hammonds, Jackson, DeGeorge, \& Morris, 1997; Levine, 1997). Slaughter and Leslie (1997) employ resource dependency theory to explain academic entrepreneurial activities in this context stating that, "organizations deprived of critical revenues will seek new resources" (p. 113). According to Wasser, OECD, Neave \& Vught, Williams, and Gellert (as cited in Slaughter \& Leslie, 1997), the result is a "shifting of the responsibility for higher education support from governments to other resource providers and modifications in the form of government support which is retained, specifically a decline in block grant funding and an increase in the use of market funding mechanisms" (p. 215). Slaughter and Leslie add that, "major changes in resource dependence relationships have occurred; universities have been pushed and pulled in the direction of competing in a quasi-market arena for more and more of their operating funds" (p. 215)

If public policy is softening regarding the importance of higher education in relation to other public services, from an economic perspective, a postsecondary education is almost an imperative in today's knowledge economy. Yudof (2002) reports, ...as state support for higher education has declined relative to other public services, the value of education to students has increased substantially. After adjusting for inflation, a male college graduate today 
makes an average of $\$ 32,000$ more each year than a high-school graduate, compared with a $\$ 15,000$ gap in $1975 \ldots$ With the wage premium rising, education is increasingly seen as a private, rather than a public good.

Given that reality, both federal and state policy makers are asking students to shoulder a larger share of their higher education expenses.... In the same vein, elected officials prefer market accountability - with institutions competing with each other for students - rather than traditional public oversight to ensure quality. And rather than provide operational support to universities, they encourage universities to charge higher tuition, then favor giving direct aid to students in the form of scholarships and tax benefits to help make that tuition affordable. (para. 8-9)

Yet, there are limits to shifting the burden to students and families. As discussed earlier regarding draft legislation to renew the Higher Education Act, Congress is placing their top priority on curbing tuition increases (Burd, 2003). The Rand Corporation's Council for Aid to Education estimated that increasing college costs, when combined with declining real wages and growing immigration rates, will create a class for whom college is out of reach (Hammonds, Jackson, DeGeorge, \& Morris, 1997). Breneman (2002) states that, "the economic difficulties that today's institutions must now grapple with are especially burdensome because higher education now faces an enrollment surge similar to that experienced during the baby boom" (p. 3). Institutions must struggle with the basic tension between quality and access. In today's knowledge economy, continued productivity gains and economic growth depend on keeping institutions both accessible and pertinent (Hammonds, Jackson, DeGeorge, \& Morris, 1997). Hammonds et al. state 
that the innovation on university campuses today attempt to address these concerns. They state that, "it is accelerating the evolution of American higher education into what some experts say is a two-tiered entity: one system of exceptionally high quality for those with the means to pay and a second for those without" (p. 3). Zemsky and Shaman (as cited in Hammond et al., 1997) found in a study of 1200 institutions that:

Colleges are sorting themselves into identifiable market segments. 'Name-brand' schools provide small classes and well-paid faculty at high prices. A second, more market-savvy group offers convenience and userfriendliness - often catering to students who want quick, cheap degrees to advance their careers. But these schools spend much less on teaching and facilities.

Colleges that flourish...will be those that identify a viable segment of the school population and equip themselves to serve it effectively.... Institutions that don't do well are those that don't develop a real signature in the market. (p. 3)

Economic issues have also arisen in terms of higher education's role in workforce preparation. Business and industry have focused increased attention on human resource development and, consequently, corporate-academic partnerships are becoming more common. Watson (as cited in ASHE-ERIC Higher Education Reports, 27, 7, 2000) indicates that present labor shortages necessitate an investment in initial and continuing training, with the skills of workers at all levels continuing to increase in response to rapid technological changes. According to Meister (as cited in ASHE-ERIC Higher Education 
Reports, 27, 7, 2000), knowledge has an increasingly shortened shelf life, exacerbated by rapid technological change. Meister continues:

Business must constantly upgrade the skill and competency levels of knowledge workers to remain competitive. To meet this challenge, corporations are increasingly developing joint degree programs with institutions of higher education.... These degrees are primarily at the graduate level in business administration, computer science, engineering, and finance. (pp. 3-4)

ASHE-ERIC Higher Education Reports (27, 7, 2000, p. 29) concludes that, "more forms of corporate-academic partnerships will take shape," including "development and delivery of programs by corporate entities within the college, as well as privatization of services within our institutions well beyond the bookstore and food service.” The Report continues, stating that, "we will look for effective means to provide distance learning, virtual textbook delivery, and 24-hour access to college services such as libraries via the Internet.” (p. 29)

\section{Global Influences}

According to Jessop (as cited in Slaughter and Leslie, 1997), as the economy globalized, the business and corporate sector pushed government to devote more resources to the enhancement and management of innovation in order to successfully compete in world markets. Slaughter and Leslie (1997) explain that business leaders wanted government to sponsor commercial research and development in research universities and government laboratories. As mentioned earlier, in the 1980s the federal government "responded by encouraging increased cooperation between universities and 
firms, allowing universities to hold patents on federally sponsored research and financing research projects in which universities and firms were both active participants" (Campbell \& Slaughter, 1997, p. 1). According to Slaughter and Rhoades (as cited in Slaughter and Leslie, 1997) "the National Science Foundation developed industryuniversity cooperative research centers in the 1980s and, under President Clinton, a national science and technology policy exemplified by the Advanced Technology Programs housed in the Department of Commerce" (p. 7).

Academic affiliation with technology commercial markets was initially resisted, but increasingly became a source of academic resources and prestige (Lee, Lee \& Gaertner, and Rahm, as cited in Campbell \& Slaughter, 1997). Campbell and Slaughter (1997) indicate that now "university relationships with industry are valorized through federal policy efforts to improve the global competitiveness of the United States through economic development and precompetitive research" (p. 3).

\section{Market-Driven Demands on Higher Education}

This entrepreneurial, market-driven approach is not always welcome in higher education. "A commitment to tradition and a disdain of commerce, especially for thinking of students as clients, or customers, often dominates the thinking of faculty members" (Kozeracki, 1998, para. 3). A more compelling argument is made by Anderson (as cited in Kozeracki, 1998) that "public support for colleges and universities could be undermined if the image of a 'service-oriented' organization is replaced by that of a commercial, money-making enterprise" (para. 5). Also, the general administrative pattern of shared governance in higher education is being challenged, with much of the research indicating a need for more centralized governance (Brawer, 1998a; Buchbinder, 
1993; Elford \& Hemstreet, 1996, Keast, 1995). However, Kozeracki points out "demands on the universities outrun their capacity to respond, and one way to reinstate the balance is for universities to become more entrepreneurial" (para. 2). In point of fact, the trend is strong, with many higher education institutions, especially universities and community colleges, initiating a variety of entrepreneurial programs (Kozeracki, 1998).

Our society and workplace reflect greater diversity and a shift to a service economy, with greater reliance on the new information and communications technologies. As we see the restructuring of our society and workplace, we also see a consequent change in demand for higher education and for continuing education. Higher education is being seen more and more as a commodity that can be sold in the marketplace (Buchbinder, 1993). With technology changing the way we do business, more non-traditional students are seeking higher education degree programs or job retraining programs to continue their careers. This non-traditional body of students continues to grow and place demands on higher education to be responsive to a different set of needs. For example, evening and weekend degree offering programs and distance learning models are designed to accommodate the needs of a diverse body of students who cannot attend college or university under the traditional model (Klor De Alva, 1999; Rosenfeld \& Liston, 2000).

Higher education is also impacted by the emergence of a global economy, in large measure resultant from greatly improved transportation systems, and information and communications technology. This has placed new demands on public higher education to prepare students for an international marketplace and to engage in programs that support a global perspective (Rosenfeld \& Liston, 2000). 
Over the last decade, higher education has been challenged to play a more vital role in economic development, again with increasing demands on institutions of higher education to provide new and innovative services, such as the recent thrust among large universities to provide technology transfer centers (Bird \& Allen, 1989; Dill, 1995; Powers, 2002).

The dynamic changes within our society, the new technologies, the emergence of a global economy, and our ever-changing domestic economy have placed significantly increased demands on higher education. Yet, at the same time, increasing government fiscal restraint has resulted in reduced support for public higher education. Furthermore, there have been increasing legislative mandates for greater accountability and for new initiatives to serve the changing job market and to prepare individuals for global competition. In short, public higher education is being asked to do more with less, to be innovative, responsive to the market, and find new ways to generate revenues (Kozeracki, 1998).

\section{Defining Entrepreneurship in Higher Education}

While many definitions of entrepreneurship have been discussed in the literature, the one apparent commonality is "creation of new enterprise" (Low, 2001). As applied to higher education, the consensus of researchers is that the concept of entrepreneurship implies a market-orientation. Traditional views of how institutions of higher education do business are being challenged by a society increasingly driven by market mechanisms (Bird \& Allen, 1989; Buchbinder, 1993; Dill, 1995; Keast, 1995, Kozeracki, 1998, Powers, 2002). 
Slaughter and Leslie, referring to academic entrepreneurship, prefer to use the term "academic capitalism" (p. 9), stating that, "academic entrepreneurism or entrepreneurial activity seemed to be euphemisms for academic capitalism which failed to capture fully the encroachment of the profit motive into the academy" (p. 9).

Slaughter and Leslie go on to emphasize how market forces are driving higher education:

We define the reality of the nascent environment of public research universities, an environment full of contradictions, in which faculty and professional staff expend their human capital stocks increasingly in competitive situations. In these situations, university employees are employed simultaneously by the public sector and are increasingly autonomous from it. They are academics who act as capitalists from within the public sector; they are state-subsidized entrepreneurs. (p. 9) Anderson (2001) simply refers to academy-industry relations (AIRS) and define AIRS as "an exchange of resources, ideas, or influence between some unit within a university (possibly even a individual) and some for-profit entity or subunit thereof" (p. 2). Anderson elaborates:

AIRS take on a wide variety of forms in addition to contractual relationships between a single research university and a corporation. Included in the general category of AIRS are technology transfer, spinoff companies based on academic research, patenting, and licensing of academic research, research parks and other collocational arrangements, and consulting. (p. 2) 
Anderson also points out that the federal government has been an active participant in AIRS over the last twenty years.

While Anderson's utilization of AIRS helps identify many of the entrepreneurial activities at research-intensive universities, there is a broader conceptualization of entrepreneurship in higher education. Slaughter and Leslie (1997) define "academic capitalism" as "institutional and professorial market or marketlike efforts to secure external funds" (p. 209). Slaughter and Leslie describe the following distinguishing behaviors as "academic capitalism":

Marketlike behaviors refer to institutional and faculty competition for money, whether these are from external grants and contracts, endowment funds, university-industry partnerships, institutional investment in professors' spinoff companies, or student tuition and fees.... Market behaviors refer to for-profit activity on the part of institutions, activity such as patenting and subsequent royalty and licensing agreements, partnerships, when these have a profit component. Market behavior also covers more mundane endeavors, such as the sale of products and services from educational endeavors (e.g., logos and sports paraphernalia), profit sharing with food services and bookstores, and the like. (p. 11)

Types of Entrepreneurial Responses

Most of the literature focuses on entrepreneurial ventures in two sectors: community colleges and universities (Kozeracki, 1998). The traditional revenue sources for community colleges have been state appropriations, tuition, local tax levies, and direct fees (Catanzaro \& Arnold, 1989; Hebel, 2003; Maradian, 1989). Kozeracki (1998) stated 
that "because of their traditional role in job training, community colleges have been very successful in obtaining money from both government and industry to prepare workers for jobs" (para. 6). Community colleges have been involved in entrepreneurship training programs, preparing students to eventually start their own businesses (Brawer, 1998a). Community colleges often engage in other entrepreneurial activities such as housing small business development centers and providing other areas of business assistance (Rosenfeld \& Liston, 2000). Also, there are many examples of innovative programs to target special student and business interest. Community colleges have effectively utilized distance-learning models utilizing satellite video teleconferencing and online course offerings (Rosenfeld \& Liston, 2000).

Universities, on the other hand, generally focus on generating revenues through research collaborations with government and industry (Kozeracki, 1998). Dill (1995) conducted a national survey of large universities to determine the extent of technology transfer, defined as "formal efforts to capitalize upon university research by bringing research outcomes to fruition as commercial ventures" (p. 371). Dill states, "universities which grant the doctorate and specialized institutions engaged in engineering and healthrelated work account for the vast majority of federally and privately sponsored research conducted in American academic institutions" (p. 371).

The research on universities, while not always explicitly stated, focuses on large, research-oriented institutions. For example, Campbell and Slaughter (1999) conducted a study of faculty and administrators attitudes toward issues impacted by universityindustry relationships that attempted to obtain responses from all types of colleges and 
universities using the 1987 classifications issued by the Carnegie Foundation for the Advancement of Teaching. Campbell and Slaughter state:

Despite these efforts to solicit input from all types of colleges and universities, more than three quarters of the participants represented research-intensive, doctorate granting universities; $21 \%$ of the responses were from individuals in institutions classified as Comprehensive I/II and Liberal Arts I/II. Given this limited response by representatives of schools that are not research intensive, we were unable to conduct meaningful analyses of connections between institutional type and attitudinal response. (p. 4)

Furthermore, Campbell and Slaughter, in their endnotes (p. 17), indicate that only three institutions were categorized as Liberal Arts I/II.

As indicated above, the focus of the research has been primarily on community colleges and large research universities. According to Kozeracki (1998), "Most of the literature reflects entrepreneurial activity in two sectors, the community colleges and the universities" (para. 6). The focus of this study will be on public baccalaureate colleges with teaching as their primary mission. These institutions face the same difficulties of decreased funding, rising operational costs, and increasing government intervention. These institutions are suffering from the same governmental budget cuts, yet often find government interventions limiting or even capping tuition increases to protect affordability and accessibility issues within their respective states (Breneman, 2002; Burd, 2003). 
Public liberal arts and general baccalaureate colleges are not presented in the literature on academic entrepreneurship. Possibly this is because they have only been reactive rather than proactive in responding to declining traditional sources of funding, increased calls for accountability, preservation of student access and quality of services. It could also be that community colleges and research-intensive universities receive greater attention in the literature because of their roles in access for the disenfranchised (community colleges), industry training needs (community colleges), and the larger national scope of research in support of economic development and competitive global advantage (research-intensive universities). It is possible, actually quite probable, that public liberal arts and general baccalaureate colleges have been entrepreneurial in many significant areas, but the literature does not reflect this because of researcher affiliation and/or familiarity with community colleges or research-intensive universities. By definition, the public liberal arts and general baccalaureate colleges' primary mission is teaching, and by virtue of less emphasis on research they possibly lose their advocacy in the literature. In support of this premise, Slaughter and Leslie (1997) indicate that: ...resource dependence theory suggests that faculty will turn to academic capitalism to maintain research (and other) resources and to maximize prestige. Put another way, if faculty were offered more resources to teach more students, it is not clear that they would compete for these moneys with the same zeal with which they compete for external research dollars. (p. 17)

While it is not necessary to agree with this statement, it does point out an emphasis on the research component. It seems reasonable that faculty, and certainly the administration, at 
institutions where teaching is the primary mission would embrace the basic premise of resource dependence theory that "organizations deprived of critical revenues will seek new resources" (Slaughter and Leslie, 1997, p. 17). This study is designed to investigate entrepreneurial activities at public liberal arts and general baccalaureate colleges.

Furthermore, these institutions typically do not share in large government and industry research grants and contracts. Nor can they significantly engage in industry job training programs, which seem to be the province of the two-year community colleges. Nevertheless, these institutions are under the same government and economic pressure to be more entrepreneurial or market-oriented in order to generate financial support for continued viability.

Regarding a more entrepreneurial orientation, what activities and programs fall within the legitimate purview of public baccalaureate colleges? What types of actions have been taken at these colleges to generate additional revenues? How do these institutions address such issues without eroding their academic mission and purpose? Without making enormous presumptions based on the studies of large research universities and the two-year community colleges, the literature sheds little light on these and other questions.

\section{Purpose of the Study}

The purpose of this study is to investigate the current patterns of entrepreneurial activities in public liberal arts and general baccalaureate colleges as defined by the Carnegie Classification of Institutions of Higher Education (The Carnegie Foundation for the Advancement of Teaching, 2000). Specifically, the following questions will be answered: 
1. To what extent do these institutions generate revenue through entrepreneurial initiatives?

2. Is there a relationship between the number of entrepreneurial initiatives and the following factors?

a. The number of years the president/chancellor has been in current position.

b. The field of study or discipline of the president/chancellor.

c. The business/industry experience of the institution's president/chancellor.

d. The institution's enrollment.

e. An increase or decrease in enrollment from the previous year.

f. The institution's tuition, both in-state and out-of-state.

g. An increase or decrease in tuition from previous year.

h. The number of faculty, both full-time and part-time.

i. The number of tenure track and non-tenure track faculty.

j. An increase or decrease in full-time faculty, both tenure track and nontenure track, from the previous year.

k. An increase or decrease in full-time tenure track faculty from the previous year.

1. An increase or decrease in part-time faculty from the previous year.

$\mathrm{m}$. The highest degree offered at the institution.

$\mathrm{n}$. The addition or elimination of programs for teaching, research, and service since the previous year.

o. An increase or decrease in state appropriations from the previous year. 
p. Whether the governing board encourages or discourages entrepreneurial activities to generate revenue.

q. The number of programs supported by generating their own revenue.

r. Administrative and/or organizational changes during the president's/chancellor's tenure.

s. Whether faculty are formally encouraged to pursue innovative and entrepreneurial activities.

t. Whether merit pay or other reward systems are used to encourage faculty to pursue innovative and entrepreneurial activities.

u. Whether the institution's purpose and/or mission has been changed to reflect greater emphasis on entrepreneurial activities.

v. Whether the faculty or staff are represented by a union.

3. What entrepreneurial institutional initiatives are proving successful in terms of generating revenue for these institutions?

4. Is there a relationship between the number of successful entrepreneurial initiatives and the following factors?

a. The number of years the president/chancellor has been in current position.

b. The field of study or discipline of the president/chancellor.

c. The business/industry experience of the institution's president/chancellor.

d. The institution's enrollment.

e. An increase or decrease in enrollment from the previous year.

f. The institution's tuition, both in-state and out-of-state.

g. An increase or decrease in tuition from previous year. 
h. The number of faculty, both full-time and part-time.

i. The number of tenure track and non-tenure track faculty.

j. An increase or decrease in full-time faculty, both tenure track and nontenure track, from the previous year.

k. An increase or decrease in full-time tenure track faculty from the previous year.

1. An increase or decrease in part-time faculty from the previous year.

m. The highest degree offered at the institution.

n. The addition or elimination of programs for teaching, research, and service since the previous year.

o. An increase or decrease in state appropriations from the previous year.

p. Whether the governing board encourages or discourages entrepreneurial activities to generate revenue.

q. The number of programs supported by generating their own revenue.

r. Administrative and/or organizational changes during the president's/chancellor's tenure.

s. Whether faculty are formally encouraged to pursue innovative and entrepreneurial activities.

t. Whether merit pay or other reward systems are used to encourage faculty to pursue innovative and entrepreneurial activities.

u. Whether the institution's purpose and/or mission has been changed to reflect greater emphasis on entrepreneurial activities.

v. Whether the faculty or staff are represented by a union. 
5. What impact have entrepreneurial initiatives had on institutional mission, purpose and academic integrity?

6. Does the institution's governing board/body encourage or discourage entrepreneurial initiatives to generate revenue?

\section{Significance of the Study}

With increasing and competing demands for government funding and with legislative mandates calling for greater accountability in public higher education, institutions at all levels will need to become more creative, innovative, and entrepreneurial in finding ways to generate revenues, while at the same time protecting mission, purpose, and academic integrity.

The literature reveals that the majority of research in the area of entrepreneurship in higher education has focused on large universities and two-year community colleges. Much has been revealed concerning the types of entrepreneurial initiatives at these two institutional levels and their degrees of success, or lack thereof, in generating revenues and sustainability for the organizations. Also, considerable effort has been made to discern the impact entrepreneurial activities have had on institutional missions, purposes, governance patterns, and academic integrity, mostly with little evidence supporting either a positive or negative conclusion. Clearly, more research is warranted on entrepreneurial activity and its impact at the university and community college levels.

McLennan (1996), recommends that further research on entrepreneurial management in higher education "should address reasons that institutional leaders choose to use some entrepreneurial concepts and activities and not others, as well as why 
concepts and activities have high levels of success at some institutions but not at others" (p. 232). This study is designed to provide insight into these issues.

What stands out even more clearly is the almost total lack of research regarding those higher education institutions in the middle: the public liberal arts and general baccalaureate colleges, whose primary mission is teaching. As stated previously, these institutions cannot compete with large universities for large government and industry research grants and contracts. By the same token, their mission and purpose does not extend to providing industry job training programs, which are typically found to be within the purview of the community colleges.

Asking the question, what activities and programs fall within the legitimate purview of public liberal arts and general baccalaureate colleges is essential to the continued viability of these institutions. In addition to the obvious importance to institutional presidents, administrators, and faculty, are the policy implications regarding the role and importance of these institutions in our system of higher education and their fiscal well-being.

The results of this study further may provide presidents, administrators, faculty, and other stakeholders with valuable insights into what entrepreneurial activities have worked, or failed, at other similar institutions, and what the impact has been on mission, purpose, governance patterns, and academic integrity. 


\section{Definition of Terms}

\section{Entrepreneurship}

For the purposes of this study, entrepreneurship will be defined as a marketoriented approach to managing institutions of higher education manifested through the creation of new ventures and new programs, along with innovative ways of performing traditional roles and responsibilities, with the objective of generating revenue for the institution.

\section{Successful Initiative}

The survey instrument asks the respondents to identify those initiatives which have been successful at their institution by choosing one of the following, (1) very successful, (2) moderately successful, (3) minimally successful, or (4) not effective. The respondents must determine which response most accurately describes their institution's level of success for each new initiative and/or traditionally used initiative.

\section{Carnegie Classification of Institutions of Higher Education}

The Carnegie Classification includes categories and definitions for all colleges and universities in the United States that are degree-granting and accredited by an agency recognized by the U.S. Secretary of Education. The 2000 edition classifies institutions based on their degree-granting activities from 1995-96 through 1997-98 (The Carnegie Foundation for the Advancement of Teaching, 2000).

Public Liberal Arts and General Baccalaureate Colleges

For purposes of this study, the definitions are taken from the Carnegie Classification of Institutions of Higher Education (The Carnegie Foundation for the 
Advancement of Teaching, 2000). Specifically selected are the public institutions from two categories within the classification as listed below:

Baccalaureate Colleges - Liberal Arts: These institutions are primarily undergraduate colleges with major emphasis on baccalaureate programs. During the period studied, they awarded at least half of their baccalaureate degrees in liberal arts fields.

Baccalaureate Colleges - General: These institutions are primarily undergraduate colleges with major emphasis on baccalaureate programs. During the period studied, they awarded less than half of their baccalaureate degrees in liberal arts fields. (p. 2) 


\section{Summary}

There are many significant factors that have shaped and restructured higher education over the years. In the wake of decreasing traditional sources of funding, higher operating costs, increasing government intervention, and institutional initiatives, entrepreneurship has gained increasing attention in public higher education (Elford \& Hemstreet, 1996; Keast, 1995; Kozeracki, 1998). Societal, economic, technological, and global influences have shaped our nation's policies regarding higher education as well as other competing public mandates. Higher education's response to these influences has been to become more entrepreneurial, utilizing market mechanisms to develop alternative funding sources and to meet the challenge for government revenues from competing public concerns, such as health care, public safety, and rebuilding infrastructure.

The focus of the research has been primarily on community colleges and large research universities. Public liberal arts and general baccalaureate colleges are not presented in the literature on academic entrepreneurship. Nevertheless, these institutions are under the same government and economic pressure to be more entrepreneurial or market-oriented in order to generate financial support for continued viability.

The purpose of this study is to investigate the current patterns of entrepreneurial activities in public liberal arts and general baccalaureate colleges as defined by the Carnegie Classification of Institutions of Higher Education (The Carnegie Foundation for the Advancement of Teaching, 2000). 


\section{CHAPTER II}

\section{REVIEW OF THE LITERATURE}

\section{Entrepreneurial Issues in Higher Education}

The dynamic changes within our society, the new technologies, the emergence of a global economy, and our ever-changing domestic economy have placed significantly increased demands on higher education. Yet, at the same time, increasing government fiscal restraint has resulted in reduced support for public higher education. Furthermore, there have been increasing legislative mandates for greater accountability and for new initiatives to serve the changing job market and to prepare individuals for global competition. In short, public higher education is being asked to do more with less, to be innovative, responsive to the market, and find new ways to generate revenues (Kozeracki, 1998).

\section{Declining Traditional Support}

Public subsidized higher education realized ever-growing state and federal programs of support from World War II to the 1970s. However, each decade from the 1970s to the 1990s has seen recessionary periods that damaged college and university budgets. Student enrollments declined by 175,000 between 1975 and 1976, the first enrollment decline since 1951 (Forest and Kinser, 2002). The early 1980s and early 1990s saw periods of economic decline that severely affected higher education. However, following each period of decline was resurgent support for higher education. For example, following the recession of 1992-1993, state support once again strengthened. Schmidt (1996) reported that the 1996-97 fiscal year saw the largest increase in state support since 1990, indicating that state appropriations exceeded $\$ 46.5$ 
billion, representing the highest ever level of support. By the 1999-2000 fiscal year the states' spending plan was up to $\$ 56.7$ billion (Schmidt, 1999). However, by fiscal year 2001-2001, while state spending continued to increase, it slowed dramatically, with an inflation adjusted growth rate of only 3.6 percent (Schmidt, 2000). This represented the first hints of a slowdown in our economy and state spending. By the 2002-2003 fiscal year, the budget crisis was deepening, with aggregate state appropriations only increasing by 1.2 percent, less than the 2.2 percent inflation rate (Arnone, 2002). By mid-year, about half of the states cut appropriations, or were considering doing so (Arnone, Hebel \& Schmidt, 2003).

Potter (August, 2003) indicates that the 2002-2003 "increases in state appropriations for higher education were the smallest in a decade" (para. 1). He goes on to say " 37 states made midyear cuts to their budgets, totaling some $\$ 14.5$ billion" (para. 2). Potter also indicates that the 2003-2004 fiscal year "may be the worst in memory for higher education" (para. 1). Selingo (2003) indicates that the states face budget shortfalls that total some $\$ 26$ billion, a gap that must be closed by June 2004. Joseph A Burke (as cited in Potter, August, 2003), who directs a program on public higher education at the Rockefeller Institute of Government at the State University of New York, says "in a weak economy, higher education always bears a disproportionate share of state budget cuts" (para. 3). An example of this is given by Theo Yu (as cited in Selingo, 2003), the higher education budget assistant to Washington's governor, stating “ ...higher education is the single largest chunk of discretionary spending in the state budget" (para. 24).

Selingo (2003) states that, "even when the recession ends, state budgets could be pinched well into the future by a vicious combination of weak revenues and rising health- 
care costs" (para. 4). Burke (as cited in Potter, August, 2003) says that tax cuts enacted in the 1990s "are coming back to haunt state legislators... and the future looks bleak" (para. 4).

Selingo (2003) indicates that public higher education is getting a smaller and smaller proportion of taxpayer dollars. According to Breneman (2002), state support for higher education has actually been declining for several years:

The states' share of public higher-education revenues peaked nationally in 1979 at 62 percent and has declined steadily ever since, in response to new needs pressed on the states by changing demographics, particularly the aging population. Leaders of public higher education sought more private support, raised tuition whenever possible, and generally diversified their revenue sources. (p. 2)

Selingo cites that "since 1980, the share of state funds used for higher education has dropped to 32 percent, from 44 percent" (para. 9).

Hebel (2003) says that many college administrators and state higher education officials believe that institutions need to look for ways to significantly restructure their financing, given that economists indicate that state subsidies are likely to continue to decline, even after the current recession. As a result, some state legislatures are beginning to give their higher education institutions more freedom to establish their own tuition policies.

The impact of the continued reductions in state appropriations is felt in a number of different ways, including the rising cost of higher education to students and their families, structural changes in the complement of faculty, and the overall mission of the 
institutions. First it has resulted in universities intensive efforts to find alternative sources of funding. This has led to privatization of public universities. Sue Coleman (as cited in Gose, 2002), who was, at the time, president of the University of Iowa, warned about the "dangers of privatizing public higher education and bringing about a radical change in our character" (p. 1). Many others believe that flagships can continue to survive without state support "by continuing to build endowments through private gifts, by bankrolling new companies derived from university research, and by gaining state approval to raise tuition to market rates" (Gose, 2002, p. 1). James J. Duderstadt (as cited in Gose, 2002), former president of the University of Michigan, stated "it may be that the flagships trade off state support for more autonomy to support their mission" (p. 2). Others worry that privatization will ultimately erode or change the mission of our public institutions of higher education. For example, continuing to provide public goods may be a challenge. Yudof (2002) states that "especially at land-grant institutions, students and parents may question using tuition dollars to pay for extension services and other outreach activities that don't directly improve students' education" (para. 14). Yudof also says they may have to explore partnerships with private foundations and organizations and charge fees for traditionally free services. Gose (2002) states, Some experts warn that dangers lurk for public universities that travel too far down the path toward privatization. By trading appropriations for the ability to set tuition at a higher level, will flagship institutions lose focus on serving students from low-income families? If universities turn to corporations for greater financial support of research, will some scientists feel pressure to shift their focus from basic research to applied research? 
Will the considerable salary gap between professors in the humanities and those in the sciences grow even larger? And lastly, how much influence will major donors wield over university affairs? (p. 4)

Buchbinder (1993) reflects further on the potential problems of privatization and a market-oriented approach to public universities,

Both unions and senates are more and more by-passed, not by conspiracy but rather by the effects of these institutional changes. Policy appears to derive almost solely from budget conditions and the university as an institution must rationalize itself in accord with those constraints. The objectives of higher education which are expressed as the production of knowledge as a social good are replaced by an emphasis on the production of knowledge as a market good, a saleable commodity. Simultaneously, the development of a market-oriented university supersedes academic decision making. This can result in an "efficient", well managed institution in which academics are marginalized, academic institutions are by-passed and social knowledge is diminished as market knowledge achieves greater prominence. (p. 335)

In addition to the impact on the university's mission and character is the effect it will have on student access. According to the College Board (as cited in Farrell, 2003), tuition in 2003-2004 at public four-year institutions surged at its highest rate in three decades, rising 14 percent over last year. These figures demonstrate that state budget cutbacks typically result in higher tuition. According to the College Board report, for the 2003-2004 academic year, the average cost of tuition, room, and board was equal to 70 
percent of family income for families earning up to $\$ 25,207$, an increase of more than 10 percent in the last three years. During this time, wages remained stagnant. For families making $\$ 98,886$ or more, the cost remained at 6 percent for the last three years.

Additionally, the proportion of need-based aid is shrinking. Many state universities, in order to elevate academic prestige, have devoted more resources to meritbased aid. The College Board report indicates that students from middle and upper income families receive the majority of merit-based aid. While Pell Grants, the most common financial aid for low-income students, increased by 15 percent, this increase was largely canceled out by an 11 percent increase in the number of students receiving these grants.

Another problem that has surfaced is that student debt to finance higher education is increasing. The College Board report indicates that, over the past decade, grant aid increased by 85 percent, while education loan volume increased by 173 percent.

As a result of the dramatic tuition increases, both Houses of Congress and Democrats in the Senate have introduced bills to control tuition. With the reauthorization of the Higher Education Act coming up next year, Rep. Howard McKeon (California), who heads the principal subcommittee in the House on higher education, has introduced a bill that would penalize colleges that raise tuition too high by preventing them from participating in some federal student aid programs (Burd, 2003). House Democrats have introduced their own plan that would penalize states instead of colleges. According to the plan, states that cut spending on higher education would be ineligible for federal funds to offset the costs of their education system (Potter, November 19, 2003). Senate Democrats have proposed a similar plan that would penalize states that cut spending on 
higher education by more than 10 percent in one year, making them ineligible for $\$ 15$ billion in federal financial aid and tax relief that the plan would establish (Potter, November 14, 2003). Sen. Hillary Rodham Clinton (New York), co-sponsor of the bill with Sen. Edward M. Kennedy (Massachusetts), said that higher education is shifting from a "public commodity well funded by the public to a private commodity priced beyond the reach of middle and low income families" (Potter, November 14, 2003, para. $3)$.

As already mentioned, the reductions in state appropriations have forced universities to rethink their financial structure, seeking funds from private sources. This search for private sources of funding has led to industry and university partnerships, through joint applied research, technology transfer, spin-off for-profit companies from university research, and collaborative training programs, just to name a few. This corporate influence in the public university system has created conflicts that affect, not just the mission and character of the institution, and not just students, but also the faculty. This private, corporate intervention into public higher education has lead to attacks on academic freedom, attacks on tenure systems, the growth of the contingent workforce of adjunct faculty, increasing use of graduate students to fulfill teaching needs, university patents of faculty research for commercial profit, leading to an emphasis on applied research over basic research, and a limiting effect on the faculty voice in administration (Lieberwitz, 2002). Lieberwitz indicates that the shift to a private corporate business model, with its accompanying norms of corporate authority and control, represent a shift of values and norms within the university that threaten academic freedom. Buchbinder (1993) reminds us that, 
Where the production of knowledge is social it is available to all. It is transmitted via academic journals or within the pedagogical process. Certainly the producer of the knowledge receives credit for the findings but it is not a marketable product....Social knowledge is an ongoing social process and is socially "owned" whereas commodified knowledge is reified as a "thing" privately owned, often secret and evaluated in terms of saleability. (p. 343)

As universities adopt the business model, "corporate planning replaces social planning, management becomes a substitute for leadership, and the private domain of individual achievement replaces the discourse of public politics and social responsibility" (Aronowitz and Giroux, 2000, p. 2). Lieberwitz (2002) states that this "new corporate university identity" (p. 28) brings values and practices that threaten academic freedom. Lieberwitz explains,

Academic freedom is essential to faculty identity, including the right to teach, research, and speak independently from the views of the administration, trustees, government, and private donors. Job security, through the tenure system, has been a key element in ensuring individual faculty rights of academic freedom by removing coercive power of such authority figures. Collective rights of academic freedom, through faculty self-governance in peer-review and through representative bodies such as faculty senates and unions, are also essential to faculty identity as fully participating members of the academic community. The shift of university policy to increase the vulnerability of faculty through 
contingent employment, dependence on corporate research funding, spinoff for-profit corporations, and "partnerships" with corporate investors brings authoritarian private sector employment values into the relationship with its faculty. Traditional "at will" employment in the private sector provides employers with enormous power to control employees' speech and activities at work and to arbitrarily hire and fire employees. (p. 28) This change in values and norms is witnessed in attempts to remove the faculty tenure process and to increase the numbers of part-time and adjunct faculty. The claims are that tenure is costly, eliminates the work incentive and competition, and supports faculty who are unaccountable for productivity (Lieberwitz, 2002). Furthermore, Lieberwitz states that the growth of part-time, adjunct, and contingent faculty lowers costs and increases administrative control. This part-time workforce usually is not tenure track, and work on an at-will basis. Also, they usually do not receive employment benefits and receive low pay for teaching on a course-by-course basis. Between 1971 and 1986 the employment of part-time faculty increased by 133 percent, while full-time faculty only increased by 22 percent (Lieberwitz, 2002).

The literature on entrepreneurship has focused on four basic dimensions: (1) an operational definition of entrepreneurship, (2) identifying the characteristics, behaviors, and cognitive processes of individual entrepreneurs, (3) the entrepreneurial process, and (4) organizational forms. The literature will be reviewed and summarized for each dimension along with discussion of its application to higher education.

For many years, the concept of entrepreneurship was almost exclusively the subject of study in the literature on business and industry. However, with increasing 
fiscal constraints at all levels of government, institutions of higher education have had to consider alternative sources of revenue. As such, entrepreneurship has gained increasing attention in the system of public higher education.

\section{Defining Entrepreneurship}

There has yet to emerge a clear and concise definition of entrepreneurship that can be agreed upon by those who study and research the topic. Low (2001), after citing various definitions found in the body of research on the subject, proposed defining entrepreneurship as the "creation of new enterprise" (p. 19). Peck (1985) defines entrepreneurship in terms of three basic characteristics: opportunism, innovation, and risk. Drucker (as cited in Keast, 1995) equates entrepreneurship with innovation. Keast (1995) states, "at least part of what entrepreneurship means is connected with the notion of self-sufficiency or independence" (p. 251).

Keast (1995) goes on to say, “...in the case of higher education, that selfsufficiency often refers to the need for increasing degrees of financial self-sufficiency or autonomy" (p. 251). Michael and Holdaway (as cited in Keast, 1995) suggest four phases of development for higher education: elitism, recontructionism, reductionism, and finally, entrepreneurialism. In this last stage institutions "can be seen to be engaged in various marketing and revenue generating activities as a response to the funding cutbacks and government interventions of the previous reductionist phase" (p. 254). They further suggest, "This amounts to a market-led educational system in which the planning and monitoring of changes reflect market values" (p. 255). This market orientation is pervasive in the literature on entrepreneurship in higher education (Buchbinder, 1993; 
Keast, 1995; Elford and Hemstreet, 1996). McWilliam (1990) indicates these market oriented entrepreneurial activities include:

...contract research, consulting, patenting, joint ventures, personnel exchanges, incubation of start-up companies, business advice to students and faculty wishing to commercialize products and processes, brokerage between post-secondary entrepreneurs and the private sector, marketing of the educational institution's resources to assist industry in product development, and technical services to industries.... (p. 86)

Other activities include innovative approaches to institutional marketing, fund-raising, student recruitment, degree offerings, and specialized programs. New technologies have created opportunities in technology transfer, commercializing applied academic research, and the increasing use of distance learning models, such as satellite video teleconferencing and online course offerings.

Slaughter and Leslie (1997), referring to academic entrepreneurship, prefer to use the term "academic capitalism" (p. 9), stating that, "academic entrepreneurism or entrepreneurial activity seemed to be euphemisms for academic capitalism which failed to capture fully the encroachment of the profit motive into the academy" (p. 9).

Describing Entrepreneurs

Within the literature on entrepreneurship, numerous approaches have been used to describe the individual entrepreneur. According to Ucbasaran, Westhead and Wright (2001), studies focusing on personalities, backgrounds, early experiences and traits have been widely criticized and have generally produced disappointing findings. As a result, more recent studies have focused on behavioral and cognitive processes of entrepreneurs. 
Busenitz and Barney (as cited in Ucbasaran, et al., 2001) argue that entrepreneurs face substantially greater levels of uncertainty than managers of well-established organizations that have access to historical trends, and past performance. Entrepreneurs often must make decisions with little or no historical data, no previous levels of performance, and with little specific market information about new products or services. Entrepreneurs tend to gain new insights from interpreting new combinations of information through a simplified heuristic-based logic that allows them to capitalize on brief windows of opportunity.

When applied to the academic community, these insights into how entrepreneurs tend to operate points to some dissimilarity between the world of scholarly endeavor and that of the market driven entrepreneur. Bird and Allen (1989), explain that there is often found a low level of faculty entrepreneurial activity based on differences in values on two dimensions: (1) values individuals have for their work, and (2) values they have for their lifestyles. On the first dimension they posit:

For the academic, work involves research and teaching in a relatively narrow disciplinary focus and service to the university and other communities. The intrinsic rewards of publishing ideas, research with students, and acceptance in scholarly circles are vastly different from the world of commerce. For the entrepreneur, work involves linking resources and opportunities and requires a myriad of technical, managerial, and interpersonal competencies. In entrepreneurial realms, knowledge is embodied in a finished, marketable product or service with 
objective success criteria measured by sales and profits and intrinsic rewards of winning the game. (p. 593)

On the second dimension, they illustrate that the time frames of the scholar differ considerably from that of the entrepreneur:

Research and teaching activities usually require some attention to historical developments in one's discipline; entrepreneurs rarely consider their own or other's history. Academic activities often take on longer future time horizons for feedback and require patience and persistence; entrepreneurship is in contrast, very here-and-now and action oriented. In general, academia is bureaucratic, slow to change and low on stress, at least among faculty; entrepreneurship involves organizational birth, rapid change and growth and considerable stress. (p. 593)

While faculty may intuitively understand that their work has economic consequence, it is through the mechanism of increasing the body of social knowledge. A commitment to tradition and a disdain of commerce, especially for thinking of students as clients, or customers, often dominates the thinking of faculty members (Kozeracki, 1998). Most often, it is the administration within higher education, facing increasing fiscal constraints, legislative intervention, and charged with institutional planning and survival, that embrace and promote the entrepreneurial process. Demands on colleges and universities outrun their capacity to respond, and one way to reinstate the balance is to become more entrepreneurial (Kozeracki, 1998).

Peck $(1984,1985)$ has identified six characteristics of entrepreneurial leadership of small independent liberal arts colleges. First is a firm commitment to a mission and a 
purpose. Peck states that the institution's mission is non-negotiable, but leaders are increasingly seeking innovative and entrepreneurial ways to fulfill the mission. Second, they are opportunity-conscious, with continual attention to changes in the environment, people's attitudes, and social values that can be turned to the institution's advantage. Third, they act as active agents in innovative and creative processes, creating a climate that encourages, supports, and catalyzes change. Fourth, they make decisions on the future based on sound judgments and intuition, not simply on data and systematic analysis. Fifth, they improve their intuitive decision making through intelligence gathering. And finally, they understand the elements of risk and how to measure risk as they investigate the variety of opportunities. They understand passive risk, or the risk of doing nothing in the face of changing circumstances, and they appreciate active risk, or the deliberate action to effect change. These characteristics of entrepreneurial leadership profile the entrepreneur and the process at the same time.

The Entrepreneurial Process

Ucbasaran, Westhead, and Wright (2001) identify three basic components to the entrepreneurial process: opportunity recognition, information search, and resource acquisition. According to Venkataraman (as cited in Ucbasaran, et al., 2001), the extent to which individuals recognize opportunities and search for relevant information is widely distributed among individuals on the basis of their set of skills, aptitudes, insights, and circumstances. What attributes and circumstances facilitate the entrepreneurial process in higher education?

Michael and Holdaway (as cited in Keast, 1995) emphasize changes in three aspects of the functioning of postsecondary institutions. They suggest a shift to a more 
corporate management approach, the allocation of resources on the basis of client demand for programs, and increasing the number of graduates while maintaining educational quality. This amounts to a market-led educational system in which the planning and monitoring of changes reflect market values.

Buchbinder (1993) indicates that this change to a market orientation leads to a basic transformation in the university:

This change affects the production and transmission of knowledge, which is the central function of the university and is stimulated by demands of the information society. It also alters patterns of governance. These changes in turn affect academic autonomy and collegiality. In addition, there is a qualitative change in the form and transfer of knowledge. There are a series of conflicts which define this process and lay the groundwork for a consideration of the role of knowledge. (pp. 332-333) Baron and Stauffer (as cited in Keast, 1995) suggest that "higher education/business relations pose the greatest threat in the area of academic freedom" ( $p$. 261). They go on to ask to what extent does corporate involvement "intrude on decisions regarding the purpose of research, its process and its results" (p. 261). Baron indicates the problem "is not so much the use of knowledge for profit, but rather the problem of secrecy and the control of the information" (p. 261). Keast (1995) goes on to say:

Universities, by definition, are committed to, and flourish within, an atmosphere of open debate and the sharing of new knowledge. How is this tradition to be reconciled with the secrecy requirements often accompanying private research and development? (p. 261) 
Furthermore, the market orientation has led many researchers to indicate that traditional models of shared governance in higher education are no longer responsive (Buchbinder, 1993; Elford and Hemstreet, 1996; Keast, 1995). For example, Buchbinder says: ...the emergence of the market university will change the ground rules. Cost will be the criterion. The market university will be characterized by less democracy, less collegiality, more privatization, more centralization. (p. 340)

\section{Organizational Forms}

The business literature on entrepreneurship focuses on four organizational forms the entrepreneurial venture may take: corporate venturing, the purchase of an existing organization, the purchase of a franchise, and the inheritance of a family firm (Ucbasraran, Westhead, and Wright, 2001). As applied to higher education, the emphasis is on corporate venturing, or the process of organizational renewal. Ucbasaran et al. address two dimensions of corporate venturing. The first dimension "stresses creating new business through market developments or by undertaking products, process, technological, and administrative innovations" (p. 63). The second dimension is associated with "the redefinition of the business concept, reorganization, and the introduction of system-wide changes for innovation" (p. 63). Both aspects have been witnessed in our institutions of higher education. For example, technology transfer centers are creating new business through the commercialization of applied research. System-wide changes have been seen in many community colleges, from changing governance patterns, to restructuring program offerings and delivery methods. 
Drucker (as cited in Keast, 1995) equates entrepreneurship with innovation. Concerning innovation he states, "To get at the new and better, you have to throw out the old, outworn, obsolete, no longer productive, as well as the mistakes, failure, and misdirections of effort of the past” (p. 251). Drucker, addressing public-service institutions, outlines three obstacles to innovation followed by four recommendations for successful entrepreneurship. The three obstacles he addresses are:

(1) Public-service institutions function on the basis of budgets rather than being paid on the basis of results.

(2) Public-sector institutions are forced to satisfy a multitude of constituents, whereas private enterprise needs only a small share of a small market.

(3) Public-service institutions tend to see their missions in terms of ethical or moral absolutes, rather than as relative economic objectives, subject to a cost/benefit calculus. (p. 252)

Drucker advocates four entrepreneurial policies needed in public-sector institutions in order to enhance innovation:

(1) public-service institutions need a clear definition of mission

(2) public-sector institutions need a realistic statement of genuinely obtainable goals.

(3) Failure to achieve objectives should indicate that objectives are wrongly defined and may need to be abandoned, and not that efforts need to be redoubled. 
(4) Public-service institutions need to constantly strive for innovative opportunity - to see change as an opportunity rather than a threat. (p. 252)

Institutions of higher education tend to operate on the basis of maximizing revenues as opposed to maximizing profit. What is being advocated is that higher education institutions need to, in the face of ever-increasing financial constraints, approach their mission more from a market orientation, generating revenues according to market demand and according to a cost/benefit system of accountability (Keast, 1995).

However, there are potential downsides that may be encountered by higher education institutions that participate in entrepreneurial activities. Anderson (as cited in Kozeracki, 1998) list three potential risks:

(1) Colleges and universities expose themselves to business risk. They may lose money in the marketplace.

(2) There is also a set of management risks. Commercial enterprises evaluate and control outcomes based on dollars, whereas, colleges and universities are much more complex, often with multitudinous goals involving value judgments.

(3) There are image risks, with the possibility of squandering the existing support for the institution's culture and goals. Public support could be undermined if the image of a "service-oriented" organization is replaced by that of a commercial, money-making enterprise. (para. 5)

Notwithstanding these potential risks and conflicts, many higher education institutions have embraced entrepreneurship. Most of the literature reflects 
entrepreneurial ventures in two sectors: the community colleges and universities. Because of their traditional role in applied educational degree programs as well as industry and job training, community colleges have been very successful in generating revenues from both government and industry. Large universities generally focus on generating revenue through collaborative research efforts with government and industry (Kozeracki, 1998). However, small public four-year colleges and universities have either not significantly engaged in entrepreneurial activities or have been overlooked by researchers.

\section{Entrepreneurial Responses in Higher Education}

Slaughter and Leslie (1997) emphasize how market forces are driving higher education:

We define the reality of the nascent environment of public research universities, an environment full of contradictions, in which faculty and professional staff expend their human capital stocks increasingly in competitive situations. In these situations, university employees are employed simultaneously by the public sector and are increasingly autonomous from it. They are academics who act as capitalists from within the public sector; they are state-subsidized entrepreneurs. (p. 9) Anderson (2001) simply refers to academy-industry relations (AIRS) and define AIRS as "an exchange of resources, ideas, or influence between some unit within a university (possibly even a individual) and some for-profit entity or subunit thereof" (p. 2). Anderson elaborates: 
AIRS take on a wide variety of forms in addition to contractual relationships between a single research university and a corporation. Included in the general category of AIRS are technology transfer, spinoff companies based on academic research, patenting, and licensing of academic research, research parks and other collocational arrangements, and consulting. (p. 2)

Anderson also points out that the federal government has been an active participant in AIRS over the last twenty years.

While Anderson's utilization of AIRS helps identify many of the entrepreneurial activities at research-intensive universities, there is a broader conceptualization of entrepreneurship in higher education. Slaughter and Leslie (1997) define "academic capitalism" as "institutional and professorial market or marketlike efforts to secure external funds" (p. 209). Slaughter and Leslie describe the following distinguishing behaviors as "academic capitalism":

Marketlike behaviors refer to institutional and faculty competition for money, whether these are from external grants and contracts, endowment funds, university-industry partnerships, institutional investment in professors' spinoff companies, or student tuition and fees.... Market behaviors refer to for-profit activity on the part of institutions, activity such as patenting and subsequent royalty and licensing agreements, partnerships, when these have a profit component. Market behavior also covers more mundane endeavors, such as the sale of products and services 
from educational endeavors (e.g., logos and sports paraphernalia), profit sharing with food services and bookstores, and the like. (p. 11) Many public and private universities are creating profit-driven Internet-based distance learning programs. Lieberwitz (2002) says that, while universities can generate revenue through distance learning programs within the existing non-profit university structure, some universities are choosing to develop programs in a for-profit structure. These programs can take many forms, such as partnerships between universities and forprofit corporations to market distance learning, for-profit subsidiaries, wholly owned by non-profit universities, or funded by venture capital, and for-profit distance learning institutions created and owned by a for-profit corporation (Lieberwitz, 2002). Leiberwitz cites numerous examples:

- California Educational Technology Initiative - a partnership between the California State University System and a business consortium consisting of Microsoft, GTE, Hughes and Fujitsu.

- UCLA Extension - a partnership with Onlinelearning.net, a for-profit firm.

- UNext.com - a partnership between UNext.com, a for-profit firm, and the business schools at the University of Chicago, Columbia University, Stanford University, Carnegie Mellon University, and the London School of Economics, using Cardean University, UNext.com's virtual university.

- Western Governor's University - a partnership of governors of seventeen western states and businesses such as IBM, Sun, AT\&T, and Microsoft.

- E-Cornell - Cornell University's wholly owned for-profit subsidiary.

- NYUonline - New York University's wholly owned for-profit subsidiary. 
- Virtual Temple - a for-profit subsidiary formed with plans to acquire funds through venture capital or partnerships with other universities or Internet businesses.

- UMUC Online.com, Inc. - University of Maryland's wholly owned for-profit subsidiary.

- A joint venture distance learning company between TSL Education Ltd., a subsidiary of Rupert Murdoch's News Corporation and Universitas 21, an 18 member incorporated network of universities, which include institutions such as, McGill University, University of Birmingham, University of Toronto, University of Melbourne, University of Edinburgh, National University of Singapore, University of Virginia, and the University of Michigan.

- Jones International University - a for-profit accredited degree-granting university.

- University of Phoenix - operated by the for-profit Apollo Group, Corinthian College, Inc.

- Concord Law School - the only law school entirely online, owned by Stanley Kaplan Corporation. (pp. 13-14)

The risk of losing money in the marketplace is illustrated by Lieberwitz (2002), who indicates that "after only three or fours years of launching distance learning forprofit companies, universities and for-profit corporations are disclosing that their initial projections of enrollments, third-party investment levels, and profit potential are not being met" (p. 18). 
Lieberwitz (2002) cites examples:

- Virtual Temple - Temple University's distance learning for-profit subsidiary closed after only two years. Temple University will continue distance learning courses solely based on academic criteria.

- NYUonline - New York University's distance learning for-profit subsidiary closed after three years, unable to attract venture capital, and after expending $\$ 25$ million in New York University funds.

- Fathom - Columbia University's for-profit subsidiary closed after an investment of $\$ 18.7$ million, failing to make a profit. (p. 19)

Lieberwitz (2002) indicates that the shift to a private corporate business model, with its accompanying norms of corporate authority and control, represents a shift of values and norms within the university that threaten academic freedom.

As universities adopt the business model, "corporate planning replaces social planning, management becomes a substitute for leadership, and the private domain of individual achievement replaces the discourse of public politics and social responsibility" (Aronowitz \& Giroux, 2000, p. 2).

According to Aronowitz and Giroux (2000), "in the name of efficiency, educational consultants across the nation advise their clients to act like corporations, selling products and seeking 'market niches' to save themselves" (p. 2). James Carlin (as cited in Aronowitz and Giroux, 2000), Commissioner on Higher Education in Massachusetts, contends that higher education requires a model of management and leadership that place more power and authority in the hands of the university president. Lieberwitz (2002) indicates "implementing these market values [efficiency and 
discipline] will require hiring managers trained and socialized in the practices of the forprofit workplace; these practices include labor relations practices seeking to cut labor and production costs in order to maximize profits" (p. 18).

Goral (2003) states, "with an apparent growing need to operate a university as a business, it would seem to make sense to draw talent from the corporate world" (para. 17). Posner (as cited in Goral, 2003), vice-president at Educational Management Network, states, "because of the economic challenges that some institutions are facing, there is an increasing movement to at least take a look at people who are not from the traditional, up-through-the-ranks world, people who are from the development world or finance" (para. 18).

There are notable examples, such as David Boren, president of the University of Oklahoma. Boren, elected governor of Oklahoma in 1975 and U.S. Senator in 1980, left the Senate in 1994 to assume the presidency of the University pf Oklahoma in 1975 (Crawford, 2003; Gorel, 2003). When Boren arrived at the University of Oklahoma they launched a \$200 million five-year capital campaign. By 2000 , the campaign had raised \$514 million, making it the fourth largest public university fundraising campaign in the nation's history (Crawford, 2003). Pat Ryan (as cited in Crawford, 2003), president of Skystone Ryan, a national fundraising consultancy, maintains it's the leadership skills of the president of the University of Oklahoma at the root of this successful campaign (para. 21).

According to Crawford (2003), Craven Williams accepted the presidency at Greensboro College in 1993. At the time, a feasibility study predicted a capital campaign could be expected to raise $\$ 6$ million at best. However, from 1994 to 2002, Greensboro 
College raised $\$ 48$ million, in large measure, due to Williams' ability to build relationships with business and professional leaders in the community, who provided the bulk of the gifts. Williams had a strong fundraising and business background. After graduating college he was in the development office at Wake Forest University. Later he served as vice president for development at two other colleges, before raising \$20 million in ten years as president of Gardner-Webb College. Additionally, Williams had a strong business background. After leaving Gardner-Webb College he started Capital Dominion Corporation, a large property management firm. Alan Sasser (as cited by Crawford, 2003), vice president of development at Greensboro College, says of Williams, "he's made a payroll, has paid corporate taxes, and has done all the kinds of things that CEOs and CFOs understand and have to do, so some doors were opened that might not have been otherwise" (para. 11).

Goral (2003) indicates that Roderick Chu, who chairs the Ohio Board of Regents, was a Commissioner of Taxation and Finance for the State of New York, and was managing partner of Government Practice for Anderson Consulting.

Despite these notable educational leaders recruited from development and business backgrounds, Goral (2003) indicates that no real trend has emerged and higher education leaders are only rarely chosen from outside academia. Jan Greenwood (as cited by Goral, 2003), vice president at AT Kearney executive search firm, states, About six years ago, schools wanted search firms to look outside academia, but they rarely proceeded with people outside higher education. Recently, however, they have been interested in looking at and actually 
interviewing some people outside the academy, but it's still a very small percentage that actually gets hired. (para. 19)

Furthermore, the increasing requirement of institutions of higher education to focus on alternative funding sources to supplement shrinking public support is likely to change the hiring practices at other levels of higher education as well. Greenwood (as cited in Goral, 2003), estimates that some university presidents spend as much as 80 percent of their time on fundraising activities, placing greater pressure on hiring vice presidents who can assume leadership and management of the institution. Academic programs and departments are being asked to be more accountable for their own financing, placing further emphasis on the need for deans and department heads to have some degree of business and development experience. Zusman (1999) indicates one strategy is to require academic programs, particularly high-demand, high-return professional programs like business or law, to be fully funded by students or business.

So what are the parameters that define the strengths and weaknesses of privatization and the adoption of the business or corporate model? As discussed above, the literature defines the strengths of the business model as cost and production efficiencies and discipline in terms of well-defined mission and purpose, long range planning, and effective utilization of resources, particularly labor. Dr. Scott Miller (2003), president of Wesley College, writes that a college or university can apply business practices to its operation, and illustrates many of the above points. He speaks of improved cost efficiencies at Wesley College by outsourcing payroll services, information technologies, physical plant maintenance, campus safety and security, bookstore operations, food service and financial aid services. To improve faculty 
performance, he urged the faculty to develop an objective evaluation system. He utilizes consultants to build enrollment, develop and expand advancement, create and implement a 10 -year campus wide master plan, and standardize branding. Finally, he is planning to provide privatized housing for students.

One weakness generally recognized in the literature is the measurement of all institutional activities on the basis of profit maximization, even though some units or programs that are less profitable may be useful, beneficial, or even necessary in terms of public good. For example, Aronowitz and Giroux (2000) point out, As large amounts of corporate capital flow into universities, those areas of study that do not translate into substantial profits get marginalized, underfunded, or eliminated. Hence, we are witnessing both a downsizing in the humanities as well as the increasing refusal on the part of universities to fund research in public health or science fields that place a high priority on public service. (pp. 1-2)

Another generally recognized weakness is that the tendency toward centralization of authority and control tends to weaken the time honored tradition of shared governance and weakens faculty autonomy and academic freedom. For example, Lieberwitz explains,

The view that for-profit corporations have greater business discipline and efficiency is premised on the assertion that unilateral control by management over business and labor relations is more efficient than the more open and deliberative organizational structure associated with universities. This approach is completely opposed to the values of 
academic freedom that underlie faculty autonomy and self-governance. Academic freedom, supported by the job security of the tenure system, enables faculty to create a unique workplace culture based on rights of expression and self-governance over hiring, promotion, and work process. In contrast, the doctrine of employment-at-will, which applies to virtually all other employees in the United States, gives employers the managerial prerogative to hire and fire employees at will and is limited only by specific statutory or contractual protections. (p. 19) In short, hiring our academic leaders from the business world instead of through the traditional academic ranks, whether it's the president, dean, or department chair, has definite benefits and definite shortcomings. For example, Bok (2003) explains that university officials will likely be less successful than business executives in operating efficiently. He supports this premise by saying, Presidents and deans lack the experience of most corporate managers in administering large organizations. Because the principal purposes of their universities are academic, they must be intellectual leaders more than administrators. For this reason, their backgrounds and training are almost always in research and teaching rather than administration. Once in office, their success is measured much more by their accomplishments in building academic programs than by their record in achieving greater efficiency. (p. 24)

Yet, Robert Birnbaum (1999) paints an entirely different picture of the presidency, stating that some presidents spend the majority of their time in fund raising, 
public representation, and resource acquisition, and little time on academic matters. $\mathrm{He}$ explains that the pace, intensity, and comprehensiveness of the presidency is much like that of managers and executives in business settings. However, he goes on to say that, in a business setting, the CEO or president is only accountable to the board of directors, whereas, the university president is layered between the board of trustees and the faculty, and is accountable to both.

Institutions of higher education are much too complex to allow for a simple answer of improving cost and productivity efficiencies by adopting the business model. Derek Bok (2003) cites an excellent example, ...whatever value consumer demand may have in deciding what goods to produce, it is not a reliable guide for choosing an appropriate curriculum or constructing and ideal research agenda. Some scientific problems are well worth investigating although they have no foreseeable commercial value, while other fields, such as Egyptology or epistemology, are deserving of first-rate scholarship even though few people care to read about them. (p. 29)

The literature clearly indicates that there are many significant factors that have shaped and restructured higher education over the years. In the wake of decreasing traditional sources of funding, higher operating costs, increasing government intervention, and institutional initiatives, entrepreneurship has gained increasing attention in public higher education (Elford \& Hemstreet, 1996; Keast, 1995; Kozeracki, 1998). Societal, economic, technological, and global influences have shaped our nation's policies regarding higher education as well as other competing public mandates. Higher 
education's response to these influences has been to become more entrepreneurial, utilizing market mechanisms to develop alternative funding sources and to meet the challenge for government revenues from competing public concerns, such as health care, public safety, and rebuilding infrastructure. 


\section{CHAPTER III \\ RESEARCH DESIGN \\ Methodology}

The purpose of this study is to investigate the current patterns of entrepreneurial activities in public liberal arts and general baccalaureate colleges as defined by the Carnegie Classification of Institutions of Higher Education (The Carnegie Foundation for the Advancement of Teaching, 2000).

To this purpose, a survey questionnaire was designed (See Appendix B) for mailing to the population of colleges identified in the Carnegie Classification as Public Liberal Arts Baccalaureate Colleges and Public General Baccalaureate Colleges.

\section{Population}

The population consists of twenty-five (25) colleges identified by the Carnegie Classification as Public Liberal Arts Baccalaureate Colleges and fifty (50) colleges identified as Public General Baccalaureate Colleges, for a total of seventy-five (75) institutions (See Appendix A).

\section{Data Collection}

Since there are only seventy-five institutions in the total population, all institutions were surveyed. Data collection was completed through the use of secondary sources of data, a mailed survey instrument, and the respondent's vita.

Secondary sources were used to collect institutional data including enrollment data, tuition data, faculty data, and academic program data. Secondary sources included institutional websites, the National Center for Education Statistics, and follow-up phone calls to the institutions for current data that could not be found through other sources. 


\section{Survey Instrument}

A survey questionnaire was designed (see Appendix B) to inform about the current patterns of entrepreneurial activities in public liberal arts and general baccalaureate colleges.

A pilot study was conducted to determine if the survey instrument would elicit the data required to meet the purpose of this study. The survey instrument was reviewed by two administrators/faculty and one faculty member at Fairmont State University:

Harry R. Faulk, Ph.D., Associate Provost and Professor of Music,

Frederick G. Fidura, Ph.D., Provost and Vice President for Academic Affairs, and Professor of Psychology, and

Craig C. White, Ph.D., Professor of Sociology

The survey instrument was revised to incorporate many of the recommendations of the three reviewers. The following revisions were incorporated into the survey instrument following the pilot study:

- One additional initiative was added regarding contract training with government agencies.

- One survey question was completely removed because the reviewers found it to be ambiguous. They recommended it be replaced with a much more concise question regarding any downsides to entrepreneurial programs or activities.

- Several grammatical errors were discovered and corrected.

- Numerous questions were revised to incorporate easy to answer checkboxes rather than asking the respondents for a lengthy written response. 
- The measure of success for each initiative was revised based on the reviewer's recommendations, eliminating the choice "unsuccessful" and replacing it with "not effective."

- It was recommended that the survey be kept as short as possible, eliminating questions that could be answered through other sources. As a result, some questions were removed and the data retrieved through other sources.

Prior to the survey instrument mailing, an introductory letter (see Appendix C) was mailed to recipients, advising them that the survey instrument would be mailed within two weeks. This was done to improve the likelihood of the recipient's response. Within two weeks the survey instrument was mailed to the president or chancellor of each institution. Each survey was accompanied by a cover letter (See Appendix D). The cover letter included an explanation of the purpose of the study and assurances that individual participation was voluntary, only aggregate data would be reported, and confidentiality and anonymity would be maintained. The surveys were coded so the researcher could maintain accurate records on respondents. Only the researcher knows the code.

Contact information was compiled from the 2004 Higher Education Directory (See Appendix F) and verified by visiting institutional websites.

\section{Response Rate}

An adequate response rate is important. A return rate of approximately thirty percent was considered a reasonable return for this study. Upcraft and Schuh (1996) indicate that, "even in the best of circumstances, mailed questionnaires rarely yield more 
than a 50 percent return response, with 25 percent to 30 percent being more typical" ( $\mathrm{p}$. 40).

To increase the likelihood of a reasonable response rate, an initial introductory letter (see Appendix C) was mailed one week prior to mailing the survey instrument. Two weeks following the mailing of the survey instrument, a follow-up letter (see Appendix E) and survey was mailed in an attempt to increase the response rate. Individual telephone contact was used as a final attempt to receive a valid number of responses.

Analysis of Data

Descriptive and inferential statistics were used to summarize and describe characteristics of the data, and analyze factor relationships. Data were presented in tabular form where appropriate. An alpha level of .05 was used as the criterion to establish significance. SPSS 11.0 for Windows was used for all statistical analysis.

Three Fairmont State University faculty provided valuable assistance on the statistical analysis: Craig White, Ph.D., Sociology, Mohamad Khalil, Ph.D., Business, and Clarence Rohrbaugh, Ph.D., Psychology.

Table 1 shows the relationship of the research questions to the survey instrument questions and indicates the appropriate statistical analysis. 
Table 1

Data Analysis Plan

\begin{tabular}{lll}
\hline Research Question & Data Source & Statistical A \\
\hline To what extent do these institutions generate & Survey Q. 10 & Descriptive \\
revenue through entrepreneurial initiatives? & &
\end{tabular}

Is there a relationship between the number

Survey Q. 10, Chi square analysis

of entrepreneurial initiatives and the

Blk. A, and

will be used to assess

following factors?

the following: relationships as

a. The number of years the

Survey Q. 2

appropriate. Other

president/chancellor has been in

statistical measures of

current position.

independence may be

b. The field of study or discipline of the Vita

used as appropriate. president/chancellor.

c. The business/industry experience of Vita the institution's president/chancellor.

d. The institution's enrollment.

Secondary source

e. An increase or decrease in

Secondary source enrollment from the previous year.

f. The institution's tuition, both in-state Secondary source and out-of-state.

g. An increase or decrease in tuition Secondary source from previous year. 


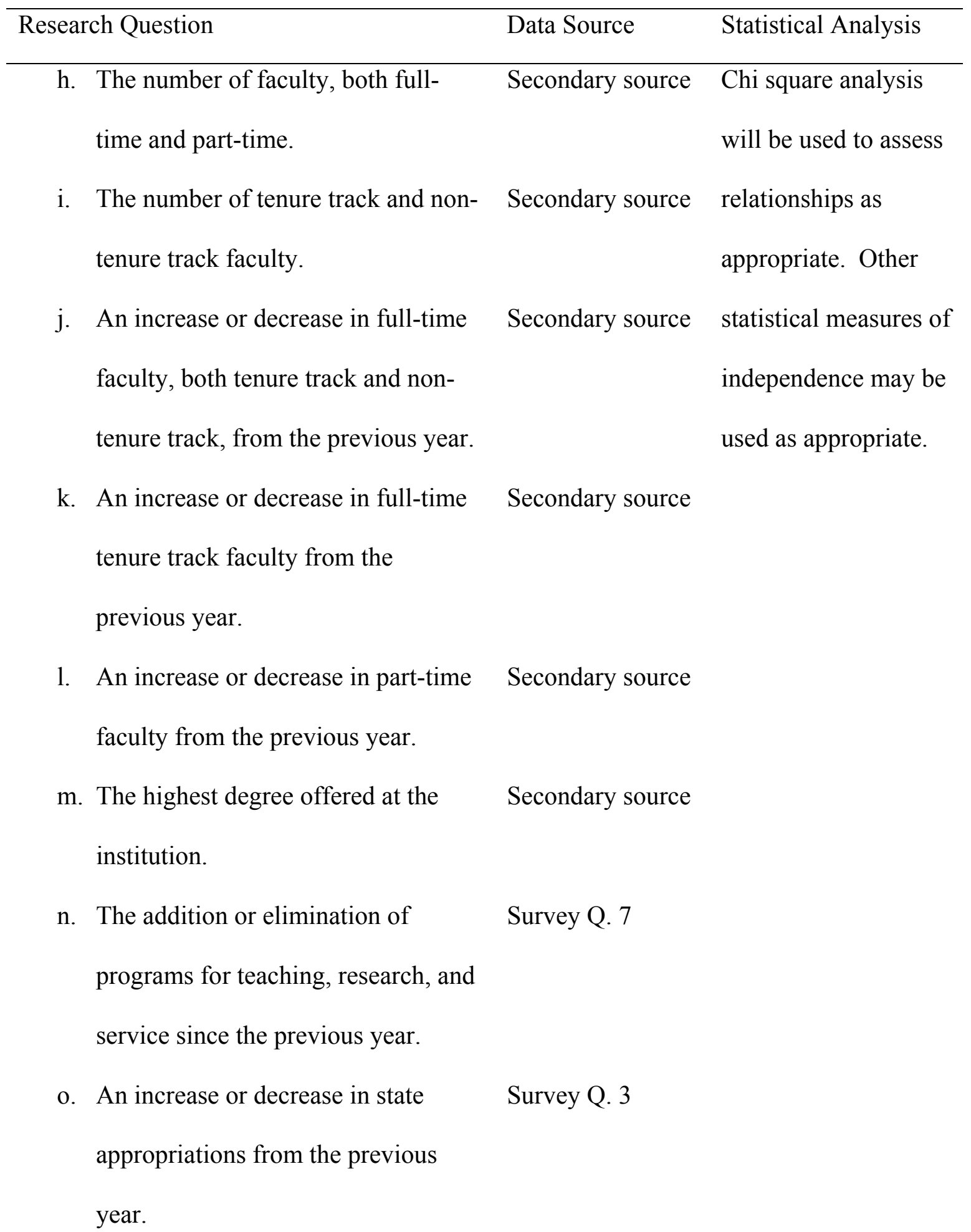




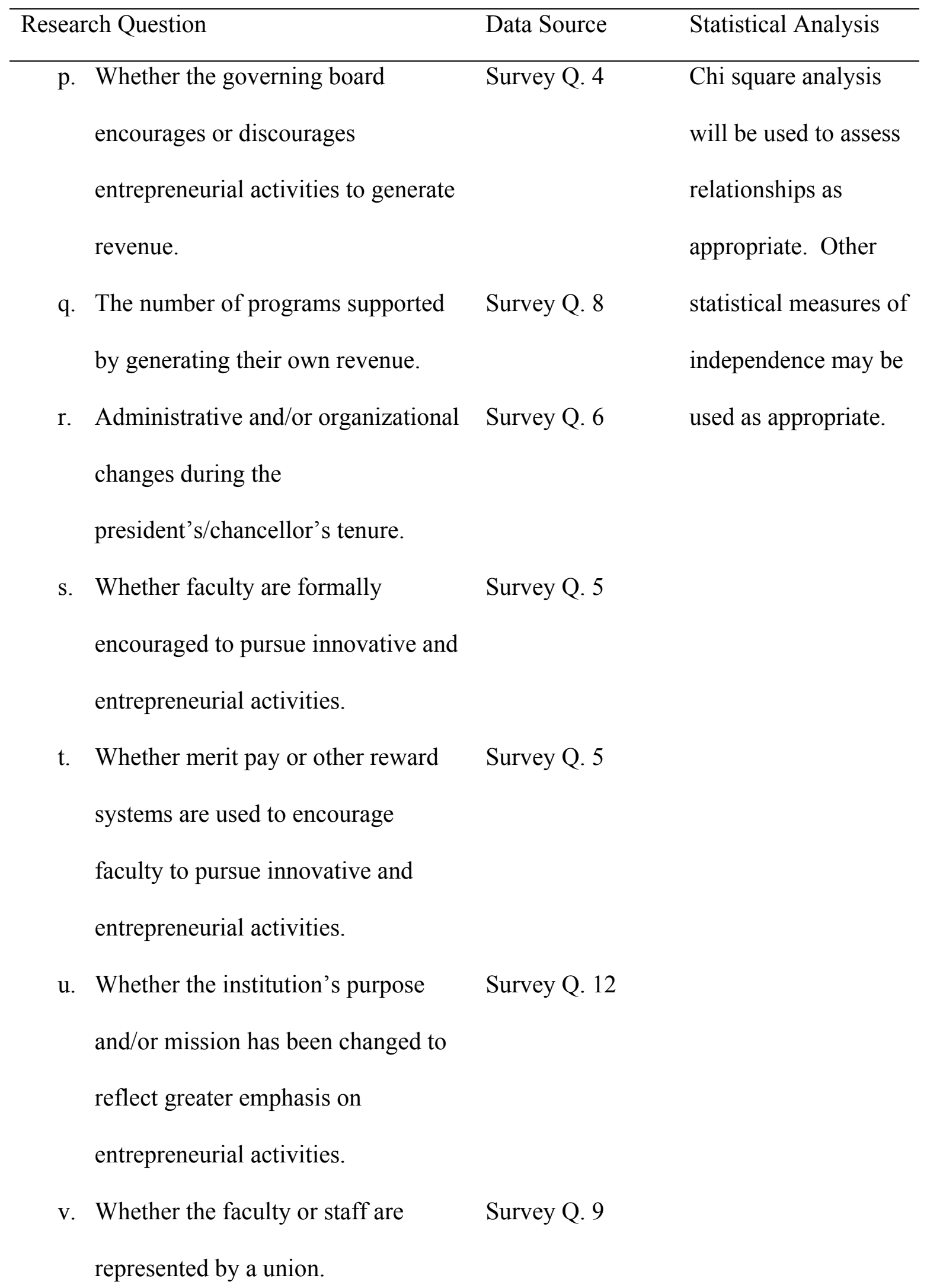




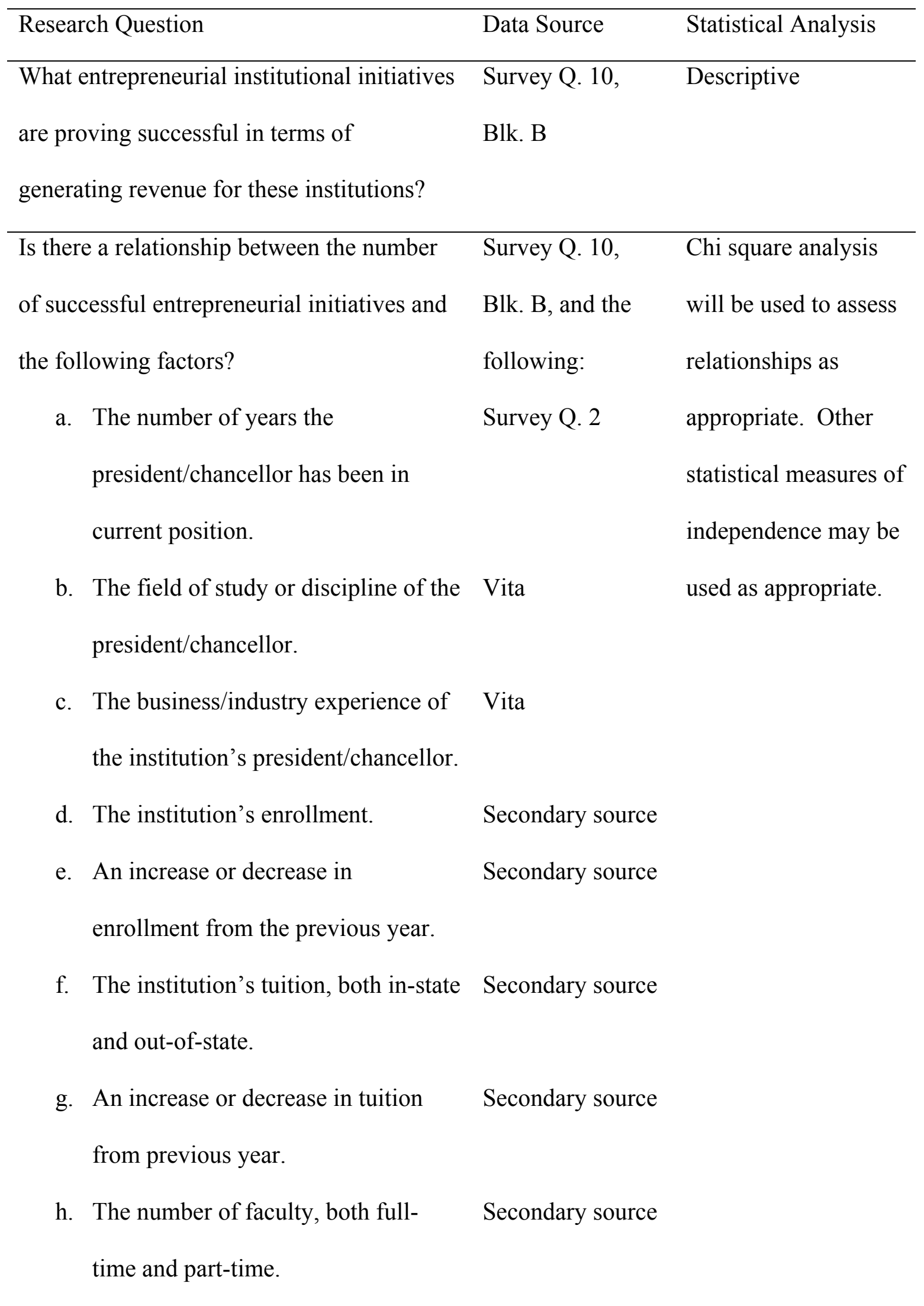




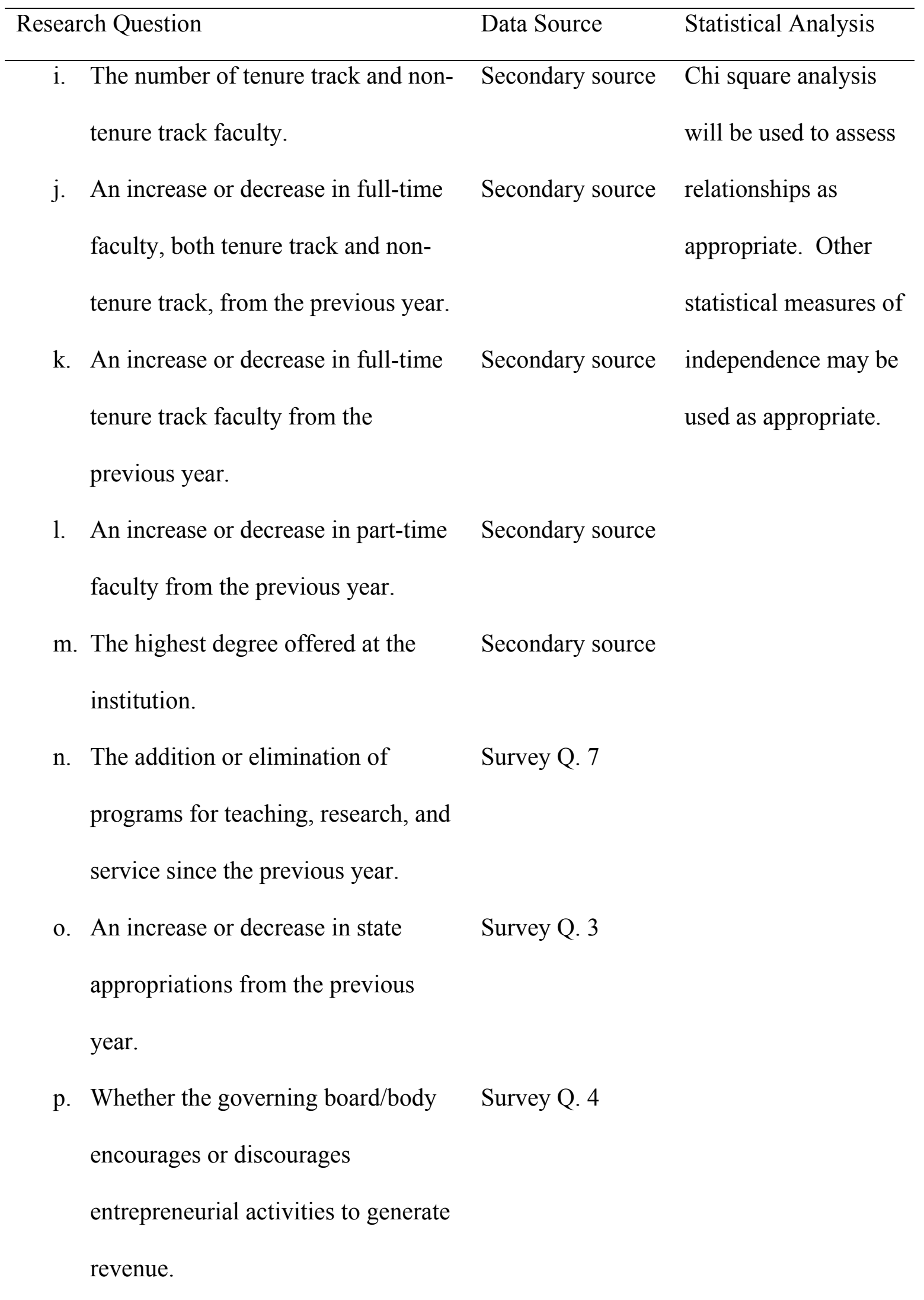




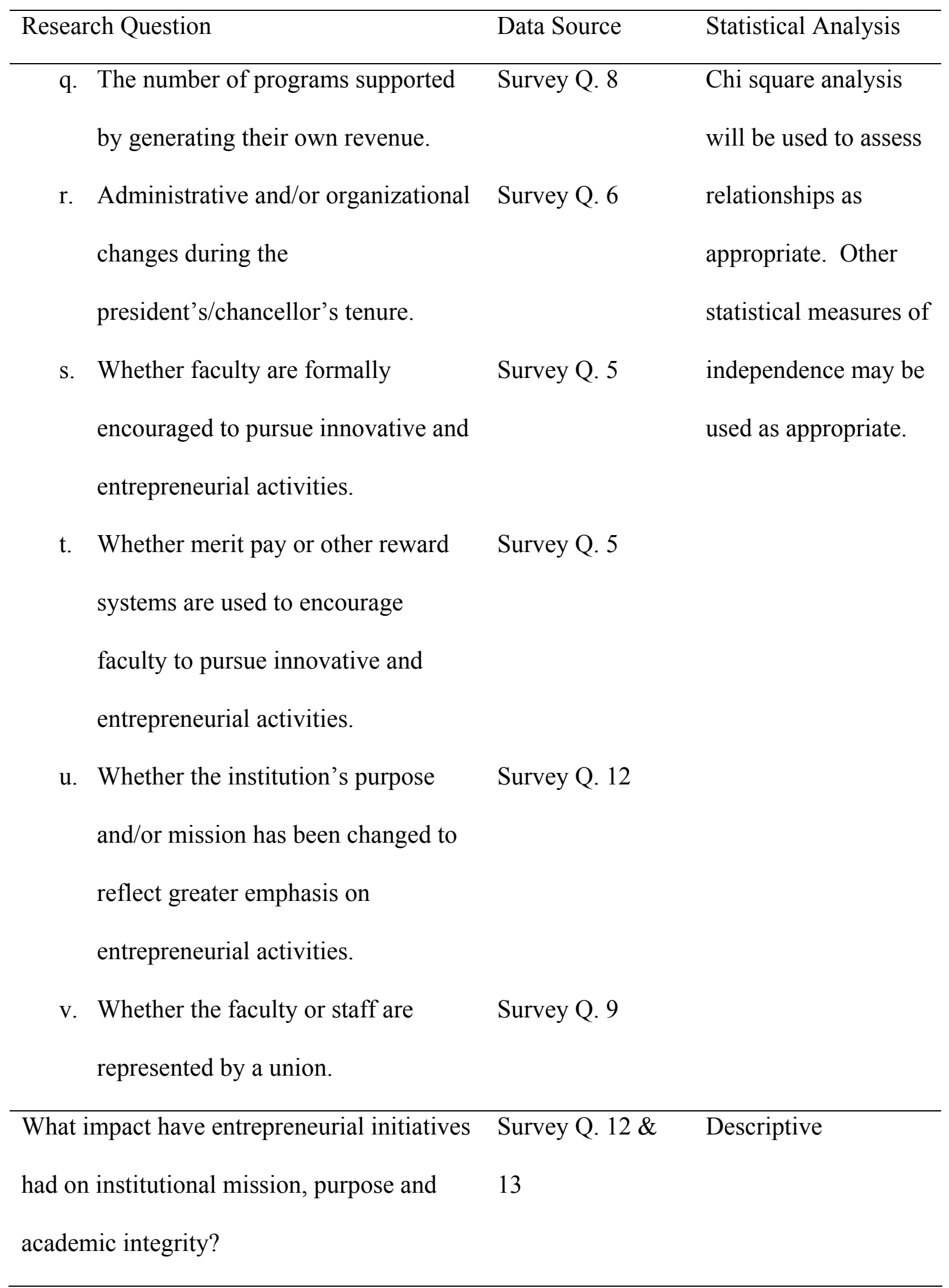




\begin{tabular}{lll}
\hline Research Question & Data Source & Statistical Analysis \\
\hline Does the institution's governing board/body & Survey Q. 4 & Descriptive \\
encourage or discourage entrepreneurial & & \\
initiatives to generate revenue? & & \\
& & \\
\hline
\end{tabular}

\section{Limitations of the Study}

This study used self-reported data and was limited to the accuracy of the participant's responses.

\section{Proposed Time Lines}

The dissertation prospectus was approved on October 13, 2004. Human Subjects approval was received on November 3, 2004. The initial introductory letter was mailed on November 8, 2004, the survey instrument was mailed on November 15, 2004, and the follow-up mailing on December 7, 2004. Follow-up telephone calls were made beginning January 3, 2005. Institutional data was collected by visiting institutional websites, the National Center for Education Statistics, and telephone calls to the institutions. This secondary data collection began November 8, 2004 and continued until all of the data was collected. The dissertation defense was scheduled for April 13, 2005, and graduation in May 2005.

\section{Background of the Researcher}

The researcher has been a resident of North Central West Virginia for most of his life. He is a Vietnam veteran, having served in the U.S. Air Force from 1968 to 1972. He completed a bachelor of arts degree in psychology at West Virginia University in 1975, and a master of science degree in industrial relations in 1976. He anticipates completion of the doctorate in Educational Leadership Studies in 2005. 
In 1977, the researcher began a career in the coal industry, working at a newly developing mine in Philippi, West Virginia. For ten years, he handled human resource management and labor relations, responsible for employment, benefits administration, employee relations, contract administration, resolution of disputes, and arbitration proceedings.

In 1987, the researcher accepted a position at Alderson-Broaddus College as Assistant Professor of Business. From 1988 to 1993, he chaired Alderson-Broaddus' Business department. During his tenure at Alderson-Broaddus College, he taught both business and computer science courses, was involved in community service projects, and regional labor \& market feasibility studies.

The researcher also worked from 1992 thru 1996 for the Community Association Reinforcing Education, first as a part-time adult education instructor and management consultant, and later as Executive Vice President, responsible for their strategic \& market planning, development of their operations procedures, and writing several successful grants to fund community economic development projects.

The researcher joined Fairmont State University in 1997 as Director of the Fairmont State University Regional Small Business Development Center. In 2001, he accepted the faculty position of Assistant Professor of Business Administration in the Fairmont State University School of Business, primarily teaching in the areas of entrepreneurship and human resource management. In 2004, he received the Fairmont State University Faculty Recognition award. 


\section{CHAPTER IV}

\section{RESULTS}

\section{Introduction}

This study examines the current patterns of entrepreneurial activities in public liberal arts and general baccalaureate colleges as defined by the Carnegie Classification of Institutions of Higher Education (The Carnegie Foundation for the Advancement of Teaching, 2000). This chapter presents an analysis of the results obtained from the returned surveys along with institutional data acquired from secondary sources. The results are presented for each of the research questions identified in Chapter I.

\section{Survey Response and Data Collection}

The entire population of 75 institutions was surveyed. A total of 31 institutions responded to the survey yielding a response rate of 41.3 percent. However, three of the survey responses could not be used. Thus, there were a total of 28 usable responses yielding a response rate of 37.3 percent.

Of the three unusable responses, one institution's president declined completing the survey instrument because the college is so non-traditional. It is an all distance learning, external degree institution with no full-time faculty, no service or research programs, and no academic units. The president of this institution indicated that the college was placed in the Carnegie Classification as a public liberal arts baccalaureate college because, in his words, "there was no place else to put us."

A second respondent declined completing the survey because the institution had only granted associate degrees until very recently. A third respondent only partially 
completed the survey instrument indicating that he was new to the institution and new to its presidency. The partial survey response was very incomplete and simply not usable.

A vita or biography was received for the president or chancellor of each institution that responded to the survey instrument. Institutional data regarding enrollments, tuition, faculty, and academic offerings was compiled for each institution that responded.

\section{Data Analysis}

With a relatively small sample size, the normality of the distributions for the numerous variables analyzed is of critical concern regarding the power of the statistical tests. The Kolmogrov-Smirnov test of normality was used to test variable distributions. Many of the variables were significantly different from the normal distribution. Some were not significantly different than the normal distribution, yet often were thick-tailed or skewed. Both of these facts suggest that nonparametric statistics, which do not require a normal distribution, be used to assess relationships between variables.

Institutional data on enrollments, tuition, faculty, and the highest degree offered at each institution were compiled for all seventy-five institutions in the population in order to provide comparative data to determine if the respondent institutions were representative of the population. 
Findings

This section presents the findings as derived from an analysis of the data for each research question identified in Chapter I.

Research Question 1: To what extent do these institutions generate revenue through entrepreneurial initiatives?

For the purposes of this study, entrepreneurship is defined as a market-oriented approach to managing institutions of higher education manifested through the creation of new ventures and new programs, along with innovative ways of performing traditional roles and responsibilities, with the objective of generating revenue for the institution. The survey instrument listed forty-three potential institutional initiatives and asked the respondents to indicate the level of use at their institution by checking a box for one of four choices: new initiative, traditionally used, planned for the future, or not applicable. Space was also provided for respondents to identify additional initiatives not listed on the survey and to make the same choices regarding usage. Two additional initiatives were added by one of the respondent institutions: off-campus housing and the purchase of a golf course. Table 2 summarizes the findings on the level of use by the respondent institutions.

Table 2

Entrepreneurial Initiatives Level of Use

\begin{tabular}{lccccccccc}
\hline Entrepreneurial Initiative & \multicolumn{2}{c}{$\begin{array}{c}\text { New } \\
\text { Initiative }\end{array}$} & \multicolumn{2}{c}{$\begin{array}{c}\text { Traditionally } \\
\text { Used }\end{array}$} & \multicolumn{2}{c}{$\begin{array}{c}\text { Planned } \\
\text { for Future }\end{array}$} & \multicolumn{2}{c}{$\begin{array}{c}\text { Apt } \\
\text { Applicable }\end{array}$} \\
\hline & $\#$ & $\%$ & $\#$ & $\%$ & $\#$ & $\%$ & $\#$ & $\%$ \\
\hline Innovation/Entrepreneurship Center & 2 & 7.1 & 1 & 3.6 & 5 & 17.9 & 20 & 71.4 \\
Small Business Development Center & 1 & 3.6 & 8 & 28.6 & 2 & 7.1 & 17 & 60.7
\end{tabular}




\begin{tabular}{|c|c|c|c|c|c|c|c|c|}
\hline \multirow[t]{2}{*}{ Entrepreneurial Initiative } & \multicolumn{2}{|c|}{$\begin{array}{c}\text { New } \\
\text { Initiative }\end{array}$} & \multicolumn{2}{|c|}{$\begin{array}{c}\text { Traditionally } \\
\text { Used }\end{array}$} & \multicolumn{2}{|c|}{$\begin{array}{l}\text { Planned } \\
\text { for Future }\end{array}$} & \multicolumn{2}{|c|}{$\begin{array}{c}\text { Not } \\
\text { Applicable }\end{array}$} \\
\hline & $\#$ & $\%$ & $\#$ & $\%$ & \# & $\%$ & $\#$ & $\%$ \\
\hline Incubation of Start-Up Companies & 1 & 3.6 & 2 & 7.1 & 4 & 14.3 & 21 & 75.0 \\
\hline \multicolumn{9}{|l|}{ Product Development Services to } \\
\hline Business/Industry & 1 & 3.6 & 2 & 7.1 & 3 & 10.7 & 22 & 78.6 \\
\hline \multicolumn{9}{|l|}{ Technical Services to } \\
\hline Business/Industry & 1 & 3.6 & 3 & 10.7 & 2 & 7.1 & 22 & 78.6 \\
\hline \multicolumn{9}{|l|}{ Personnel Exchanges with } \\
\hline Business/Industry & 1 & 3.6 & 3 & 10.7 & 5 & 17.9 & 19 & 67.9 \\
\hline \multicolumn{9}{|l|}{ Personnel Exchanges with } \\
\hline Government Agencies & 0 & 0 & 4 & 14.3 & 4 & 14.3 & 20 & 71.4 \\
\hline \multicolumn{9}{|l|}{ Contract-Training Programs with } \\
\hline Business/Industry & 4 & 14.3 & 10 & 35.7 & 2 & 7.1 & 12 & 42.9 \\
\hline \multicolumn{9}{|l|}{ Contract-Training Programs with } \\
\hline Government Agencies & 2 & 7.1 & 9 & 32.1 & 2 & 7.1 & 15 & 53.6 \\
\hline \multicolumn{9}{|l|}{ Executive Training Programs for } \\
\hline Business/Industry & 3 & 10.7 & 3 & 10.7 & 4 & 14.3 & 18 & 64.3 \\
\hline \multicolumn{9}{|l|}{ Specialized Training Programs and } \\
\hline \multicolumn{9}{|l|}{ Certificate Programs for } \\
\hline Business/Industry & 2 & 7.1 & 11 & 39.3 & 7 & 25.0 & 8 & 28.6 \\
\hline \multicolumn{9}{|l|}{ Research Contracts with Government } \\
\hline Agencies & 2 & 7.1 & 14 & 50.0 & 2 & 7.1 & 10 & 35.7 \\
\hline \multicolumn{9}{|l|}{ Research Contracts with Private } \\
\hline Sector Enterprises & 3 & 10.7 & 5 & 17.9 & 9 & 32.1 & 11 & 39.3 \\
\hline \multicolumn{9}{|l|}{ Joint Ventures or Partnerships with } \\
\hline Private Sector Enterprises & 2 & 7.1 & 7 & 25.0 & 6 & 21.4 & 13 & 46.4 \\
\hline \multicolumn{9}{|l|}{ Technology Transfer Centers to } \\
\hline \multicolumn{9}{|l|}{ Patent, License and/or Commercialize } \\
\hline Research Outcomes & 0 & 0 & 1 & 3.6 & 3 & 10.7 & 24 & 85.7 \\
\hline
\end{tabular}




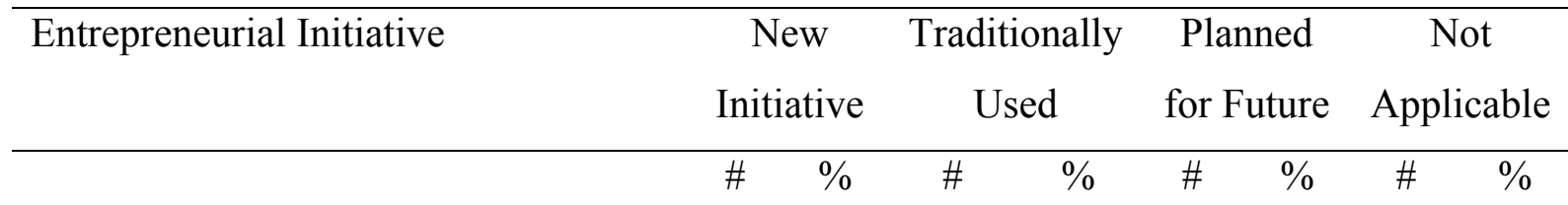

Spin-Off Companies from Research

Outcomes

$\begin{array}{llllllll}0 & 0 & 1 & 3.6 & 4 & 14.3 & 23 & 82.1\end{array}$

Distance-Learning Programs within

Existing Organizational Structure

$\begin{array}{llllllll}4 & 14.3 & 19 & 67.9 & 2 & 7.1 & 3 & 10.7\end{array}$

Distance-Learning Programs in

Partnership with Private Sector

Enterprise

$\begin{array}{llllllll}1 & 3.6 & 1 & 3.6 & 6 & 21.4 & 20 & 71.4\end{array}$

Distance-Learning Programs as For-

Profit Subsidiaries

$\begin{array}{llllllll}1 & 3.6 & 0 & 0 & 4 & 14.3 & 23 & 82.1\end{array}$

Distance-Learning Programs Funded

through Venture Capital

$\begin{array}{llllllll}2 & 7.1 & 0 & 0 & 1 & 3.6 & 25 & 89.3\end{array}$

Evening Degree Offering Programs

$\begin{array}{llllllll}1 & 3.6 & 16 & 57.1 & 4 & 14.3 & 7 & 25.0\end{array}$

Weekend Degree Offering Programs

$\begin{array}{lll}2 & 7.1 & 8\end{array}$

Degree Completion Programs

$\begin{array}{llllllll}2 & 7.1 & 18 & 64.3 & 0 & 0 & 8 & 28.6\end{array}$

Certificate Programs

$\begin{array}{llllllll}0 & 0 & 15 & 53.6 & 2 & 7.1 & 11 & 39.3\end{array}$

Fast Track Programs

$\begin{array}{llllllll}1 & 3.6 & 4 & 14.3 & 2 & 7.1 & 21 & 75.0\end{array}$

Executive Programs

$\begin{array}{llllllll}0 & 0 & 3 & 10.7 & 3 & 10.7 & 22 & 78.6\end{array}$

College/University Foundation to

Raise Funds to Support Programs and

Services

$\begin{array}{llllllll}2 & 7.1 & 21 & 75.0 & 1 & 3.6 & 4 & 14.3\end{array}$

Alumni Association to Raise Funds to

Support Programs and Services

Initiated a Capital Campaign

$\begin{array}{llllllll}4 & 14.3 & 14 & 50.0 & 5 & 17.9 & 5 & 17.9\end{array}$

$\begin{array}{llllllll}5 & 17.9 & 7 & 25.0 & 8 & 28.6 & 8 & 28.6\end{array}$

Sale of Products and Services from

Educational Endeavors

$\begin{array}{llllllll}1 & 3.6 & 6 & 21.4 & 2 & 7.1 & 19 & 67.9\end{array}$

Licensing of Products and Services

from Educational Endeavors

$\begin{array}{llllllll}2 & 7.1 & 5 & 17.9 & 2 & 7.1 & 19 & 67.9\end{array}$ 


\begin{tabular}{|c|c|c|c|c|}
\hline \multirow[t]{2}{*}{ Entrepreneurial Initiative } & $\begin{array}{c}\text { New } \\
\text { Initiative }\end{array}$ & $\begin{array}{c}\text { Traditionally } \\
\text { Used }\end{array}$ & $\begin{array}{l}\text { Planned } \\
\text { for Future }\end{array}$ & $\begin{array}{c}\text { Not } \\
\text { Applicable }\end{array}$ \\
\hline & & $\%$ & $\%$ & $\%$ \\
\hline
\end{tabular}

Profit-Sharing with Food Service,

Bookstores, and Other Auxiliary

Services

Develop Real Estate Endowments

$\begin{array}{llllllll}1 & 3.6 & 19 & 67.9 & 0 & 0 & 8 & 28.6\end{array}$

$\begin{array}{llllllll}2 & 7.1 & 2 & 7.1 & 1 & 3.6 & 23 & 82.1\end{array}$

Debt Financing, such as Revenue

Bonds

Develop or Expand Endowments

$\begin{array}{llllllll}0 & 0 & 16 & 57.1 & 0 & 0 & 12 & 42.9\end{array}$

Develop New Revenues from

$\begin{array}{lllllllll}\text { Sports/Athletic Events and Activities } & 3 & 10.7 & 7 & 25.0 & 6 & 21.4 & 12 & 42.9\end{array}$

Lease/Rent Institutional Facilities

and/or Equipment

$\begin{array}{llllllll}2 & 7.1 & 14 & 50.0 & 2 & 7.1 & 10 & 35.7\end{array}$

Retail Sales of Institutional Resources.

Such as Computer Time and Internet

\begin{tabular}{lcccccccc} 
Access & 1 & 3.6 & 3 & 10.7 & 2 & 7.1 & 22 & 78.6 \\
Catering Food Services & 0 & 0 & 12 & 42.9 & 1 & 3.6 & 15 & 53.6 \\
Increasing Tuition and Fees & 2 & 7.1 & 21 & 75.0 & 0 & 0 & 5 & 17.9 \\
Increasing Residence Fees & 1 & 3.6 & 18 & 64.3 & 0 & 0 & 9 & 32.1 \\
Increasing Cost of Campus Food & & & & & & & & \\
Services & 0 & 0 & 17 & 60.7 & 0 & 0 & 11 & 39.3 \\
Increasing Student Laboratory, & & & & & & & & \\
Supplies, and Other Service Fees & 1 & 3.6 & 20 & 71.4 & 1 & 3.6 & 6 & 21.4 \\
Off Campus Housing & 1 & 3.6 & 0 & 0 & 0 & 0 & 27 & 96.4 \\
Purchase Golf Course & 1 & 3.6 & 0 & 0 & 0 & 0 & 27 & 96.4 \\
\hline
\end{tabular}

The highest used new initiative was the initiation of a capital campaign (17.9\%).

Over fourteen percent reported new initiatives using contract-training programs with business/industry, distance-learning programs within existing organizational structure, 
and alumni associations to raise funds to support programs and services. Executive training programs for business/industry, research contracts with private sector enterprises, development or expansion of endowments, and development of new revenues from sports/athletic events and activities were reported by 10.7 percent of the institutions as new initiatives. None of the institutions reported new initiatives for personnel exchanges with government agencies, technology transfer centers, spin-off companies from research outcomes, certificate programs, executive programs, debt financing, catering food services, or increasing cost of campus food services.

Over seventy percent of the institutions reported traditionally increasing tuition and fees, using the college/university foundation to raise funds, and increasing student laboratory, supplies, and other service fees. Fifty percent or more traditionally use research contracts with government agencies, distance learning programs within the existing organizational structure, evening degree offering programs, degree completion programs, certificate programs, alumni association to raise funds, profit-sharing with food service, bookstore, and other auxiliary services, debt financing, lease/rent institutional facilities and/or equipment, increasing residence fees, and increasing costs of campus food services. None of the institutions reported traditionally using distancelearning programs as for-profit subsidiaries, distance-learning programs funded through venture capital, off campus housing, or the purchase of a golf course.

The highest reported initiative planned for the future was research contracts with private sector enterprises $(32.1 \%)$. The next highest was to initiate a capital campaign $(28.6 \%)$. Over twenty percent reported new initiatives planned for the future in the areas of specialized training programs and certificate programs for business/industry, joint 
ventures or partnerships with private sector enterprises, distance-learning programs in partnership with private sector enterprise, and develop new revenues from sports/athletic events and activities. None of the institutions reported new initiatives planned for the future in the areas of degree completion programs, profit-sharing with food service, bookstores, and other auxiliary services, debt financing, increasing tuition and fees, increasing residence fees, increasing cost of campus food services, off campus housing, and purchase of golf course.

Table 3 identifies, in rank order, the number of institutions currently using each initiative, whether as a new initiative or a traditionally used initiative.

Table 3

Rank Order Listing of Number of Institutions Currently Using Each Entrepreneurial Initiative

\begin{tabular}{lccc}
\hline Entrepreneurial Initiative & $\mathrm{n}=28$ & $\#$ & $\%$ \\
\hline Increasing Tuition and Fees & & 23 & 82.1
\end{tabular}

College/University Foundation to Raise Funds to Support Programs and

Services

Distance-Learning Programs within Existing Organizational Structure

Profit-Sharing with Food Service, Bookstores, and Other Auxiliary

Services 


\begin{tabular}{|c|c|c|}
\hline Entrepreneurial Initiative & \# & $\%$ \\
\hline Increasing Cost of Campus Food Services & 17 & 60.7 \\
\hline Evening Degree Offering Programs & 17 & 60.7 \\
\hline Lease/Rent Institutional Facilities and/or Equipment & 16 & 57.1 \\
\hline Develop or Expand Endowments & 16 & 57.1 \\
\hline Debt Financing, such as Revenue Bonds & 16 & 57.1 \\
\hline Research Contracts with Government Agencies & 16 & 57.1 \\
\hline Certificate Programs & 15 & 53.6 \\
\hline Contract-Training Programs with Business/Industry & 14 & 50.0 \\
\hline \multicolumn{3}{|l|}{ Specialized Training Programs and Certificate Programs for } \\
\hline Business/Industry & 13 & 46.4 \\
\hline Catering Food Services & 12 & 42.9 \\
\hline Initiated a Capital Campaign & 12 & 42.9 \\
\hline Contract-Training Programs with Government Agencies & 11 & 39.3 \\
\hline Develop New Revenues from Sports/Athletic Events and Activities & 10 & 35.7 \\
\hline Weekend Degree Offering Programs & 10 & 35.7 \\
\hline Joint Ventures or Partnerships with Private Sector Enterprises & 9 & 32.1 \\
\hline Small Business Development Center & 9 & 32.1 \\
\hline Research Contracts with Private Sector Enterprises & 8 & 28.6 \\
\hline Sale of Products and Services from Educational Endeavors & 7 & 25.0 \\
\hline Licensing of Products and Services from Educational Endeavors & 7 & 25.0 \\
\hline Executive Training Programs for Business/Industry & 6 & 21.4 \\
\hline Fast Track Programs & 5 & 17.9 \\
\hline
\end{tabular}




\begin{tabular}{|c|c|c|c|}
\hline Entrepreneurial Initiative & $\mathrm{n}=28$ & \# & $\%$ \\
\hline Technical Services to Business/Industry & & 4 & 14.3 \\
\hline Personnel Exchanges with Business/Industry & & 4 & 14.3 \\
\hline Personnel Exchanges with Government Agencies & & 4 & 14.3 \\
\hline Develop Real Estate Endowments & & 4 & 14.3 \\
\hline \multicolumn{4}{|l|}{ Retail Sales of Institutional Resources, such as Computer Time and } \\
\hline Internet Access & & 4 & 14.3 \\
\hline Innovation/Entrepreneurship Center & & 3 & 10.7 \\
\hline Incubation of Start-Up Companies & & 3 & 10.7 \\
\hline Product Development Services to Business/Industry & & 3 & 10.7 \\
\hline Executive Programs & & 3 & 10.7 \\
\hline Distance-Learning Programs Funded through Venture Capital & & 2 & 7.1 \\
\hline \multicolumn{4}{|c|}{ Technology Transfer Centers to Patent, License and/or Commercialize } \\
\hline Research Outcomes & & 1 & 3.6 \\
\hline Spin-Off Companies from Research Outcomes & & 1 & 3.6 \\
\hline \multicolumn{4}{|l|}{ Distance-Learning Programs in Partnership with Private Sector } \\
\hline Enterprise & & 1 & 3.6 \\
\hline Distance-Learning Programs as For-Profit Subsidiaries & & 1 & 3.6 \\
\hline Off Campus Housing & & 1 & 3.6 \\
\hline Purchase Golf Course & & 1 & 3.6 \\
\hline
\end{tabular}

The respondent institutions reported most frequently using increasing tuition and fees, college/university foundations, and distance-learning within the existing organizational structure (82.1\%). It was also found that technology transfer centers, spin- 
off companies, distance-learning programs in partnership with private sector enterprise, distance-learning programs as for-profit subsidiaries, off campus housing, and purchase of a golf course were reported by only 3.6 percent of the respondents.

The number of new initiatives used ranged from zero (13 respondents, 46.4\%) to thirteen ( 1 respondent, 3.6\%). Table 4 summarizes the number of new initiatives used by the respondent institutions.

Table 4

Number of New Initiatives Used by Respondent Institutions

\begin{tabular}{ccc}
\hline Number of New Initiatives & Frequency & Percent \\
\hline 0 & 13 & 46.4 \\
1 & 5 & 17.9 \\
2 & 1 & 3.6 \\
3 & 1 & 3.6 \\
4 & 1 & 3.6 \\
5 & 2 & 7.1 \\
6 & 1 & 3.6 \\
7 & 1 & 3.6 \\
9 & 1 & 3.6 \\
12 & 1 & 3.6 \\
13 & 1 & 3.6 \\
\hline Total & 28 & 100.0 \\
\hline
\end{tabular}

A one-sample Kolmogrov-Smirnov test of normality was conducted on the distribution of new initiatives to assess whether it is normally distributed. With alpha set at .05 , the results of the test were significant, $K-S($ Lilliefors $)(28)=.301, p<.01$. The distribution of new initiatives is significantly different from a normal distribution, as clearly represented by the histogram in Figure 1. 
Figure 1. Distribution of New Initiatives Used by the Respondent Institutions Compared to the Normal Distribution

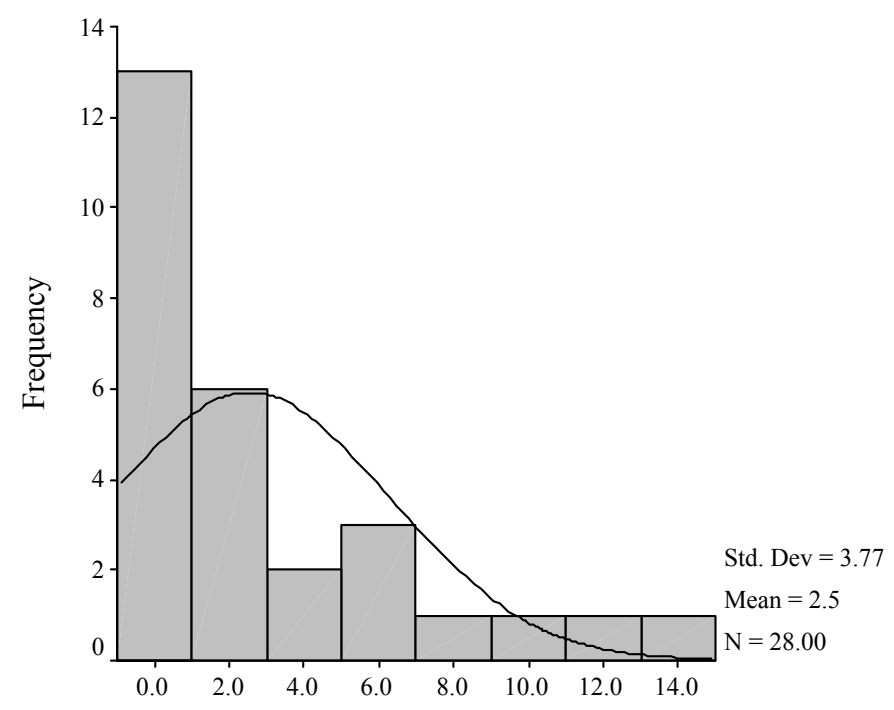

Number of New Initiatives

The number of traditionally used initiatives ranged from zero (1 respondent, $3.6 \%$ ) to thirty ( 1 respondent, 3.6\%). Table 5 summarizes the distribution. A one-sample Kolmogrov-Smirnov test of normality was conducted on the distribution to assess normality. With alpha set at .05 , the results of the test were not significant, $K$ $S($ Lilliefors $)(28)=.147, \mathrm{p}>.05$. As represented in Figure 2, the distribution of traditionally used initiatives is not significantly different from a normal distribution.

Table 5

Number of Traditionally Used Initiatives Reported by Respondent Institutions

\begin{tabular}{ccc}
\hline $\begin{array}{c}\text { Number of Traditionally } \\
\text { Used Initiatives }\end{array}$ & Frequency & Percent \\
\hline 0 & 1 & 3.6 \\
5 & 1 & 3.6 \\
7 & 1 & 3.6 \\
8 & 1 & 3.6
\end{tabular}




\begin{tabular}{ccc}
\hline $\begin{array}{c}\text { Number of Traditionally } \\
\text { Used Initiatives }\end{array}$ & Frequency & Percent \\
\hline 9 & 1 & 3.6 \\
10 & 3 & 10.7 \\
11 & 2 & 7.1 \\
12 & 2 & 7.1 \\
13 & 1 & 3.6 \\
14 & 5 & 17.9 \\
15 & 1 & 3.6 \\
16 & 1 & 3.6 \\
17 & 4 & 14.3 \\
18 & 1 & 3.6 \\
23 & 1 & 3.6 \\
25 & 1 & 3.6 \\
30 & 1 & 3.6 \\
\hline Total & 28 & 100.0 \\
\hline
\end{tabular}

Figure 2. Distribution of Traditionally Used Initiatives Reported by Respondent Institutions Compared to the Normal Distribution

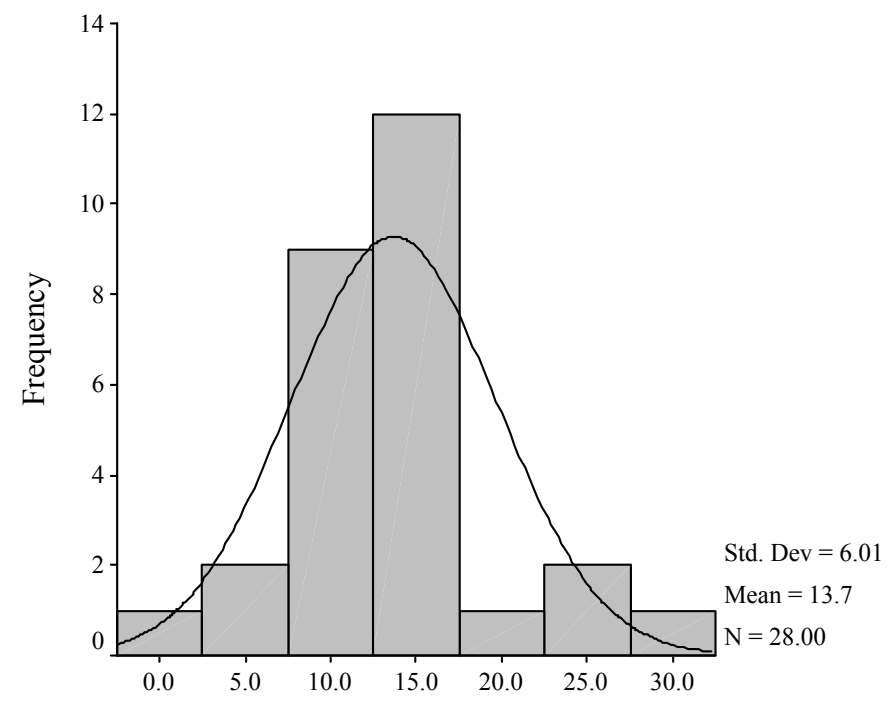

Number of Traditionally Used Initiatives 
The number of initiatives planned for the future ranged from zero ( 8 respondents, $28.6 \%$ ) to twelve ( 1 respondent, 3.6\%). Table 6 summarizes the number of initiatives planned for the future by the respondent institutions. A one-sample Kolmogrov-Smirnov test of normality was conducted on the distribution to assess whether it is normally distributed. With alpha set at .05 , the results of the test were not significant, $K$ $S($ Lilliefors $)(28)=.161, \mathrm{p}>.05$. The distribution of initiatives planned for the future is not significantly different from a normal distribution, as represented by the histogram in Figure 3 .

Table 6

Distribution of Initiatives Planned for the Future Reported by Respondent Institutions

\begin{tabular}{ccc}
\hline $\begin{array}{c}\text { Number of Initiatives } \\
\text { Planned for the Future }\end{array}$ & Frequency & Percent \\
\hline 0 & 8 & 28.6 \\
2 & 2 & 7.1 \\
3 & 2 & 7.1 \\
4 & 1 & 3.6 \\
5 & 2 & 7.1 \\
6 & 1 & 3.6 \\
7 & 2 & 7.1 \\
8 & 2 & 7.1 \\
9 & 1 & 3.6 \\
10 & 1 & 3.6 \\
11 & 4 & 14.3 \\
12 & 1 & 3.6 \\
\hline Total & 1 & 3.6 \\
\hline
\end{tabular}


Figure 3. Distribution of Initiatives Planned for the Future as Reported by Respondent Institutions Compared to the Normal Distribution

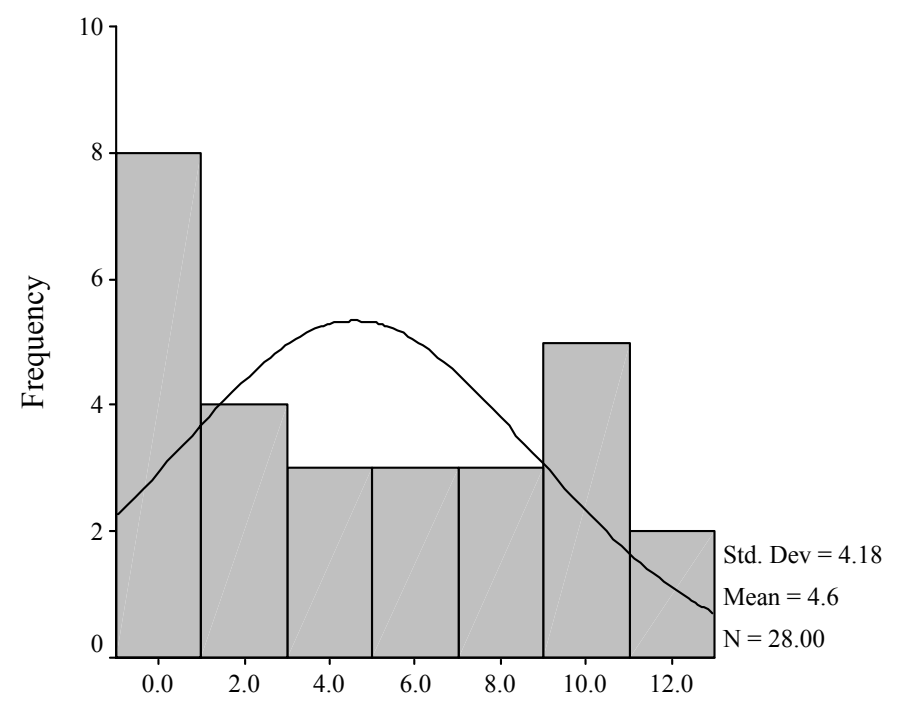

Number of Initiatives Planned for the Future

In order to further analyze the data on entrepreneurial initiatives, an

Entrepreneurial Score was calculated for each respondent. Calculation of the score was accomplished by summing numerical weights for all selected New Initiatives (weight = 3), all selected Traditionally Used (weight $=2$ ), all selected Planned for the Future $($ weight $=1)$, and all selected Not Applicable $($ weight $=0)$ for each respondent. The scores were then placed in rank order from lowest to highest score. Table 7 lists the calculated entrepreneurial scores. 
Table 7

Entrepreneurial Scores

\begin{tabular}{|c|c|c|c|}
\hline Score & Frequency & Score & Frequency \\
\hline 13 & 1 & 38 & 1 \\
\hline 19 & 1 & 39 & 2 \\
\hline 24 & 1 & 43 & 1 \\
\hline 26 & 1 & 44 & 1 \\
\hline 29 & 2 & 48 & 1 \\
\hline 31 & 1 & 50 & 1 \\
\hline 32 & 2 & 55 & 2 \\
\hline 33 & 1 & 58 & 1 \\
\hline 34 & 1 & 59 & 1 \\
\hline 35 & 1 & 65 & 1 \\
\hline 36 & 1 & 66 & 1 \\
\hline 37 & 2 & & $\mathrm{n}=28$ \\
\hline
\end{tabular}

The scores ranged from a minimum score of 13 to a maximum score of $66(M=$ 39.50, $S D=13.39)$. Higher scores indicate higher entrepreneurial activity. The Entrepreneurial Score is the dependent variable used for further statistical analysis of possible relationships with numerous independent variables. For testing some variable relationships, the Entrepreneurial Score will be divided at the median into two groups. Scores at or below the median will be considered low entrepreneurial scores. Scores above the median will be considered high entrepreneurial scores. 
A one-sample Kolmogrov-Smirnov test of normality was conducted on the distribution of entrepreneurial scores to assess whether the scores are normally distributed. With alpha set at .05 , the results of the test were not significant, $K$ $S($ Lilliefors $)(28)=.158, \mathrm{p}>.05$. The distribution of entrepreneurial scores is not significantly different from a normal distribution, as represented in Figure 4.

Figure 4. Distribution of Entrepreneurial Scores Compared to the Normal Distribution

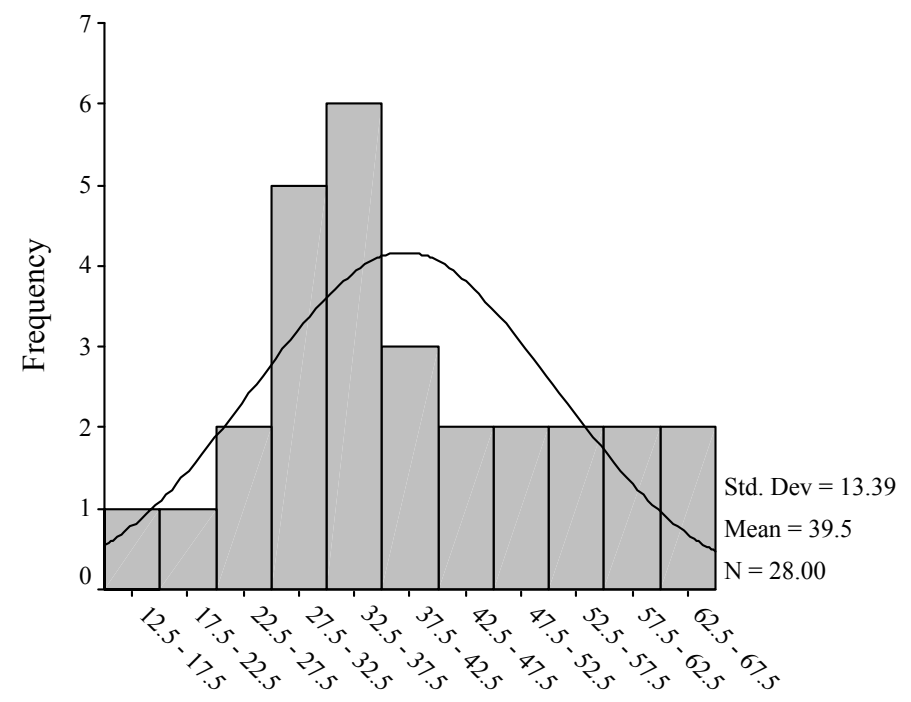

Entrepreneurial Score

Research Question 2: Is there a relationship between the number of entrepreneurial initiatives and the following factors:

The number of years the president/chancellor has been in current position?

The findings regarding the president's/chancellor's number of years in current position and the entrepreneurial activity for each corresponding institution is summarized in Table 8. 
Table 8 .

Cross Tabulation of High and Low Entrepreneurial Scores with President's/Chancellor's Length of Time in Current Position

\begin{tabular}{cccc}
\hline $\begin{array}{c}\text { Length of Time in Current } \\
\text { Position }\end{array}$ & $\begin{array}{c}\text { Low Entrepreneurial } \\
\text { Score }\end{array}$ & $\begin{array}{c}\text { High Entrepreneurial } \\
\text { Score }\end{array}$ & Total \\
\hline 5 or Fewer Years & 10 & 8 & 18 \\
6 to 10 Year & 3 & 3 & 3 \\
11 to 15 Years & 0 & 1 & 3 \\
16 to 20 Years & 2 & 1 & 3 \\
21 or More Years & 0 & 13 & 28 \\
\hline Total & 15 & & 1 \\
\hline
\end{tabular}

The majority of presidents/chancellors have been in their current position five or fewer years $(64.3 \%)$. Of the fifteen institutions with low entrepreneurial scores $(\leq 37)$, ten $(66.7 \%)$ of the presidents/chancellors have been in their current position five or fewer years. Of the thirteen institutions with high entrepreneurial scores $(>37)$, eight $(61.5 \%)$ have been in their current positions five or fewer years. It appears that the president's/chancellor's length of service in that capacity has either an inverse relationship or no relationship to the level of entrepreneurial activity.

A one-sample Kolmogrov-Smirnov test of normality was conducted on the distribution of the president's/chancellor's length of service to assess whether the responses are normally distributed. With alpha set at .05 , the results of the test were significant, $K-S($ Lilliefors $)(28)=.277, \mathrm{p}<.01$. The distribution of the 
president's/chancellor's length of service is significantly different from a normal distribution, as represented in Figure 5.

Figure 5. Distribution of President's/Chancellor's Length of Service Compared to the Normal Distribution

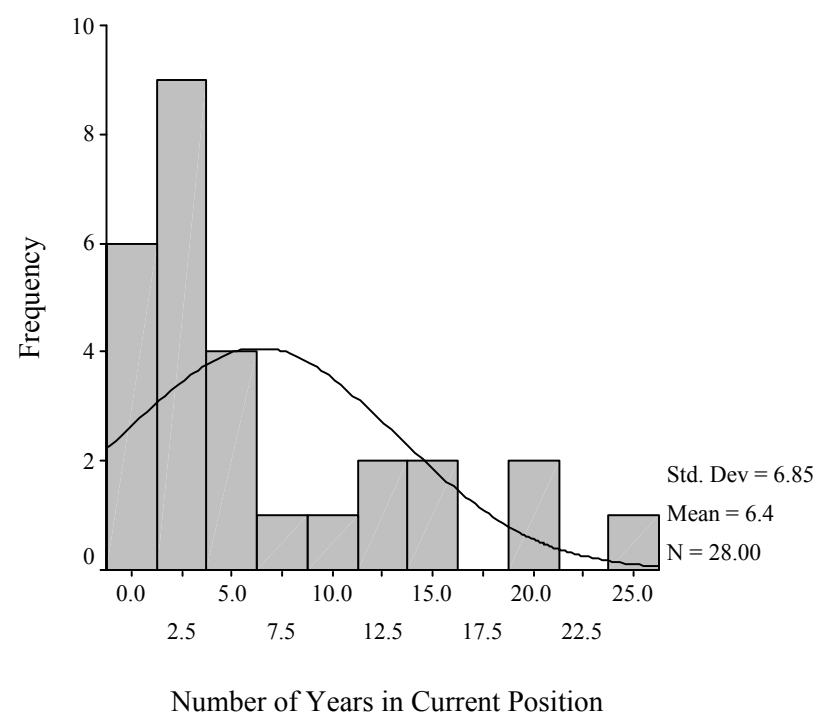

A Kruskal-Wallis test was conducted to evaluate the differences among the five length of service categories on median change in the level of entrepreneurial activity using the Entrepreneurial Score. With alpha set at .05 , the test was not significant, $\chi^{2}(4, N$ $=28)=7.185, p>.05$. The critical value was 9.49. This suggests that there is no significant relationship between the time in office of the president/chancellor and the level of entrepreneurial activity at the institution as measured by the Entrepreneurial Score.

Assessing specifically the number of new initiatives as a measure of entrepreneurial activity yields some additional insight. A Kruskal-Wallis test was conducted to evaluate the differences among the five length of service categories on median change in the level of entrepreneurial activity using the number of new initiatives 
as a measure of entrepreneurial activity. With alpha set at .05, the test was significant, $\chi^{2}(4, N=28)=10.031, p<.05$. The critical value was 9.49 . The proportion of variability in the ranked dependent variable accounted for by the president's/chancellor's years of service in current position was $\eta^{2}=.37$, indicating a fairly strong relationship between the length of service in current position of the president/chancellor and the number of new initiatives.

Follow-up tests were conducted to evaluate pair wise differences among the five length of service categories, controlling for Type I error across tests using Holm's sequential Bonferroni approach. The results of these tests indicate a significant difference between the five or fewer years group and the eleven to fifteen years group (see Figure 6). The median number of new initiatives was higher for the eleven to fifteen years group than for the five or fewer years group, offering support that the length of service of the president/chancellor does affect entrepreneurial activity, at least in terms of new initiatives.

Figure 6. Significant Difference in Number of New Initiatives Between 5 or Fewer Years in Current Position Group and 11 to 15 Years in Current Position Group

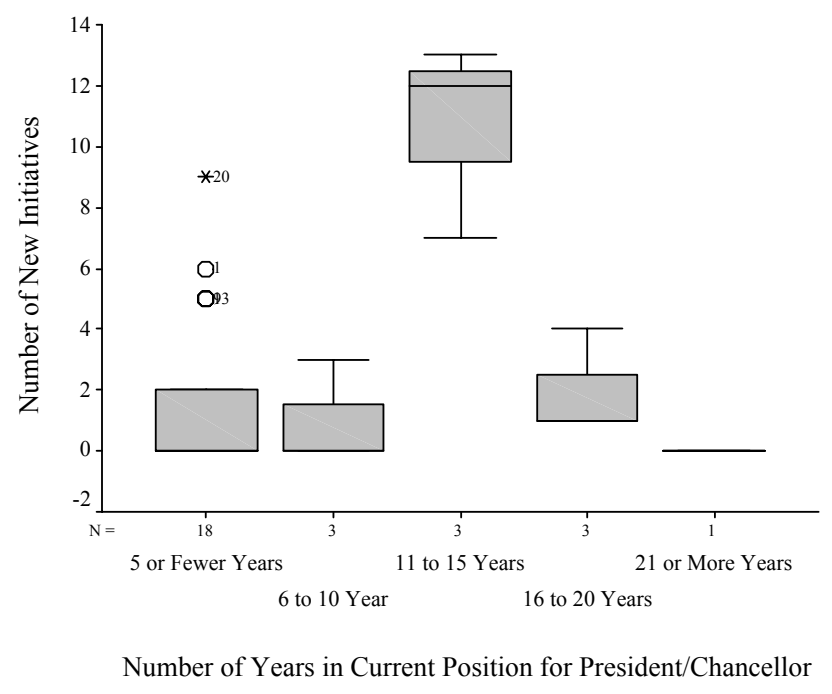


Assessing specifically the number of new initiatives planned for the future as a measure of entrepreneurial activity failed to provide any significant results. A KruskalWallis test was conducted to evaluate the differences among the five length of service categories on median change in the level of entrepreneurial activity using the number of new initiatives planned for the future as a measure of entrepreneurial activity. With alpha set at .05 , the test was not significant, $\chi^{2}(4, N=28)=3.145, p>.05$. The critical value was 9.49 .

The field of study or discipline of the president/chancellor?

The field of study or discipline of the president/chancellor varied significantly with the largest representation in the social sciences $(8,28.6 \%)$ and education $(10$, $35.7 \%$ ). Table 9 summarizes the distribution of fields of study or disciplines represented by the president/chancellor for each respondent institution.

Table 9

Field of Study or Discipline of the President/Chancellor

\begin{tabular}{lcc}
\hline Field of Study or Discipline & Frequency & Percent \\
\hline Fine Arts/Humanities & 2 & 7.1 \\
Social Sciences & 8 & 28.6 \\
Physical/Natural Sciences & 2 & 7.1 \\
Medicine & 1 & 3.6 \\
Law & 1 & 3.6 \\
Business & 1 & 3.6 \\
Education & 10 & 35.7 \\
Physical Education/Sports & 1 & 3.6 \\
Religious Studies & 1 & 3.6 \\
No Response & 1 & 3.6 \\
\hline Total & 28 & 100.0 \\
\hline
\end{tabular}


A Kruskal-Wallis test was conducted to evaluate differences among the various fields of study or disciplines on median change in entrepreneurial activity as measured by the Entrepreneurial Score. With alpha set at .05 , the test was not significant, $\chi^{2}(9, N=28)$ $=10.005, p>.05$. The critical value was 16.92 .

Entrepreneurial activity was also assessed by the number of new initiatives for each institution. Again, a Kruskal-Wallis test was conducted to evaluate differences among the various fields of study or disciplines on median change in entrepreneurial activity as measured by the number of new initiatives. With alpha set at .05 , the test was not significant, $\chi^{2}(9, N=28)=13.443, p>.05$. The critical value was 16.92 .

Entrepreneurial activity was finally assessed by the number of new initiatives planned for the future for each institution. A Kruskal-Wallis test was conducted to evaluate differences among the various fields of study or disciplines on median change in entrepreneurial activity as measured by the number of new initiatives planned for the future. With alpha set at .05 , the test was not significant, $\chi^{2}(9, N=28)=10.330, p>.05$. The critical value was 16.92 .

The analysis failed to reveal any significant relationship between the field of study or discipline of the president/chancellor and the level of entrepreneurial activity as measured by the Entrepreneurial Score, the number of new initiatives, and the number of new initiatives planned for the future.

The business/industry experience of the institution's president/chancellor?

The data revealed that all of the presidents/chancellors for the respondent institutions $(N=28)$ came to their current positions through academic positions, 
reflecting no business/industry experience. While this finding is not surprising, it offers no basis for further assessment.

The institution's enrollment?

Data was collected on enrollments for full-time undergraduate students, part-time undergraduate students, full-time graduate students, and part-time graduate students. The enrollment data is summarized in Table 10.

Table 10

Enrollments for Full-Time and Part-time Undergraduate Students and Full-Time and Part-Time Graduate Students for Respondent Institutions

Full-Time Undergraduate Students

\begin{tabular}{lcc}
\hline Enrollments & Frequency & Percent \\
\hline$<1,000$ & 6 & 21.4 \\
$1,000-5,000$ & 21 & 75.0 \\
$5,001-10,000$ & 1 & 3.6 \\
$>10,000$ & 0 & 0 \\
\hline Total & 28 & 100.0 \\
\hline
\end{tabular}

Full-Time Graduate Students

\begin{tabular}{lcc}
\hline Enrollments & Frequency & Percent \\
\hline$<1,000$ & 28 & 100.0 \\
$1,000-5,000$ & 0 & 0 \\
$5,001-10,000$ & 0 & 0 \\
$>10,000$ & 0 & 0 \\
\hline Total & 28 & 100.0 \\
\hline
\end{tabular}

Part-Time Undergraduate Students

\begin{tabular}{lcc}
\hline Enrollments & Frequency & Percent \\
\hline$<1,000$ & 20 & 71.4 \\
$1,000-5,000$ & 8 & 28.6 \\
$5,001-10,000$ & 0 & 0 \\
$>10,000$ & 0 & 0 \\
\hline Total & 28 & 100.0 \\
\hline
\end{tabular}

Part-Time Graduate Students

\begin{tabular}{lcc}
\hline Enrollments & Frequency & Percent \\
\hline$<1,000$ & 27 & 96.4 \\
$1,000-5,000$ & 1 & 3.6 \\
$5,001-10,000$ & 0 & 0 \\
$>10,000$ & 0 & 0 \\
\hline Total & 28 & 100.0 \\
\hline
\end{tabular}

The majority of institutions had full-time undergraduate enrollments in the category of 1,000 to $5,000(21,75 \%)$. However, the largest number of institutions fell 
into the $<1,000$ category for part-time undergraduate enrollments $(20,71.4 \%)$. Since, by definition, the institutions surveyed were baccalaureate institutions, it was expected that graduate enrollments would be small. The data support this observation. All of the institutions reported full-time graduate student enrollments in the $<1,000$ category (28, $100 \%$ ), and all but one institution reported part-time graduate student enrollments in the $<1,000$ category $(27,96.4 \%)$.

Statistical tests were conducted to evaluate differences among the various levels of enrollment at the institutions on median change in entrepreneurial activity as measured by the Entrepreneurial Score. These tests were done for full-time undergraduate, parttime undergraduate and part-time graduate enrollments. No further assessment was made for full-time graduate enrollments since all $(N=28)$ institutions reported the same enrollment level of $<1,000$.

A Kruskal-Wallis test was conducted for the full-time undergraduate enrollments. With alpha set at .05 , the test was not significant, $\chi^{2}(2, N=28)=1.910, p>.05$. The critical value was 5.99 .

A Kruskal-Wallis test was conducted for the part-time undergraduate enrollments. With alpha set at .05 , the test was not significant, $\chi^{2}(1, N=28)=.373, p>.05$. The critical value was 3.84 .

A Kruskal-Wallis test was conducted for the part-time graduate enrollments. With alpha set at .05 , the test was not significant, $\chi^{2}(1, N=28)=2.398, p>.05$. The critical value was 3.84 .

Statistical tests were conducted to evaluate differences among the various levels of enrollment at the institutions on median change in entrepreneurial activity as measured 
by the number of new initiatives. These tests were done for full-time undergraduate, part-time undergraduate and part-time graduate enrollments. Again, no further assessment was made for full-time graduate enrollments since all $(N=28)$ institutions reported the same enrollment level of $<1,000$.

A Kruskal-Wallis test was conducted for the full-time undergraduate enrollments. With alpha set at .05 , the test was not significant, $\chi^{2}(2, N=28)=3.401, p>.05$. The critical value was 5.99 .

A Kruskal-Wallis test was conducted for the part-time undergraduate enrollments. With alpha set at .05 , the test was not significant, $\chi^{2}(1, N=28)=.937, p>.05$. The critical value was 3.84 .

A Kruskal-Wallis test was conducted for the part-time graduate enrollments. With alpha set at .05 , the test was not significant, $\chi^{2}(1, N=28)=1.889, p>.05$. The critical value was 3.84 .

Statistical tests were conducted to evaluate differences among the various levels of enrollment at the institutions on median change in entrepreneurial activity as measured by the number of new initiatives planned for the future. These tests were done for fulltime undergraduate, part-time undergraduate and part-time graduate enrollments. Once again, no further assessment was made for full-time graduate enrollments since all $(N=$ 28) institutions reported the same enrollment level of $<1,000$.

A Kruskal-Wallis test was conducted for the full-time undergraduate enrollments. With alpha set at .05 , the test was not significant, $\chi^{2}(2, N=28)=1.558, p>.05$. The critical value was 5.99 . 
A Kruskal-Wallis test was conducted for the part-time undergraduate enrollments. With alpha set at .05 , the test was not significant, $\chi^{2}(1, N=28)=.130, p>.05$. The critical value was 3.84 .

A Kruskal-Wallis test was conducted for the part-time graduate enrollments. With alpha set at .05 , the test was not significant, $\chi^{2}(1, N=28)=1.575, p>.05$. The critical value was 3.84 .

The analysis failed to reveal any significant relationship between enrollments and the level of entrepreneurial activity as measured by the Entrepreneurial Score, the number of new initiatives, and the number of new initiatives planned for the future. An increase or decrease in enrollment from the previous year?

Enrollments for the respondent institutions $(N=28)$ decreased for nine institutions (32.1\%) and increased for the other nineteen institutions $(67.9 \%)$. To test for a relationship between a change in enrollment and the level of entrepreneurial activity, Mann-Whitney tests were conducted to assess whether an increase or decrease in enrollment affects the level of entrepreneurial activity as measured first by the entrepreneurial score, second by the number of new initiatives, and third by the number of new initiatives planned for the future.

With alpha set at .05 , the Mann-Whitney $(U=78)$ test yielded no significant finding when testing the relationship of decreased or increased enrollments to the level of entrepreneurial activity as measured by the Entrepreneurial Score, $z=-.369, p>.05$.

With alpha set at .05, the Mann-Whitney $(U=75)$ test yielded no significant finding when testing the relationship of decreased or increased enrollments to the level of entrepreneurial activity as measured by the number of new initiatives, $z=-.546, p>.05$. 
With alpha set at .05 , the Mann-Whitney $(U=64)$ test yielded no significant finding when testing the relationship of decreased or increased enrollments to the level of entrepreneurial activity as measured by the number of new initiatives planned for the future, $z=-1.072, p>.05$.

The analysis failed to reveal any significant relationship between decreased or increased enrollments and the level of entrepreneurial activity as measured by the Entrepreneurial Score, the number of new initiatives, and the number of new initiatives planned for the future.

The institution's tuition, both in-state and out-of-state?

The majority of institutions reported in-state tuition in two categories, \$2,001 $\$ 4,000(9,32.1 \%)$ and $\$ 4,001-\$ 6,000(13,46.4 \%)$. The majority of institutions reported out-of-state tuition in two categories, $\$ 5,001-\$ 10,000(14,50 \%)$ and $\$ 10,001-\$ 15,000$ $(10,35.7 \%)$. Table 11 summarizes the tuition data.

Table 11

In-State and Out-of-State Tuition Reported by Respondent Institutions

In-State Tuition

\begin{tabular}{lcc}
\hline Tuition & Frequency & Percent \\
\hline Less Than $\$ 2,000$ & 2 & 7.1 \\
$\$ 2,001-\$ 4,000$ & 9 & 32.1 \\
$\$ 4,001-\$ 6,000$ & 13 & 46.4 \\
$\$ 6,001-\$ 8,000$ & 3 & 10.7 \\
More Than $\$ 8,000$ & 1 & 3.6 \\
\hline Total & 28 & 100.0 \\
\hline
\end{tabular}


Out-Of-State Tuition

\begin{tabular}{lcc}
\hline Tuition & Frequency & Percent \\
\hline Less Than $\$ 5,000$ & 2 & 7.1 \\
$\$ 5,001-\$ 10,000$ & 14 & 50.0 \\
$\$ 10,001-\$ 15,000$ & 10 & 35.7 \\
More Than $\$ 15,000$ & 2 & 7.1 \\
\hline Total & 28 & 100.0 \\
\hline
\end{tabular}

Kruskal-Wallis statistical tests were conducted to evaluate differences among the various levels of tuition at the institutions, in-state and out-of-state, on median change in entrepreneurial activity as measured by the Entrepreneurial Score, the number of new initiatives, and the number of new initiatives planned for the future.

A Kruskal-Wallis test was conducted to evaluate differences among the various levels of in-state tuition on median change in entrepreneurial activity as measured by the Entrepreneurial Score. With alpha set at .05 , the test was not significant, $\chi^{2}(4, N=28)=$ $.809, p>.05$. The critical value was 9.49 .

A Kruskal-Wallis test was conducted to evaluate differences among the various levels of in-state tuition on median change in entrepreneurial activity as measured by the number of new initiatives. With alpha set at .05 , the test was not significant, $\chi^{2}(4, N=28)$ $=3.546, p>.05$. The critical value was 9.49 .

A Kruskal-Wallis test was conducted to evaluate differences among the various levels of in-state tuition on median change in entrepreneurial activity as measured by the number of new initiatives planned for the future. With alpha set at .05 , the test was not significant, $\chi^{2}(4, N=28)=1.848, p>.05$. The critical value was 9.49 . 
A Kruskal-Wallis test was conducted to evaluate differences among the various levels of out-of-state tuition on median change in entrepreneurial activity as measured by the Entrepreneurial Score. With alpha set at .05 , the test was not significant, $\chi^{2}(3, N=28)$ $=1.454, p>.05$. The critical value was 7.82 .

A Kruskal-Wallis test was conducted to evaluate differences among the various levels of out-of-state tuition on median change in entrepreneurial activity as measured by the number of new initiatives. With alpha set at .05 , the test was not significant, $\chi^{2}(3, N=$ $28)=1.549, p>.05$. The critical value was 7.82 .

A Kruskal-Wallis test was conducted to evaluate differences among the various levels of out-of-state tuition on median change in entrepreneurial activity as measured by the number of new initiatives planned for the future. With alpha set at .05 , the test was not significant, $\chi^{2}(3, N=28)=3.420, p>.05$. The critical value was 7.82

The analysis failed to reveal any significant relationship between the levels of instate and out-of-state tuition and the level of entrepreneurial activity as measured by the Entrepreneurial Score, the number of new initiatives, and the number of new initiatives planned for the future.

An increase or decrease in tuition from previous year?

Survey respondents were asked to identify whether tuition, both in-state and outof-state, had increased, decreased, or not changed from the previous year. Only one institution $(3.6 \%)$ indicated a decrease in in-state tuition by 7.2 percent. Five institutions $(17.9 \%)$ indicated that in-state tuition had not changed from the previous year. The remaining twenty-two institutions (78.5\%) reported increases in in-state tuition ranging from 3.8 percent to 27 percent. 
For out-of-state tuition, one institution (3.6\%) indicated a decrease of 4.2 percent. Six institutions $(21.4 \%)$ indicated that out-of-state tuition had not changed from the previous year. The remaining twenty institutions (75\%) reported increases in out-of-state tuition ranging from 4 percent to 18 percent. Table 12 summarizes the data.

Table 12

Changes in In-State and Out-of-State Tuition

\begin{tabular}{lcc}
\hline In-State Tuition Change & Frequency & Percent \\
\hline Decrease & 1 & 3.6 \\
No Change & 5 & 17.9 \\
Increase $0.1 \%-5.0 \%$ & 2 & 7.1 \\
Increase 5.1\% - 10.0\% & 10 & 35.7 \\
Increase $10.1 \%-15.0 \%$ & 5 & 17.9 \\
Increase $15.1 \%-20.0 \%$ & 4 & 14.3 \\
Increase $>20.0 \%$ & 1 & 3.6 \\
\hline Total & 28 & 100.0 \\
\hline Out-of-State Tuition Change & Frequency & Percent \\
\hline Decrease & 1 & 3.6 \\
No Change & 6 & 21.4 \\
Increase $0.1 \%-5.0 \%$ & 2 & 7.1 \\
Increase $5.1 \%-10.0 \%$ & 10 & 35.7 \\
Increase $10.1 \%$ - $15.0 \%$ & 8 & 28.6 \\
Increase $15.1 \%-20.0 \%$ & 1 & 3.6 \\
Increase $>20.0 \%$ & 0 & 0 \\
\hline Total & 28 & 100.0 \\
\hline & & \\
\hline
\end{tabular}

A Kruskal-Wallis test was conducted to evaluate differences among the various levels of the frequency distribution of changes in in-state tuition on median change in 
entrepreneurial activity as measured by the Entrepreneurial Score. With alpha set at .05, the test was not significant, $\chi^{2}(6, N=28)=6.424, p>.05$. The critical value was 12.59 .

A Kruskal-Wallis test was conducted to evaluate differences among the various levels of the frequency distribution of changes in in-state tuition on median change in entrepreneurial activity as measured by the number of new initiatives. With alpha set at .05 , the test was not significant, $\chi^{2}(6, N=28)=9.817, p>.05$. The critical value was 12.59 .

A Kruskal-Wallis test was conducted to evaluate differences among the various levels of the frequency distribution of changes in in-state tuition on median change in entrepreneurial activity as measured by the number of new initiatives planned for the future. With alpha set at .05 , the test was not significant, $\chi^{2}(6, N=28)=.849, p>.05$. The critical value was 12.59 .

A Kruskal-Wallis test was conducted to evaluate differences among the various levels of the frequency distribution of changes in out-of-state tuition on median change in entrepreneurial activity as measured by the Entrepreneurial Score. With alpha set at .05, the test was not significant, $\chi^{2}(5, N=28)=9.960, p>.05$. The critical value was 11.07 . Spearman's rank correlation coefficient was also calculated indicating a statistically significant relationship between changes in out-of-state tuition and the Entrepreneurial Score, $r_{\mathrm{s}}=.415, N=28, \mathrm{p}<.05$.

A Kruskal-Wallis test was conducted to evaluate differences among the various levels of the frequency distribution of changes in out-of-state tuition on median change in entrepreneurial activity as measured by the number of new initiatives. With alpha set at 
.05 , the test was not significant, $\chi^{2}(5, N=28)=4.277, p>.05$. The critical value was 11.07.

A Kruskal-Wallis test was conducted to evaluate differences among the various levels of the frequency distribution of changes in out-of-state tuition on median change in entrepreneurial activity as measured by the number of new initiatives planned for the future. With alpha set at .05 , the test was not significant, $\chi^{2}(5, N=28)=3.448, p>.05$. The critical value was 11.07 .

The analysis failed to reveal any significant relationship between the levels of instate and out-of-state tuition and the level of entrepreneurial activity as measured by the number of new initiatives, and the number of new initiatives planned for the future. The analysis did reveal a significant relationship between the level of out-of-state tuition and the level of entrepreneurial activity as measured by the Entrepreneurial Score, suggesting that entrepreneurial activity tends to move in the same direction as out-of-state tuition. The number of faculty, both full-time and part-time?

The survey respondents were asked to provide data on the number of full-time and part-time faculty. For full-time faculty $(N=28)$ the range was 556 with a minimum of thirty-two and a maximum of $588(M=123.04, S D=104.88)$. Table 13 summarizes the data. The standard deviation is large because of an outlier (588). A one-sample Kolmogrov-Smirnov test of normality was conducted on the distribution to assess whether it is normally distributed. With alpha set at .05 , the results of the test were significant, $K-S($ Lilliefors $)(28, N=28)=.230, \mathrm{p}<.01$. The distribution of full-time faculty is significantly different from a normal distribution, as represented by the histogram in Figure 7. 
Table 13

Total Full-Time Faculty

\begin{tabular}{lcc}
\hline Total Full-Time Faculty & Frequency & Percent \\
\hline$<50$ & 5 & 17.9 \\
$51-100$ & 10 & 35.7 \\
$101-150$ & 4 & 14.3 \\
$151-200$ & 7 & 25.0 \\
$>200$ & 2 & 7.1 \\
\hline Total & 28 & 100.0 \\
\hline
\end{tabular}

Figure 7. Distribution of Total Full-Time Faculty Compared To the Normal Distribution

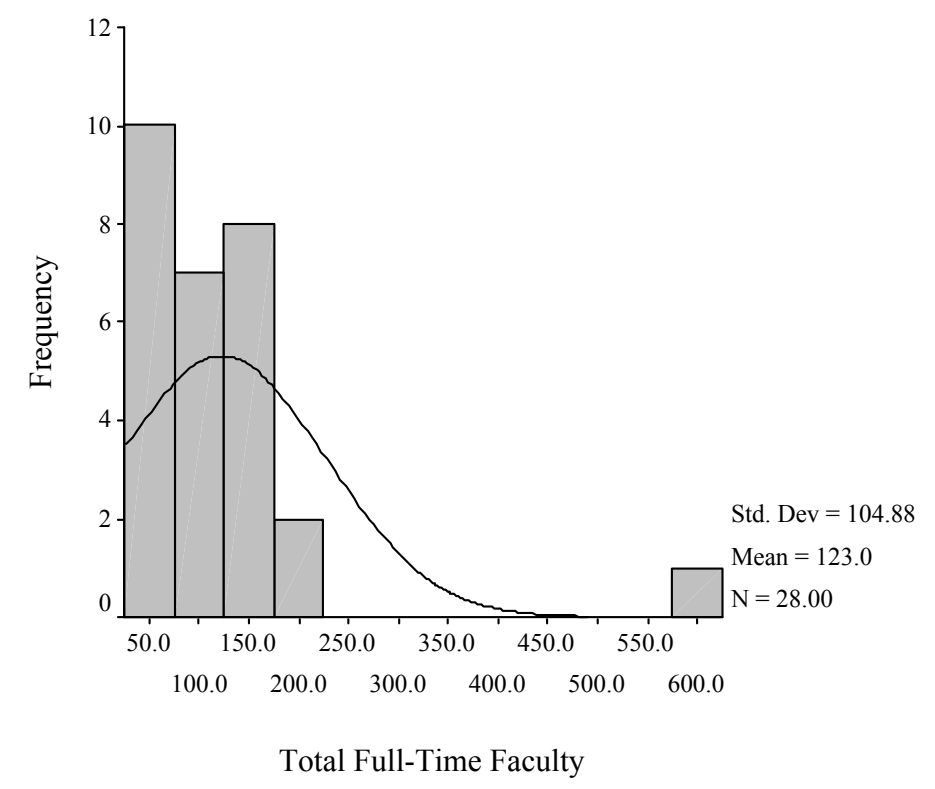

The range for part-time faculty $(N=28)$ was 328 with a minimum of zero and a maximum of $328(M=79.25, S D=81.00)$. Table 14 summarizes the data. The standard deviation is large because of several outliers. A one-sample Kolmogrov-Smirnov test of normality was conducted on the distribution to assess whether it is normally distributed. With alpha set at .05 , the results of the test were significant, $K$-S(Lilliefors $)(28, N=28)=$ 
$.233, \mathrm{p}<.01$. The distribution of part-time faculty is significantly different from a normal distribution, as represented by the histogram in Figure 8 .

Table 14

Total Part-Time Faculty

\begin{tabular}{lcc}
\hline Total Part-Time Faculty & Frequency & Percent \\
\hline$<50$ & 13 & 46.4 \\
$51-100$ & 9 & 32.1 \\
$101-150$ & 1 & 3.6 \\
$151-200$ & 2 & 7.1 \\
$>200$ & 3 & 10.7 \\
\hline Total & 28 & 100.0 \\
\hline
\end{tabular}

Figure 8. Distribution of Total Part-Time Faculty Compared to the Normal Distribution

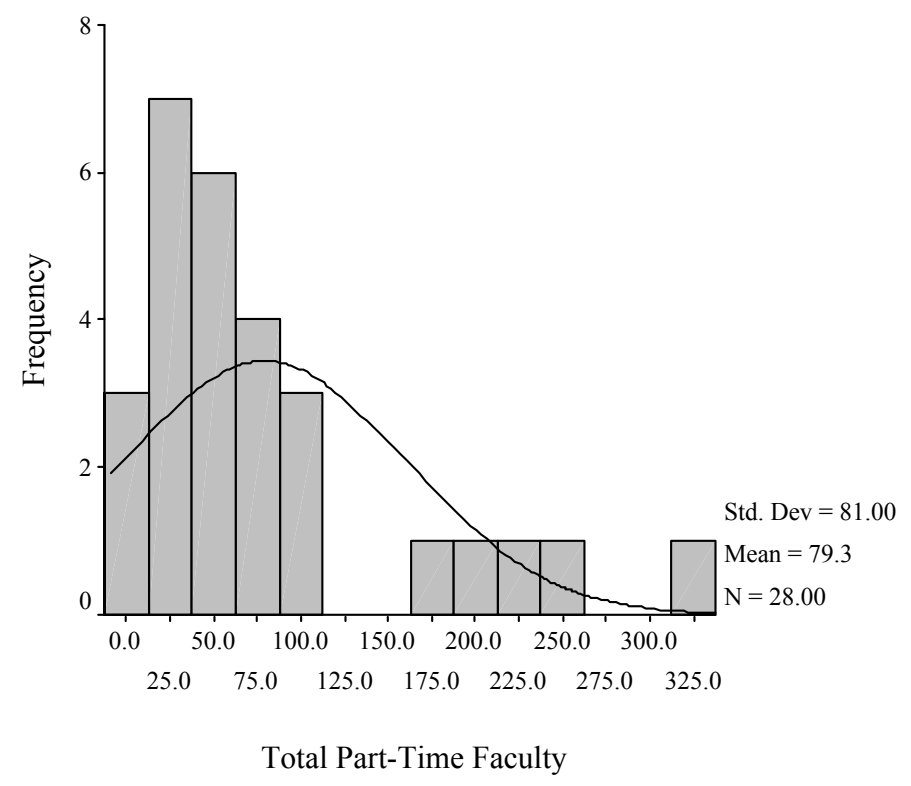

A Kruskal-Wallis test was conducted to evaluate the differences in total full-time faculty on median change in the level of entrepreneurial activity using the Entrepreneurial 
Score. With alpha set at .05 , the test was not significant, $\chi^{2}(4, N=28)=6.822, p>.05$. The critical value was 9.49 .

Entrepreneurial activity was also assessed by the number of new initiatives for each institution. Again, a Kruskal-Wallis test was conducted to evaluate the differences in total full-time faculty on median change in the level of entrepreneurial activity using the number of new initiatives. With alpha set at .05 , the test was not significant, $\chi^{2}(4, N=$ $28)=9.289, p>.05$. The critical value was 9.49. Spearman's rank correlation coefficient indicated a significant relationship, $r_{s}=.375, N=28, \mathrm{p}<.05$.

Entrepreneurial activity was further assessed by the number of new initiatives planned for the future for each institution. A Kruskal-Wallis test was conducted to evaluate the differences in total full-time faculty on median change in the level of entrepreneurial activity using the number of new initiatives planned for the future. With alpha set at .05 , the test was not significant, $\chi^{2}(4, N=28)=2.604, p>.05$. The critical value was 9.49 .

This suggests that there is no significant relationship between the total full-time faculty and the level of entrepreneurial activity at the institution as measured by the Entrepreneurial Score or the number of new initiatives planned for the future. The analysis did reveal a significant relationship between the total full-time faculty and the level of entrepreneurial activity as measured by the number of new initiatives, suggesting that entrepreneurial activity tends to move in the same direction as total full-time faculty. A Kruskal-Wallis test was conducted to evaluate the differences in total part-time faculty on median change in the level of entrepreneurial activity using the Entrepreneurial 
Score. With alpha set at .05 , the test was not significant, $\chi^{2}(4, N=28)=3.546, p>.05$. The critical value was 9.49 .

A Kruskal-Wallis test was also conducted to evaluate the differences in total parttime faculty on median change in the level of entrepreneurial activity using the number of new initiatives. With alpha set at .05 , the test was not significant, $\chi^{2}(4, N=28)=4.220, p$ $>$.05. The critical value was 9.49 .

Finally, a Kruskal-Wallis test was also conducted to evaluate the differences in total part-time faculty on median change in the level of entrepreneurial activity using the number of new initiatives planned for the future. With alpha set at .05 , the test was not significant, $\chi^{2}(4, N=28)=2.862, p>.05$. The critical value was 9.49 .

There appears to be no significant relationship between the total part-time faculty and the level of entrepreneurial activity at the institution as measured by the Entrepreneurial Score, the number of new initiatives, or the number of new initiatives planned for the future.

The number of tenure track and non-tenure track faculty?

The survey respondents were asked to provide data on the number of full-time tenure track and non-tenure track faculty. For full-time tenure track faculty $(N=28)$ the range was 488 with a minimum of twenty-seven and a maximum of $515(M=101.50, S D$ $=94.99)$. Table 15 summarizes the data. The standard deviation is large because of an outlier (515). A one-sample Kolmogrov-Smirnov test of normality was conducted on the distribution to assess whether it is normally distributed. With alpha set at .05 , the results of the test were significant, $K-S($ Lilliefors $)(28, N=28)=.216, \mathrm{p}<.01$. The distribution of 
full-time tenure track faculty is significantly different from a normal distribution, as represented by the histogram in Figure 9 .

Table 15

Total Full-Time Tenure Track Faculty

Total Full-Time $\quad$ Frequency $\quad$ Percent

Tenure Track Faculty

\begin{tabular}{lcc}
\hline$<50$ & 10 & 35.7 \\
$51-100$ & 7 & 25.0 \\
$101-150$ & 7 & 25.0 \\
$151-200$ & 2 & 7.1 \\
$>200$ & 2 & 7.1 \\
\hline Total & 28 & 100.0 \\
\hline
\end{tabular}

Figure 9. Distribution Total Full-Time Tenure Track Faculty Compared to the Normal Distribution

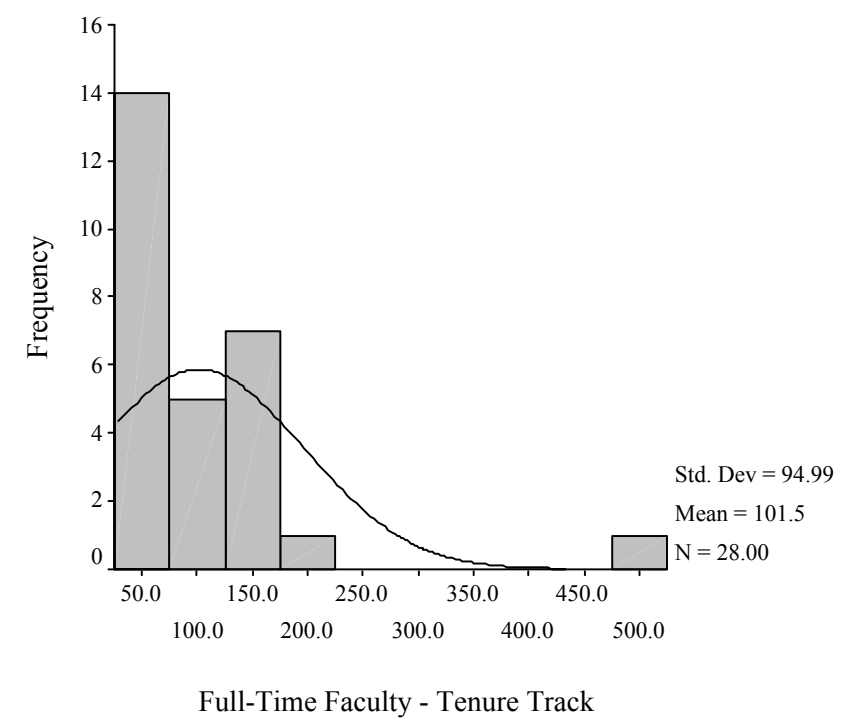

The range for full-time non-tenure track faculty $(N=28)$ was 73 with a minimum of zero and a maximum of $73(M=21.54, S D=17.79)$. Table 16 summarizes the data. 
The standard deviation is large because of several outliers. A one-sample KolmogrovSmirnov test of normality was conducted on the distribution to assess whether it is normally distributed. With alpha set at .05 , the results of the test were not significant, $K$ $S($ Lilliefors $)(28, N=28)=.159, \mathrm{p}>.05$. The distribution of part-time faculty is not significantly different from a normal distribution, as represented by the histogram in Figure 10.

Table 16

Total Full-Time Non-Tenure Track Faculty

Total Full-Time Non- Frequency Percent

Tenure Track Faculty

\begin{tabular}{lcc}
\hline$<50$ & 26 & 92.9 \\
$51-100$ & 2 & 7.1 \\
\hline Total & 28 & 100.0 \\
\hline
\end{tabular}

Figure 10. Distribution of Total Full-Time Non-Tenure Track Faculty Compared to the Normal Distribution

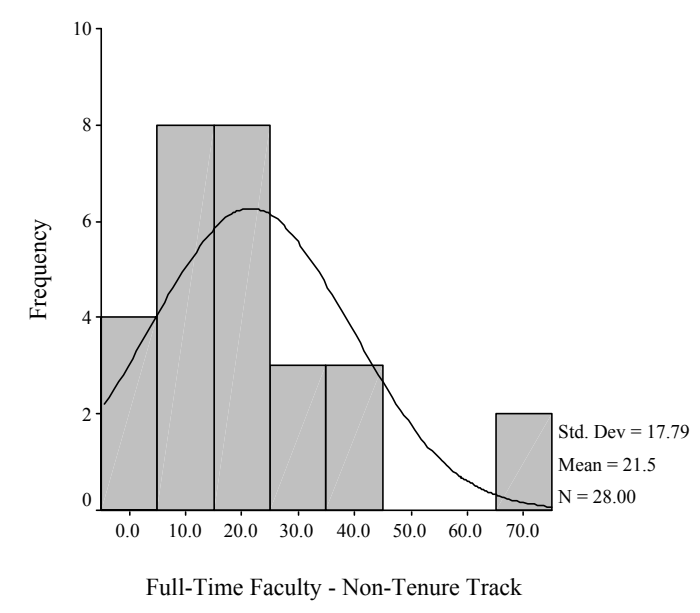

A Kruskal-Wallis test was conducted to evaluate the differences in total full-time tenure track faculty on median change in the level of entrepreneurial activity using the 
Entrepreneurial Score, the number of new initiatives, and the number of new initiatives planned for the future. Using the Entrepreneurial Score as the measure of the level entrepreneurial activity, with alpha set at .05 , the test was not significant, $\chi^{2}(4, N=28)=$ $8.537, p>.05$. The critical value was 9.49 .

Using the number of new initiatives as the measure of the level of entrepreneurial activity, with alpha set at .05 , the Kruskal-Wallis test of median difference was not significant, $\chi^{2}(4, N=28)=8.940, p>.05$. The critical value was 9.49. However, the Spearman's rank correlation coefficient indicated a significant relationship between total full-time tenure track faculty and entrepreneurial activity as measured by the number of new initiatives, $r_{s}=.511, N=28, \mathrm{p}<.01$.

Using the number of new initiatives planned for the future as the measure of the level of entrepreneurial activity, with alpha set at .05, the Kruskal-Wallis test of median difference was not significant, $\chi^{2}(4, N=28)=1.084, p>.05$. The critical value was 9.49.

There appears to be no significant relationship between the total full-time tenure track faculty and the level of entrepreneurial activity at the institutions as measured by the Entrepreneurial Score and the number of new initiatives planned for the future. There is a significant relationship, at the .01 alpha level, indicating that as the total number of full-time tenure track faculty increases, the number of new initiatives increases.

A Kruskal-Wallis test was also conducted to evaluate the differences in total fulltime non-tenure track faculty on median change in the level of entrepreneurial activity using the Entrepreneurial Score. With alpha set at .05 , the test was not significant, $\chi^{2}(1, N$ $=28)=1.147, p>.05$. The critical value was 3.84 . 
A Kruskal-Wallis test was conducted to evaluate the differences in total full-time non-tenure track faculty on median change in the level of entrepreneurial activity using the number of new initiatives. With alpha set at .05 , the test was not significant, $\chi^{2}(1, N=$ $28)=.142, p>.05$. The critical value was 3.84 .

Finally, a Kruskal-Wallis test was conducted to evaluate the differences in total full-time non-tenure track faculty on median change in the level of entrepreneurial activity using the number of new initiatives planned for the future. With alpha set at .05, the test was not significant, $\chi^{2}(1, N=28)=.818, p>.05$. The critical value was 3.84 .

There appears to be no significant relationship between the total full-time nontenure track faculty and the level of entrepreneurial activity at the institution as measured by the Entrepreneurial Score, the number of new initiatives, or the number of new initiatives planned for the future.

An increase or decrease in full-time faculty, both tenure track and non-tenure track, from the previous year?

Survey respondents were asked to identify whether full-time faculty had increased, decreased, or not changed from the previous year. Only three institutions $(10.7 \%)$ indicated no change in full-time faculty. Thirteen institutions (46.4\%) indicated that full-time faculty had decreased from the previous year. The remaining twelve institutions $(42.9 \%)$ reported increases in full-time faculty.

A Kruskal-Wallis test was used to assess the median change in the level of entrepreneurial activity using the Entrepreneurial Score, based on an increase, decrease, or no change in full-time faculty from the previous year. With alpha set at .05 , the test was not significant, $\chi^{2}(2, N=28)=.417, p>.05$. The critical value was 5.99 . 
Using the number of new initiatives to measure entrepreneurial activity, the results were still not significant, $\chi^{2}(2, N=28)=1.931, p>.05$. The critical value was 5.99 .

Once again, using the number of new initiatives planned for the future to measure entrepreneurial activity, the results were not significant, $\chi^{2}(2, N=28)=.966, p>.05$. The critical value was 5.99 .

No significant relationship was found between the changes in full-time faculty and the level of entrepreneurial activity at the institution as measured by the Entrepreneurial Score, the number of new initiatives, or the number of new initiatives planned for the future.

An increase or decrease in full-time tenure track faculty from the previous year?

Survey respondents were asked to identify whether full-time tenure track faculty had increased, decreased, or not changed from the previous year. Only two institutions (7.1\%) indicated no change in full-time tenure track faculty. Thirteen institutions (46.4\%) indicated that full-time tenure track faculty had decreased from the previous year. The remaining thirteen institutions $(46.4 \%)$ reported increases in full-time tenure track faculty.

A Kruskal-Wallis test was used to assess the median change in the level of entrepreneurial activity using the Entrepreneurial Score, based on an increase, decrease, or no change in full-time tenure track faculty from the previous year. With alpha set at .05 , the test was not significant, $\chi^{2}(2, N=28)=.584, p>.05$. The critical value was 5.99 . 
Using the number of new initiatives to measure entrepreneurial activity, the results were still not significant, $\chi^{2}(2, N=28)=.220, p>.05$. The critical value was 5.99 .

Once again, using the number of new initiatives planned for the future to measure entrepreneurial activity, the results were not significant, $\chi^{2}(2, N=28)=.029, p>.05$. The critical value was 5.99 .

No significant relationship was found between the changes in full-time tenure track faculty and the level of entrepreneurial activity at the institution as measured by the Entrepreneurial Score, the number of new initiatives, or the number of new initiatives planned for the future.

An increase or decrease in part-time faculty from the previous year?

Survey respondents were asked to identify whether part-time faculty had increased, decreased, or not changed from the previous year. Seven institutions $(25.0 \%)$ indicated no change in part-time faculty. Twelve institutions (42.9\%) indicated that parttime faculty had decreased from the previous year. The remaining nine institutions $(32.1 \%)$ reported increases in part-time faculty.

A Kruskal-Wallis test was used to assess the median change in the level of entrepreneurial activity using the Entrepreneurial Score, based on an increase, decrease, or no change in part-time faculty from the previous year. With alpha set at .05 , the test was not significant, $\chi^{2}(2, N=28)=3.970, p>.05$. The critical value was 5.99 .

Using the number of new initiatives to measure entrepreneurial activity, the results were still not significant, $\chi^{2}(2, N=28)=1.076, p>.05$. The critical value was 5.99 . 
Once again, using the number of new initiatives planned for the future to measure entrepreneurial activity, the results were not significant, $\chi^{2}(2, N=28)=2.907, p>.05$. The critical value was 5.99 .

No significant relationship was found between the changes in part-time faculty and the level of entrepreneurial activity at the institution as measured by the Entrepreneurial Score, the number of new initiatives, or the number of new initiatives planned for the future.

The highest degree offered at the institution?

Survey respondents were asked to identify the highest degree offered at their institution. Sixteen institutions (57.1\%) offer the baccalaureate degree as their highest degree. The remaining twelve institutions (42.9\%) offer masters degree programs.

A Mann-Whitney $(U=78)$ test was conducted to evaluate whether institutions offering the masters degree as their highest degree have higher entrepreneurial scores than institutions that only offer the baccalaureate degree as their highest degree. The results were not significant, $z=-.836, \mathrm{p}>.05$.

The test was conducted again, first using the number of new initiatives as the measure of entrepreneurial activity and second, the number of new initiatives planned for the future. Both tests found nothing significant, $U=86.5, z=-.466, p>.05, U=88, z=-$ $.377, \mathrm{p}>.05$ 
The addition or elimination of programs for teaching, research, and service since the previous year?

Table 17 summarizes the data on program additions and eliminations.

Table 17

Program Additions and Eliminations

\begin{tabular}{lcccccc}
\hline Programs & \multicolumn{2}{c}{ Teaching } & \multicolumn{2}{c}{ Research } & \multicolumn{2}{c}{ Service } \\
\cline { 2 - 7 } & Frequency & Percent & Frequency & Percent & Frequency & Percent \\
\hline Added & 15 & 53.6 & 5 & 17.9 & 8 & 28.6 \\
Eliminated & 1 & 3.6 & 1 & 3.6 & 1 & 3.6 \\
No Change & 12 & 42.9 & 22 & 78.6 & 19 & 67.9 \\
\hline Total & 28 & 100.0 & 28 & 100.0 & 28 & 100.0 \\
\hline
\end{tabular}

The Kruskal-Wallis test was used to assess the median change in the level of entrepreneurial activity using the Entrepreneurial Score, based on the teaching programs added or eliminated since the previous year. With alpha set at .05, the test was not significant, $\chi^{2}(2, N=28)=5.363, p>.05$. The critical value was 5.99 .

Using the number of new initiatives to measure entrepreneurial activity, the results were still not significant, $\chi^{2}(2, N=28)=.397, p>.05$. The critical value was 5.99 .

Once again, using the number of new initiatives planned for the future to measure entrepreneurial activity, the results were not significant, $\chi^{2}(2, N=28)=1.778, p>.05$. The critical value was 5.99 .

The Kruskal-Wallis test was used to assess the median change in the level of entrepreneurial activity using the Entrepreneurial Score, based on the research programs 
added or eliminated since the previous year. With alpha set at .05 , the test was not significant, $\chi^{2}(2, N=28)=3.029, p>.05$. The critical value was 5.99.

Using the number of new initiatives to measure entrepreneurial activity, the results were still not significant, $\chi^{2}(2, N=28)=.596, p>.05$. The critical value was 5.99 .

Once again, using the number of new initiatives planned for the future to measure entrepreneurial activity, the results were not significant, $\chi^{2}(2, N=28)=1.617, p>.05$. The critical value was 5.99 .

The Kruskal-Wallis test was used to assess the median change in the level of entrepreneurial activity using the Entrepreneurial Score, based on the service programs added or eliminated since the previous year. With alpha set at .05 , the test was not significant, $\chi^{2}(2, N=28)=5.660, p>.05$. The critical value was 5.99.

Using the number of new initiatives to measure entrepreneurial activity, the results were still not significant, $\chi^{2}(2, N=28)=4.547, p>.05$. The critical value was 5.99. However, the Spearman's rank correlation coefficient indicated a significant relationship between the number of new initiatives and the service programs added or eliminated. $r_{s}=-.407, N=28, \mathrm{p}<.05$. As a result of this finding, individual correlations were calculated for the number of service programs added and the number of service programs eliminated. The Spearman's rank correlation coefficient indicated that the number of new initiatives and the number of service programs added was significant at the .05 level, $r_{s}=.399, N=28, \mathrm{p}<.05$. The Spearman's rank correlation coefficient indicated no significant relationship between the number of new initiatives and the 
number of service programs eliminated, which is not surprising since only one institution eliminated programs.

Finally, using the number of new initiatives planned for the future to measure entrepreneurial activity, the Kruskal-Wallis test results were not significant, $\chi^{2}(2, N=28)$ $=1.688, p>.05$. The critical value was 5.99 .

An increase or decrease in state appropriations from the previous year.

State appropriations either decreased $(42.9 \%)$ or stayed the same $(42.9 \%)$ for the majority of respondent institutions. Table 18 summarizes the data. Of the twelve institutions that reported decreased state appropriations, only eight provided the percentage of decrease. The reported percentage decreases ranged from a low of two percent to a high of seventeen percent $(M=5.64 \%)$. Only four institutions indicated that state appropriations increased. The increases ranged from a low of 0.98 percent to a high of eleven percent $(M=5.0 \%)$

Table 18

State Appropriation

\begin{tabular}{lcc}
\hline State Appropriations & Frequency & Percent \\
\hline Increased & 4 & 14.3 \\
Decreased & 12 & 42.9 \\
No Change & 12 & 42.9 \\
\hline Total & 28 & 100.0 \\
\hline
\end{tabular}

A comparison of changes in state appropriations with a median split of the entrepreneurial scores indicates a greater number of institutions with decreased appropriations had low entrepreneurial scores (66.7\%) and a greater number of 
institutions with increased appropriations had high entrepreneurial scores (75.0\%). Table 19 summarizes these findings.

Table 19

Cross Tabulation of High and Low Entrepreneurial Scores and State Appropriations

\begin{tabular}{lcccc}
\cline { 2 - 5 } & \multicolumn{4}{c}{ State Appropriations } \\
\cline { 2 - 5 } & Increased & Decreased & No Change & Total \\
\hline Low Entrepreneurial Score & 1 & 8 & 6 & 15 \\
High Entrepreneurial Score & 3 & 4 & 6 & 13 \\
\hline Total & 4 & 12 & 12 & 28 \\
\hline
\end{tabular}

A Kruskal-Wallis test was conducted to evaluate the differences in state appropriations (increase, decrease, or no change) on median change in the level of entrepreneurial activity using the Entrepreneurial Score, the number of new initiatives, and the number of new initiatives planned for the future. Using the Entrepreneurial Score as the measure of the level entrepreneurial activity, with alpha set at .05, the test was not significant, $\chi^{2}(2, N=28)=1.049, p>.05$. The critical value was 5.99 .

Using the number of new initiatives to measure entrepreneurial activity, the results were still not significant, $\chi^{2}(2, N=28)=5.749, p>.05$. The critical value was 5.99 .

Using the number of new initiatives planned for the future to measure entrepreneurial activity, the results were not significant, $\chi^{2}(2, N=28)=.470, p>.05$. The critical value was 5.99 .

Statistical analysis revealed no significant relationship between the level of state appropriations and the level of entrepreneurial activity as measured by the 
Entrepreneurial Score, the number of new initiatives, and the number of new initiatives planned for the future.

Whether the governing board encourages or discourages entrepreneurial activities to generate revenue?

Twenty-three $(82.1 \%)$ of the responding institutions indicated that the governing board strongly encouraged $(25.0 \%)$ or encouraged $(57.1 \%)$ entrepreneurial activities to generate revenue. Of the remaining five institutions, three $(10.7 \%)$ indicated that the governing board was neutral, and two $(7.1 \%)$ did not respond to the question. None of the institutions indicated that the governing board discouraged or strongly discouraged entrepreneurial activity to generate revenue. Table 20 summarizes the data.

Table 20

Governing Board Support for Entrepreneurial Activities

\begin{tabular}{lcc}
\hline Governing Board Support & Frequency & Percent \\
\hline Strongly Encouraged & 7 & 25.0 \\
Encouraged & 16 & 57.1 \\
Neutral & 3 & 10.7 \\
Discouraged & 0 & 0 \\
Strongly Discouraged & 0 & 0 \\
\hline Total & 26 & 92.9 \\
\hline No Response & 2 & 7.1 \\
\hline & $N=28$ & 100.0
\end{tabular}

Statistical analysis using the Kruskal-Wallis independent-samples test revealed no significant relationship between the level of governing board support for entrepreneurial activities and three measures of entrepreneurial activity using the Entrepreneurial Score, the number of new initiatives, and the number of new initiatives planned for the future. 
Using the Entrepreneurial Score as the measure of the level entrepreneurial activity, with alpha set at .05 , the Kruskal-Wallis test was not significant, $\chi^{2}(2, N=26)=$ $2.280, p>.05$. The critical value was 5.99 .

Using the number of new initiatives to measure entrepreneurial activity, the results were still not significant, $\chi^{2}(2, N=26)=2.494, p>.05$. The critical value was 5.99.

Using the number of new initiatives planned for the future to measure entrepreneurial activity, the results were not significant, $\chi^{2}(2, N=26)=1.671, p>.05$. The critical value was 5.99 . The number of programs supported by generating their own revenue?

Nineteen $(67.9 \%)$ of the respondent institutions indicated that they had no programs supported by generating their own revenue. Six $(21.4 \%)$ indicated one program was responsible for generating some portion of its own revenue. One of these actually indicated that the entire college was responsible for generating eighty-five percent of its revenue. Three (10.7\%) institutions indicated that two programs were responsible for generating some portion of their own revenue. Table 21 summarizes the data.

Table 21

Programs Generating Own Revenue

\begin{tabular}{lcc}
\hline Programs & Frequency & Percent \\
\hline 0 & 19 & 67.9 \\
1 & 6 & 21.4 \\
2 & 3 & 10.7 \\
\hline Total & 28 & 100.0 \\
\hline
\end{tabular}


The percentage of support that these programs were responsible for ranged from a low of two percent to a high of 100 percent. The types of programs identified are listed in Table 22.

Table 22

Types of Programs Identified as Generating a Portion of Their Own Revenue

Program Percentage

\begin{tabular}{ll}
\hline Professional Development and Continuing Education & 100
\end{tabular}

$\begin{array}{ll}\text { Coastal Research Center } & 100\end{array}$

$\begin{array}{ll}\text { Special Education Teacher Training } & 100\end{array}$

$\begin{array}{ll}\text { Education and Training Partnership } & 100\end{array}$

$\begin{array}{ll}\text { Education Leadership Masters } & 100\end{array}$

$\begin{array}{lr}\text { Continuing Education } & 90\end{array}$

$\begin{array}{ll}\text { Child Development Program } & 60\end{array}$

Humanities/Languages $\quad 5$

$\begin{array}{ll}\text { Drama } & 2\end{array}$

Statistical analysis revealed no significant relationship between the number of programs responsible for a portion of their own revenue and the level of entrepreneurial activity. A Kruskal-Wallis test was conducted to evaluate the differences in the number of at least partially self-supported programs on median change in the level of entrepreneurial activity using the Entrepreneurial Score. With alpha set at .05 , the test was not significant, $\chi^{2}(2, N=28)=2.450, p>.05$. The critical value was 5.99 . 
Using the number of new initiatives to measure entrepreneurial activity, the results were still not significant, $\chi^{2}(2, N=28)=1.320, p>.05$. The critical value was 5.99 .

Using the number of new initiatives planned for the future to measure entrepreneurial activity, the results were not significant, $\chi^{2}(2, N=28)=1.267, p>.05$. The critical value was 5.99 .

Administrative and/or organizational changes during the president's/chancellor's tenure?

All but six institutions (78.6\%) indicated administrative and/or organizational changes in one or more of the three identified categories. Table 23 summarizes the data regarding administrative and/or organizational changes. Twenty institutions (71.4\%) reported administrative and/or organizational restructuring. Eight institutions (28.6\%) reported changes in decision-making authority patterns. Ten institutions (35.7\%) reported creation of new positions in central administration.

Table 23

Administrative and/or Organizational Changes

\begin{tabular}{lcc}
\hline \multicolumn{1}{c}{ Areas of Change } & Frequency & Percent \\
\hline Administrative and/or Organizational Restructuring Only & 10 & 35.7 \\
Changes in Decision-Making Authority Patterns Only & 0 & 0 \\
Creation of New Positions in Central Administration Only & 2 & 7.1 \\
$\begin{array}{c}\text { Administrative and/or Organizational Restructuring \& } \\
\quad \text { Changes in Decision-Making Authority Patterns }\end{array}$ & 2 & 7.1 \\
$\begin{array}{c}\text { Administrative and/or Organizational Restructuring \& } \\
\quad \text { Creation of New Positions in Central Administration }\end{array}$ & 2 & 7.1 \\
Changes in Decision-Making Authority Patterns \& & &
\end{tabular}




\begin{tabular}{lcc}
\hline \multicolumn{1}{c}{ Areas of Change } & Frequency & Percent \\
\hline Creation of New Positions in Central Administration & 0 & 0 \\
Administrative and/or Organizational Restructuring, & & \\
Changes in Decision-Making Authority Patterns \& & & \\
$\quad$ Creation of New Positions in Central Administration & 6 & 21.4 \\
No Changes & 6 & 21.4 \\
\hline Total & 28 & 100.0 \\
\hline
\end{tabular}

A Kruskal-Wallis test was conducted to evaluate the differences in the various levels of administrative and/or organizational change (from no changes through and including changes in all three categories) on median change in the level of entrepreneurial activity using the Entrepreneurial Score. With alpha set at .05 , the test was not significant, $\chi^{2}(5, N=28)=5.184, p>.05$. The critical value was 11.07. A

Using the number of new initiatives to measure entrepreneurial activity, the results were still not significant, $\chi^{2}(5, N=28)=1.337, p>.05$. The critical value was 11.07 .

Using the number of new initiatives planned for the future to measure entrepreneurial activity, the results were not significant, $\chi^{2}(5, N=28)=6.200, p>.05$. The critical value was 11.07 .

Statistical analysis was also conducted for each separate category of administrative and/or organizational change. Mann-Whitney tests were conducted to assess whether administrative and/or organizational restructuring affects the level of entrepreneurial activity as measured first by the Entrepreneurial Score, second by the number of new initiatives, and third by the number of new initiatives planned for the future. 
With alpha set at .05 , the Mann-Whitney $(U=44)$ test yielded no significant finding when testing the relationship of administrative and/or organizational restructuring to the level of entrepreneurial activity as measured by the Entrepreneurial Score, $z=-$ $1.832, p>.05$

With alpha set at .05 , the Mann-Whitney $(U=74.5)$ test yielded no significant finding when testing the relationship of administrative and/or organizational restructuring to the level of entrepreneurial activity as measured by the number of new initiatives, $z=-$ $.296, p>.05$

With alpha set at .05 , the Mann-Whitney $(U=76)$ test yielded no significant finding when testing the relationship of administrative and/or organizational restructuring to the level of entrepreneurial activity as measured by the number of new initiatives planned for the future, $z=-.206, p>.05$.

Mann-Whitney tests were conducted to assess whether changes in decisionmaking authority patterns affects the level of entrepreneurial activity as measured first by the Entrepreneurial Score, second by the number of new initiatives, and third by the number of new initiatives planned for the future.

With alpha set at .05 , the Mann-Whitney $(U=68)$ test yielded no significant finding when testing the relationship of changes in decision-making authority patterns to the level of entrepreneurial activity as measured by the Entrepreneurial Score, $z=-.611, p$ $>.05$.

With alpha set at .05 , the Mann-Whitney $(U=69)$ test yielded no significant finding when testing the relationship of changes in decision-making authority patterns to 
the level of entrepreneurial activity as measured by the number of new initiatives, $z=-$ $.591, p>.05$.

With alpha set at .05 , the Mann-Whitney $(U=52.5)$ test yielded no significant finding when testing the relationship of changes in decision-making authority patterns to the level of entrepreneurial activity as measured by the number of new initiatives planned for the future, $z=-1.418, p>.05$.

Mann-Whitney tests were conducted to assess whether creation of new positions in central administration affects the level of entrepreneurial activity as measured first by the Entrepreneurial Score, second by the number of new initiatives, and third by the number of new initiatives planned for the future.

With alpha set at .05 , the Mann-Whitney $(U=71)$ test yielded no significant finding when testing the relationship of creation of new positions in central administration to the level of entrepreneurial activity as measured by the Entrepreneurial Score, $z=-.912, p>.05$.

With alpha set at .05 , the Mann-Whitney $(U=69.5)$ test yielded no significant finding when testing the relationship of creation of new positions in central administration to the level of entrepreneurial activity as measured by the number of new initiatives, $z=-1.039, p>.05$.

With alpha set at .05 , the Mann-Whitney $(U=74)$ test yielded no significant finding when testing the relationship of creation of new positions in central administration to the level of entrepreneurial activity as measured by the number of new initiatives planned for the future, $z=-.778, p>.05$. 
There appears to be no significant relationship between the reported types of administrative and/or organizational change and the level of entrepreneurial activity at the institution as measured by the Entrepreneurial Score, the number of new initiatives, or the number of new initiatives planned for the future.

Whether faculty are formally encouraged to pursue innovative and entrepreneurial activities?

Twenty-five institutions (89.3\%) reported that they either encourage or strongly encourage faculty entrepreneurial activities. None of the institutions reported discouragement of faculty entrepreneurial activities. Table 24 summarizes the data. Table 24

Level of Institutional Support for Faculty Entrepreneurship

\begin{tabular}{lcc}
\hline Level of Institutional Support & Frequency & Percent \\
\hline Strongly Encouraged & 4 & 14.3 \\
Encouraged & 21 & 75.0 \\
Neutral & 3 & 10.7 \\
\hline Discouraged & 0 & 0 \\
\hline Strongly Discouraged & 0 & 0 \\
\hline Total & 28 & 100.0 \\
\hline
\end{tabular}

A Kruskal-Wallis test was used to assess the median change in the level of entrepreneurial activity using the Entrepreneurial Score, based on the level of institutional support for faculty entrepreneurial activities. With alpha set at .05, the test was not significant, $\chi^{2}(2, N=28)=2.778, p>.05$. The critical value was 5.99 . 
Using the number of new initiatives to measure entrepreneurial activity, the results were still not significant, $\chi^{2}(2, N=28)=2.666, p>.05$. The critical value was 5.99 .

Once again, using the number of new initiatives planned for the future to measure entrepreneurial activity, the results were not significant, $\chi^{2}(2, N=28)=1.307, p>.05$. The critical value was 5.99 .

No significant relationship was found between the level of institutional support for faculty entrepreneurial activities and the level of entrepreneurial activity at the institution as measured by the Entrepreneurial Score, the number of new initiatives, or the number of new initiatives planned for the future.

Whether merit pay or other reward systems are used to encourage faculty to pursue innovative and entrepreneurial activities?

Table 25 summarizes the data regarding reward systems the respondent institutions reported to reward faculty entrepreneurial activities.

Table 25

Reward Systems Used to Encourage Faculty Entrepreneurial Activities

\begin{tabular}{lcc}
\hline Reward System & Frequency & Percent \\
\hline Merit Pay & 4 & 14.3 \\
Other Reward System & 8 & 28.6 \\
No Reward System & 16 & 57.1 \\
\hline Total & 28 & 100.0 \\
\hline
\end{tabular}

Four $(14.3 \%)$ institutions reported using a merit pay system to reward faculty for entrepreneurial activities. Eight (28.6\%) institutions reported using a variety of other reward systems. The reward systems identified are as follows: 
- Support for ideas-to-reality organizational culture (no additional explanation).

- Intellectual property.

- Equipment or technology rewards.

- Compensation.

- Indirect costs split with principal investigator.

- Points for each project developed, which are granted upon requesting promotion.

- Release from class time.

- Percentage of dollars obtained.

Sixteen (57.1\%) of the institutions have no identified reward system to encourage faculty entrepreneurial activities. One of these institutions indicated that they are moving in the direction of a reward system for faculty entrepreneurship. Another institution indicated that money is not available for a reward system. Finally, one institution indicated that with current budget cuts, they are at the point of layoffs.

A Kruskal-Wallis test was used to assess the median change in the level of entrepreneurial activity using the Entrepreneurial Score, based on the reward system used to encourage faculty entrepreneurial activities. With alpha set at .05 , the test was not significant, $\chi^{2}(2, N=28)=2.413, p>.05$. The critical value was 5.99.Using the number of new initiatives to measure entrepreneurial activity, the results were significant at the .05 alpha level, $\chi^{2}(2, N=28)=6.307, p<.05$. The critical value was 5.99. The proportion of variability in the ranked dependent variable accounted for by the reward system used was $\eta^{2}=.23$, indicating a fairly strong relationship between the reward system used to encourage faculty entrepreneurial activities and the number of new initiatives. 
However, follow-up tests were conducted to evaluate pair wise differences among the three reward system categories, controlling for Type I error across tests using Holm's sequential Bonferroni method. The results of these tests indicated no significant difference as a result of the reward system used.

The Spearman's rank correlation coefficient indicated a significant relationship between the number of new initiatives and the reward system used to encourage faculty entrepreneurial activities, $r_{s}=-.403, N=28, \mathrm{p}<.05$.

While it appears there may be some relationship between the reward system used to encourage faculty entrepreneurial activities and the number of new initiatives, the test results are inconclusive.

Finally, using the number of new initiatives planned for the future to measure entrepreneurial activity, the results were not significant, $\chi^{2}(2, N=28)=.225, p>.05$. The critical value was 5.99 .

No significant relationship was found between the reward system used to encourage faculty entrepreneurial activities and the level of entrepreneurial activity at the institution as measured by the Entrepreneurial Score or the number of new initiatives planned for the future. Some relationship may exist between the reward system used to encourage faculty entrepreneurial activities and the level of entrepreneurial activity at the institution as measured by the number of new initiatives, but the results were inconclusive. 
Whether the institution's purpose and/or mission has been changed to reflect greater emphasis on entrepreneurial activities?

Table 26 summarizes the responses regarding changes in institutional purpose or mission. Four institutions (14.3\%) indicated that their institutional purpose or mission had changed to reflect a greater emphasis on entrepreneurial activities.

Table 26

Change in Institution's Purpose or Mission

\begin{tabular}{ccc}
\hline Change in Purpose or Mission? & Frequency & Percent \\
\hline Yes & 4 & 14.3 \\
No & 22 & 78.6 \\
\hline Total & 26 & 92.9 \\
\hline No Response & 2 & 7.1 \\
\hline $\mathrm{N}=$ & 28 & 100.0 \\
\hline
\end{tabular}

Three of these respondents provided comments. One indicated that its purpose or mission had changed to better serve two-year college graduates. Another respondent indicated that the old mission reflected a focus on traditional program offerings and that the new mission focused on expected benefits to students, the region, and to society. They further indicated that their new vision now focused on the institution's impact on the region. The third respondent commented that the purpose or mission changed to optimize entrepreneurial opportunities and to think in terms of investment and fundraising opportunities.

Mann-Whitney tests were conducted to assess whether changes in the institution's purpose or mission affects the level of entrepreneurial activity as measured first by the 
Entrepreneurial Score, second by the number of new initiatives, and third by the number of new initiatives planned for the future.

With alpha set at .05 , the Mann-Whitney $(U=16)$ test yielded a significant relationship between the change in the institution's purpose or mission and the level of entrepreneurial activity as measured by the Entrepreneurial Score, $z=-1.992, p<.05$. The proportion of variability in the ranked dependent variable accounted for by the change in institutional purpose or mission was $\eta^{2}=.16$, indicating a small relationship between changes in institutional purpose or mission and the level of entrepreneurial activity as measured by the Entrepreneurial Score. The Spearman's rank correlation coefficient was also significant at the .05 level, $\mathrm{r}_{\mathrm{s}}=-.398, N=26, \mathrm{p}<.05$. Figure 11 illustrates the difference entrepreneurial activity as measured by the Entrepreneurial Score as affected by whether or not there was a change in the institution's purpose or mission to reflect a greater emphasis on entrepreneurial activities.

Figure 11. Significant Difference in Entrepreneurial Score Based on Whether or Not There Was a Change in the Institution's Purpose or Mission to Reflect a Greater Emphasis on Entrepreneurial Activities

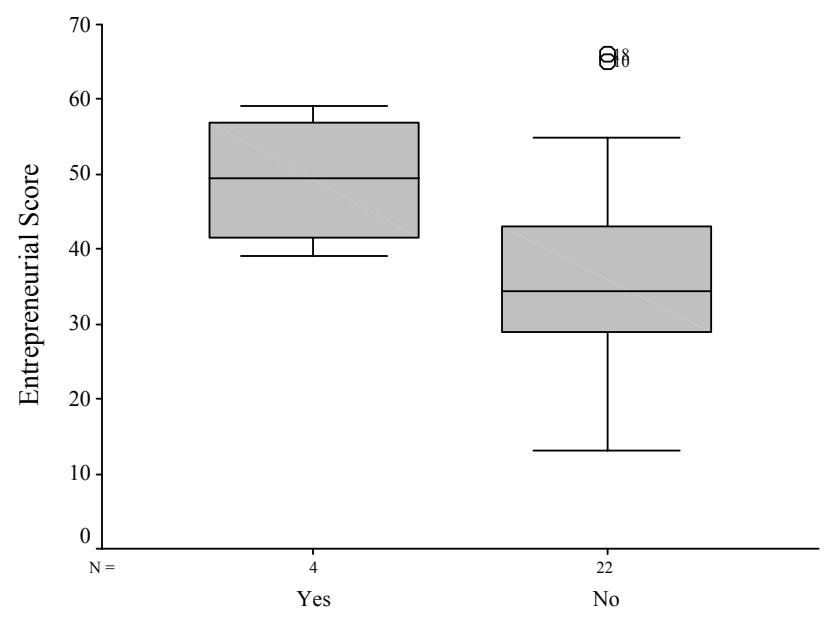

Has Institution's Purpose of Mission Changed? 
With alpha set at .05 , the Mann-Whitney $(U=35)$ test yielded no significant finding when testing the relationship between the change in the institution's purpose or mission and the level of entrepreneurial activity as measured by the number of new initiatives, $z=-.668, p>.05$.

With alpha set at .05 , the Mann-Whitney $(U=44)$ test yielded no significant finding when testing the relationship between the change in the institution's purpose or mission and the level of entrepreneurial activity as measured by the number of new initiatives planned for the future, $z=.000, p>.05$.

There appears to be no significant relationship between the change in the institution's purpose or mission and the level of entrepreneurial activity at the institution as measured by the number of new initiatives, or the number of new initiatives planned for the future. However, there is a significant relationship between the change in the institution's purpose or mission and the level of entrepreneurial activity at the institution as measured by the Entrepreneurial Score.

Whether faculty or staff are represented by a union?

Tables 27 and 28 summarize the data regarding union representation of faculty and staff. Eleven (39.3\%) indicated that their faculty are represented by a union and twelve (42.9\%) institutions indicated that their staff are represented by a union.

Table 27

Are Faculty Represented by a Union?

\begin{tabular}{ccc}
\hline Faculty Represented by a Union? & Frequency & Percent \\
\hline Yes & 11 & 39.3 \\
No & 17 & 60.7 \\
\hline Total & 28 & 100.0 \\
\hline
\end{tabular}


Table 28

Are Staff Represented by a Union?

\begin{tabular}{ccc}
\hline Staff Represented by a Union? & Frequency & Percent \\
\hline Yes & 12 & 42.9 \\
No & 16 & 57.1 \\
\hline Total & 28 & 100.0 \\
\hline
\end{tabular}

Mann-Whitney tests were conducted to assess whether faculty representation by a union affects the level of entrepreneurial activity as measured first by the Entrepreneurial Score, second by the number of new initiatives, and third by the number of new initiatives planned for the future.

With alpha set at .05 , the Mann-Whitney $(U=67)$ test yielded no significant relationship between whether faculty are represented by a union and the level of entrepreneurial activity as measured by the Entrepreneurial Score, $z=-.686, p>.05$.

With alpha set at .05 , the Mann-Whitney $(U=75.5)$ test yielded no significant relationship between whether faculty are represented by a union and the level of entrepreneurial activity as measured by the number of new initiatives, $z=-.255, p>.05$.

With alpha set at .05 , the Mann-Whitney $(U=70.5)$ test yielded no significant relationship between whether faculty are represented by a union and the level of entrepreneurial activity as measured by the number of new initiatives planned for the future, $z=-.509, p>.05$.

Mann-Whitney tests were conducted to assess whether staff representation by a union affects the level of entrepreneurial activity as measured first by the Entrepreneurial 
Score, second by the number of new initiatives, and third by the number of new initiatives planned for the future.

With alpha set at .05 , the Mann-Whitney $(U=83)$ test yielded no significant relationship between whether staff are represented by a union and the level of entrepreneurial activity as measured by the Entrepreneurial Score, $z=-.247, p>.05$.

With alpha set at .05 , the Mann-Whitney $(U=55.5)$ test yielded no significant relationship between whether staff are represented by a union and the level of entrepreneurial activity as measured by the number of new initiatives, $z=-1.707, p>.05$.

With alpha set at .05 , the Mann-Whitney $(U=77.5)$ test yielded no significant relationship between whether staff are represented by a union and the level of entrepreneurial activity as measured by the number of new initiatives planned for the future, $z=-.526, p>.05$.

There appears to be no significant relationship regarding whether faculty or staff are represented by a union and the level of entrepreneurial activity at the institution. Question 2 Summary

Question 2 focused on whether or not there is a relationship between the number of entrepreneurial initiatives and twenty-two institutional factors. Table 29 summarizes the results of the data analysis indicating which factors were found to have a significant relationship and which ones were found to have no significant relationship with the number of entrepreneurial initiatives. 
Table 29.

Relationship between the Number of Entrepreneurial Initiatives and 22 Institutional Factors

Institutional Factor

Results*

The number of years the president/chancellor has been in current position.

Significant

The field of study or discipline of the president/chancellor.

Not Significant

The business/industry experience of the institution's president chancellor.

Not Significant

The institution's enrollment.

Not Significant

An increase or decrease in enrollment from the previous year.

Not Significant

The institution's tuition, both in-state and out-of-state.

Not Significant

An increase or decrease in tuition from the previous year:

In-state tuition

Out-of-state tuition

Not Significant

Significant

The number of faculty, both full-time and part-time:

Full-time faculty

Part-time faculty

Significant

Not Significant

The number of tenure track and non-tenure track faculty:

Tenure track faculty

Non-tenure track faculty

Significant

Not Significant

An increase or decrease in full-time faculty, both tenure track and non-

Not Significant tenure track, from the previous year.

An increase or decrease in full-time tenure track faculty from the

Not Significant previous year.

An increase or decrease in part-time faculty from the previous year.

Not Significant

The highest degree offered at the institution.

Not Significant 
Institutional Factor

Results*

The addition or elimination of programs for teaching, research, and service since the previous year:

Teaching programs added

Teaching programs eliminated

Research programs added

Research programs eliminated

Service programs added

Service programs eliminated

Not Significant

Not Significant

Not Significant

Not Significant

Significant

Not Significant

An increase or decrease in state appropriations

Not Significant

Whether the governing board encourages or discourages entrepreneurial activities to generate revenue.

Not Significant

The number of programs supported by generating their own revenue.

Not Significant

Administrative and/or organizational changes during the

Not Significant

president's/chancellor's tenure.

Whether faculty are formally encouraged to pursue innovative and entrepreneurial activities.

Not Significant

Whether merit pay or other reward systems are used to encourage

Significant

faculty to pursue innovative and entrepreneurial activities.

Whether the institution's purpose and/or mission has been changed to reflect greater emphasis on entrepreneurial activities.

Significant

Whether faculty or staff are represented by a union.

Not Significant

* An alpha level of .05 was used as the criterion to establish significance.

Research Question 3: What entrepreneurial institutional initiatives are proving successful in terms of generating revenue for these institutions?

The survey instrument listed forty-three potential institutional initiatives and asked the respondents to indicate the level of use at their institution by checking a box for one of four choices: new initiative, traditionally used, planned for the future, or not applicable. Space was also provided for respondents to identify additional initiatives not 
listed on the survey and to make the same choices regarding usage. Two additional initiatives were added by one of the respondent institutions: off-campus housing and the purchase of a golf course.

The survey instrument also asked the respondents to indicate the level of success in generating revenue for each new initiative or traditionally used initiative. Table 30 summarizes the findings on the level of success reported by the respondent institutions. It should be noted that two of the respondents did not check a success level for some of the new initiatives they identified as being used by their institution. It may be that the new initiatives were so new that a measure of success could not yet be made.

Table 30

Level of Success for New Initiatives and Traditionally Used Initiatives

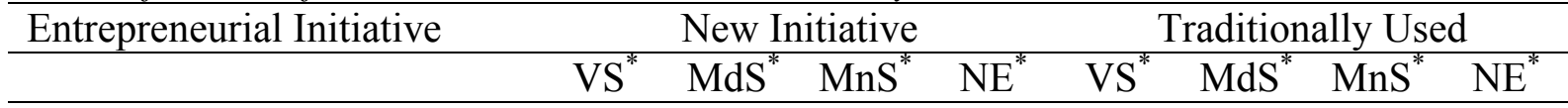

Innovation/Entrepreneurship

Center

Small Business Development

Center

Incubation of Start-Up

Companies

Product Development

Services to

Business/Industry

Technical Services to

Business/Industry

Personnel Exchanges with

Business/Industry

1

Personnel Exchanges with

Government Agencies

1

1

$\begin{array}{llll}1 & 1 & 4 & 3\end{array}$

$1 \quad 1$

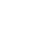




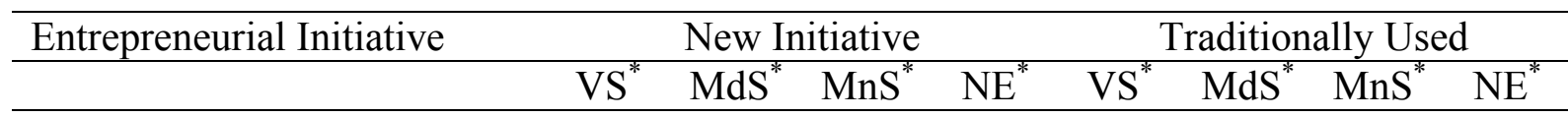

Contract-Training Programs

with Business/Industry

$\begin{array}{lllll}1 & 2 & 2 & 7 & 1\end{array}$

Contract-Training Programs

with Government

Agencies

1

$\begin{array}{lll}2 & 6 & 1\end{array}$

Executive Training Programs for Business/Industry $1 \quad 1$

Specialized Training

Programs and Certificate

Programs for

Business/Industry

Research Contracts with

Government Agencies

Research Contracts with

Private Sector Enterprises

Joint Ventures or Partnerships

with Private Sector

Enterprises

$1 \quad 1$

222

Technology Transfer Centers

to Patent, License and/or

Commercialize Research

Outcomes

Spin-Off Companies from

Research Outcomes

Distance-Learning Programs

within Existing

Organizational Structure $\quad 2$

$\begin{array}{llll}7 & 7 & 3 & 2\end{array}$




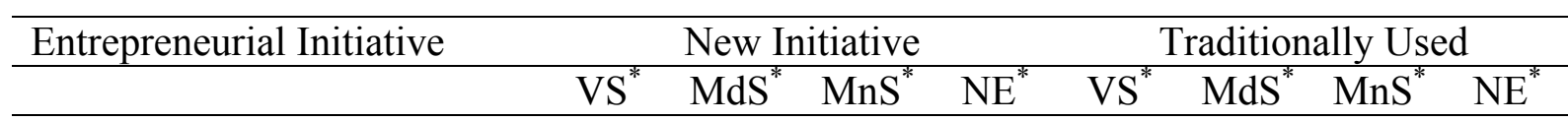

Distance-Learning Programs

in Partnership with Private

Sector Enterprise

Distance-Learning Programs

as For-Profit Subsidiaries

Distance-Learning Programs

Funded through Venture

Capital 1

Evening Degree Offering

Programs

1

$6 \quad 10$

Weekend Degree Offering

Programs

Degree Completion Programs

$4 \quad 4$

Certificate Programs

Fast Track Programs

Executive Programs

$\begin{array}{lll}9 & 8 & 1\end{array}$

$\begin{array}{llll}5 & 8 & 1 & 1\end{array}$

College/University

Foundation to Raise Funds

to Support Programs and

Services

1

1

$\begin{array}{lll}6 & 10 & 5\end{array}$

Alumni Association to Raise

Funds to Support

$\begin{array}{clllllll}\text { Programs and Services } & 1 & & 2 & 1 & 4 & 8 & 1 \\ \text { Initiated a Capital Campaign } & 1 & 1 & 1 & 4 & 3 & & \end{array}$

Sale of Products and Services

from Educational

Endeavors

1

$3 \quad 3$ 


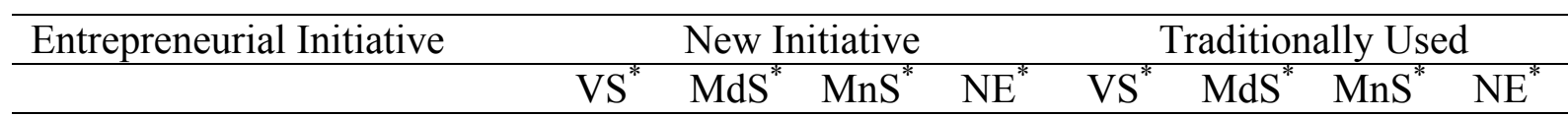

Licensing of Products and

Services from Educational

Endeavors

1

32

Profit-Sharing with Food

Service, Bookstores, and

Other Auxiliary Services

Develop Real Estate

Endowments

Debt Financing, such as

Revenue Bonds

$\begin{array}{lll}8 & 8 & 1\end{array}$

Develop or Expand

Endowments

1

$10 \quad 2$

Develop New Revenues from

Sports/Athletic Events and

Activities

1

24

Lease/Rent Institutional

Facilities and/or

Equipment

$1 \quad 1$

45

2

Retail Sales of Institutional

Resources. Such as

Computer Time and

Internet Access

Catering Food Services

Increasing Tuition and Fees 2

Increasing Residence Fees

1

Increasing Cost of Campus

Food Services

$2 \quad 12 \quad 3$




\begin{tabular}{|c|c|c|c|c|c|c|c|c|}
\hline \multirow[t]{2}{*}{ Entrepreneurial Initiative } & \multicolumn{4}{|c|}{ New Initiative } & \multicolumn{4}{|c|}{ Traditionally Used } \\
\hline & $\mathrm{VS}^{*}$ & $\mathrm{MdS}^{*}$ & $\mathrm{MnS}^{*}$ & $\mathrm{NE}^{*}$ & $\mathrm{VS}^{*}$ & $\mathrm{MdS}^{*}$ & $\mathrm{MnS}^{*}$ & $\mathrm{NE}^{*}$ \\
\hline \multicolumn{9}{|l|}{ Increasing Student } \\
\hline \multicolumn{9}{|l|}{ Laboratory, Supplies, and } \\
\hline Other Service Fees & 1 & & & & 2 & 13 & 5 & \\
\hline Off Campus Housing & & & & & 1 & & & \\
\hline Purchase Golf Course & & & & & 1 & & & \\
\hline
\end{tabular}

*VS = Very Successful MdS = Moderately Successful $\mathrm{MnS}=$ Minimally Successful NE $=$ Not Effective

The initiatives that were reported most frequently as successful new initiatives were contract training programs with business/industry, alumni association, capital campaign, and development of real estate endowments, with three institutions reporting some level of success with these initiatives. No institution reported a new initiative as being not effective.

Over seventy percent of the institutions reported some level of success with college/university foundations, increasing tuition and fees, and increasing student laboratory, supplies, and other service fees as traditionally used initiatives. At least one institution reported technology transfer centers, distance-learning programs within the existing organizational structure, certificate programs, alumni associations, and leasing/renting institutional facilities and equipment as not effective traditionally used initiatives.

Table 31 identifies, in rank order from highest to lowest, the entrepreneurial initiatives with a success score calculated by summing assigned weights to the various levels of success. For the traditionally used initiatives the weights assigned were: not effective $=0$, minimally successful $=1$, moderately successful $=2$, and very successful $=$ 
3. For the new initiatives the weights assigned were: not effective 0 , minimally

successful $=2$, moderately successful $=4$, and very successful $=6$.

Table 31

Rank Ordered Success Scores for Each Entrepreneurial Initiative

Entrepreneurial Initiative

Increasing Tuition and Fees

Score

54

College/University Foundation to Raise Funds to Support Programs and

Services

Distance-Learning Programs within Existing Organizational Structure

Degree Completion Programs

Profit-Sharing with Food Service, Bookstores, and Other Auxiliary

Services

Evening Degree Offering Programs 44

Increasing Residence Fees $\quad 42$

Debt Financing, such as Revenue Bonds 41

Research Contracts with Government Agencies 41

Increasing Cost of Campus Food Services 33

Certificate Programs 32

Lease/Rent Institutional Facilities and/or Equipment 31

Increasing Student Laboratory, Supplies, and Other Service Fees 30

Weekend Degree Offering Programs 30

Initiated a Capital Campaign 30

Contract-Training Programs with Business/Industry 29 


\begin{tabular}{lc}
\hline Entrepreneurial Initiative & Score \\
\hline Alumni Association to Raise Funds to Support Programs and Services & 29 \\
Catering Food Services & 28 \\
Develop or Expand Endowments & 26
\end{tabular}

Specialized Training Programs and Certificate Programs for

Business/Industry 26

Contract-Training Programs with Government Agencies 23

Joint Ventures or Partnerships with Private Sector Enterprises 22

Small Business Development Center 20

Develop Real Estate Endowments 16

Executive Training Programs for Business/Industry 16

Research Contracts with Private Sector Enterprises 14

Licensing of Products and Services from Educational Endeavors 12

Sale of Products and Services from Educational Endeavors 11

Personnel Exchanges with Business/Industry 11

Develop New Revenues from Sports/Athletic Events and Activities $\quad 10$

Fast Track Programs 9

Personnel Exchanges with Government Agencies 9

Executive Programs 8

$\begin{array}{ll}\text { Technical Services to Business/Industry } & 7\end{array}$

Distance-Learning Programs Funded through Venture Capital 6

Product Development Services to Business/Industry 6

Retail Sales of Institutional Resources, such as Computer Time and 5 


\begin{tabular}{lc}
\hline Entrepreneurial Initiative & Score \\
\hline Internet Access & 5 \\
Innovation/Entrepreneurship Center & 5 \\
Incubation of Start-Up Companies & 3 \\
Off Campus Housing & 3 \\
Purchase Golf Course & 2 \\
Spin-Off Companies from Research Outcomes & \\
Distance-Learning Programs in Partnership with Private Sector & 2 \\
Enterprise & \\
Technology Transfer Centers to Patent, License and/or Commercialize & \\
Research Outcomes & 0 \\
Distance-Learning Programs as For-Profit Subsidiaries & 0 \\
\hline
\end{tabular}

The most successful initiatives were increasing tuition and fees, college/university foundation, distance-learning programs within the existing organizational structure, and degree completion programs. The least successful initiatives were distance-learning programs as for-profit subsidiaries, technology transfer centers, distance-learning programs in partnership with private sector enterprise, and spin-off companies.

In order to get a comparative measure between respondents on overall success, three success scores were calculated: New Initiatives Success Score, Traditionally Used Initiatives Success Score, and Composite Success Score. Calculation of the New Initiatives Success Score and the Traditionally Used Initiatives Success Score were accomplished by summing numerical weights for the level of success indicated for each selected initiative. The assigned weights are as follows: Very Successful $=3$, Moderately 
Successful $=2$, Minimally Successful $=1$, and Not Effective $=0$. The scores were then placed in rank order from lowest to highest score. Table 32 lists the calculated New Initiatives Success Score, and Table 33 lists the calculated Traditionally Used Initiatives Success Score.

Table 32

New Initiatives Success Scores

\begin{tabular}{ccc}
\hline Success Score & Frequency & Percent \\
\hline 0 & 15 & 53.6 \\
1 & 4 & 14.3 \\
2 & 2 & 7.1 \\
3 & 1 & 3.6 \\
4 & 1 & 3.6 \\
6 & 1 & 3.6 \\
13 & 2 & 7.1 \\
20 & 1 & 3.6 \\
37 & 1 & 3.6 \\
\hline Total & 28 & 100.0 \\
\hline
\end{tabular}

The New Initiatives Success Score ranged from a low of zero to a high of thirtyseven $(M=3.71, S D=8.151)$. Fifteen $(53.6 \%)$ of the respondent institutions had New Initiative Success Scores of zero. Two of these institutions had indicated some new initiatives, but did not select a success level. The other thirteen reported no new initiatives.

A one-sample Kolmogrov-Smirnov test of normality was conducted on the distribution of the New Initiatives Success Score to assess whether the scores are normally distributed. With alpha set at .05 , the results of the test were significant, $K$ - 
$S($ Lilliefors $)(28)=.333, \mathrm{p}<.01$. The distribution of New Initiatives Success Scores is significantly different from a normal distribution, as represented in Figure 12.

Figure 12. Distribution of the New Initiatives Success Scores Compared to the Normal Distribution

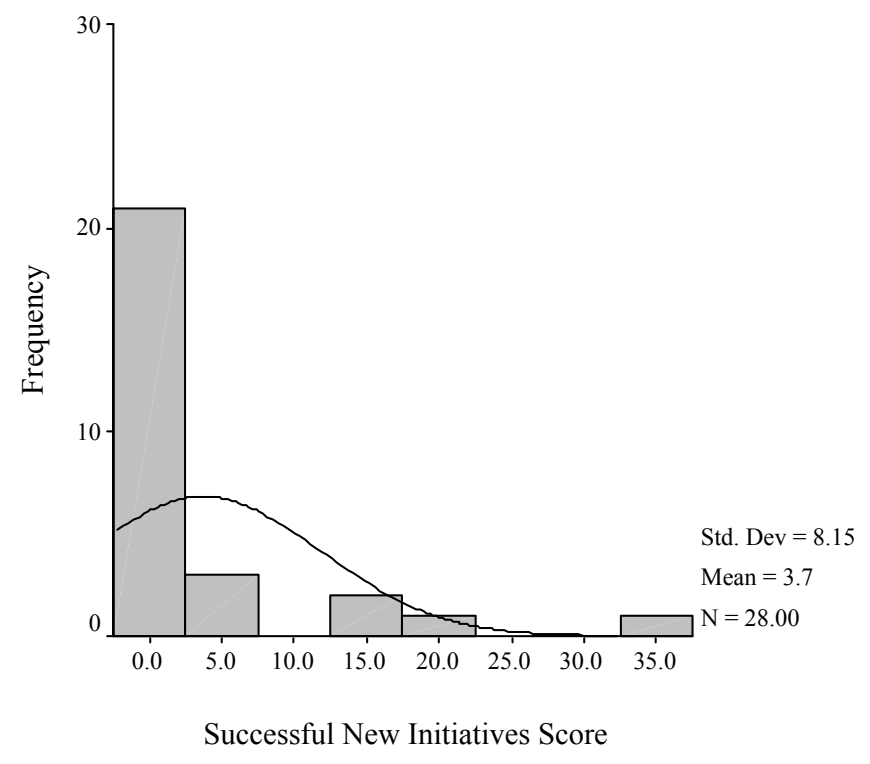

The Traditionally Used Initiatives Success Score ranged from a low of zero to a high of sixty $(M=27.61, S D=12.905)$. A one-sample Kolmogrov-Smirnov test of normality was conducted on the distribution of the Traditionally Used Initiatives Success Score to assess whether the scores are normally distributed. With alpha set at .05 , the results of the test were not significant, $K-S($ Lilliefors $)(28)=.110, \mathrm{p}>.05$. The distribution of Traditionally Used Initiatives Success Scores is not significantly different from a normal distribution, as represented in Figure 13. 
Table 33

Traditionally Used Initiatives Success Scores

\begin{tabular}{|c|c|c|}
\hline Success Score & Frequency & Percent \\
\hline 0 & 1 & 3.6 \\
\hline 8 & 1 & 3.6 \\
\hline 14 & 1 & 3.6 \\
\hline 15 & 1 & 3.6 \\
\hline 19 & 3 & 10.7 \\
\hline 20 & 1 & 3.6 \\
\hline 21 & 2 & 7.1 \\
\hline 22 & 1 & 3.6 \\
\hline 23 & 1 & 3.6 \\
\hline 24 & 1 & 3.6 \\
\hline 27 & 3 & 10.7 \\
\hline 29 & 1 & 3.6 \\
\hline 31 & 2 & 7.1 \\
\hline 32 & 1 & 3.6 \\
\hline 33 & 1 & 3.6 \\
\hline 34 & 1 & 3.6 \\
\hline 36 & 1 & 3.6 \\
\hline 39 & 1 & 3.6 \\
\hline 43 & 1 & 3.6 \\
\hline 47 & 1 & 3.6 \\
\hline 52 & 1 & 3.6 \\
\hline 60 & 1 & 3.6 \\
\hline Total & 28 & 100.0 \\
\hline
\end{tabular}


Figure 13. Distribution of the Traditionally Used Initiatives Success Scores Compared to the Normal Distribution

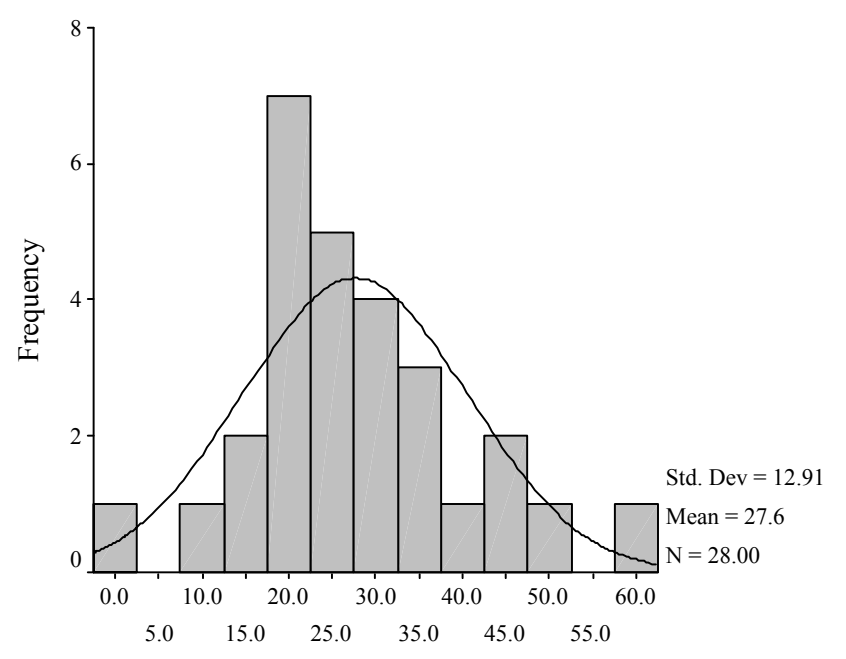

Successful Traditionally Used Initiatives Score

A Composite Success Score was calculated for each respondent institution to reflect institutional levels of success for both new initiatives and traditionally used initiatives. The score was calculated by summing the Traditionally Used Initiatives Success Score with twice the value of the New Initiatives Success Score. The New Initiatives Success Score was given more weight to reflect more entrepreneurial activity. Table 34 lists the calculated Composite Success Scores.

The Composite Success Score ranged from a low of fourteen to a high of seventynine $(M=35.04, S D=17.238)$. A one-sample Kolmogrov-Smirnov test of normality was conducted on the distribution of the Composite Success Score to assess whether the scores are normally distributed. With alpha set at .05 , the results of the test were significant, $K-S($ Lilliefors $)(28)=.190, \mathrm{p}<.05$. The distribution of Composite Success Scores is significantly different from a normal distribution, as represented in Figure 14. 
Table 34

Composite Success Scores

\begin{tabular}{|c|c|c|}
\hline Success Score & Frequency & Percent \\
\hline 14 & 1 & 3.6 \\
\hline 16 & 1 & 3.6 \\
\hline 17 & 1 & 3.6 \\
\hline 19 & 1 & 3.6 \\
\hline 20 & 1 & 3.6 \\
\hline 21 & 1 & 3.6 \\
\hline 22 & 1 & 3.6 \\
\hline 23 & 1 & 3.6 \\
\hline 24 & 1 & 3.6 \\
\hline 27 & 4 & 14.3 \\
\hline 29 & 1 & 3.6 \\
\hline 31 & 2 & 7.1 \\
\hline 32 & 1 & 3.6 \\
\hline 33 & 1 & 3.6 \\
\hline 39 & 1 & 3.6 \\
\hline 40 & 1 & 3.6 \\
\hline 43 & 1 & 3.6 \\
\hline 45 & 1 & 3.6 \\
\hline 47 & 1 & 3.6 \\
\hline 52 & 1 & 3.6 \\
\hline 60 & 1 & 3.6 \\
\hline 62 & 1 & 3.6 \\
\hline 74 & 1 & 3.6 \\
\hline 79 & 1 & 3.6 \\
\hline Total & 28 & 100.0 \\
\hline
\end{tabular}


Figure 14. Distribution of the Composite Success Scores Compared to the Normal Distribution

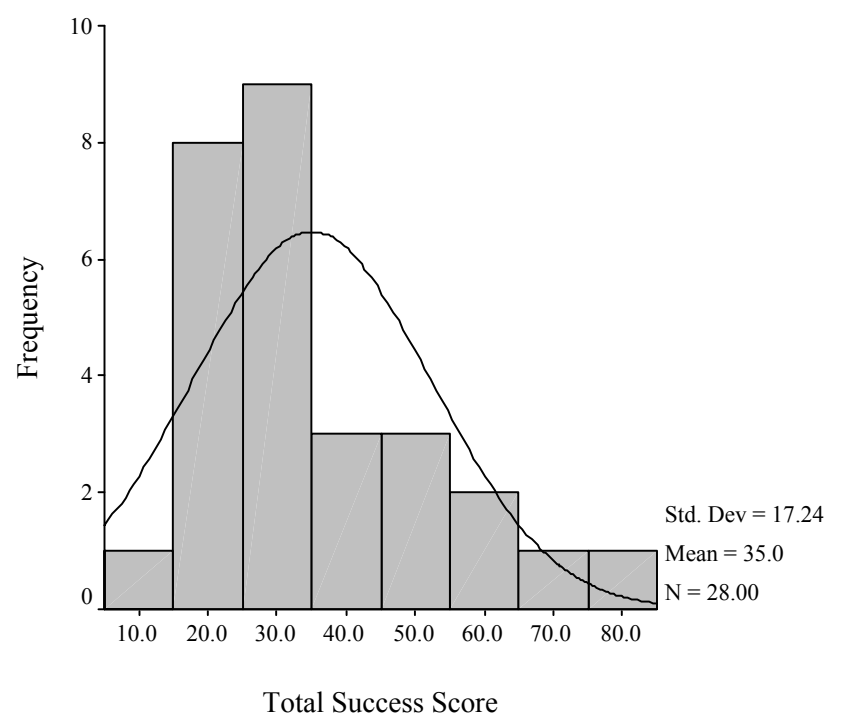

In order to test consistency in the measurement of entrepreneurial activity, a Spearman's rank correlation coefficient was conducted to determine if a relationship existed between the Entrepreneurial Score and the Composite Success Score. The Spearman's rank correlation coefficient was significant at the .05 level, $\mathrm{r}_{\mathrm{s}}=.677, N=28$, $\mathrm{p}<.01$. A Spearman's rank correlation coefficient was conducted to determine if a relationship existed between the number of new initiatives and the New Initiatives Success Score. The Spearman's rank correlation coefficient was significant at the .05 level, $\mathrm{r}_{\mathrm{s}}=.817, N=28, \mathrm{p}<.01$. Finally, a Spearman's rank correlation coefficient was conducted to determine if a relationship existed between the number of traditionally used initiatives and the Traditionally Used Initiatives Success Score. The Spearman's rank correlation coefficient was significant at the .05 level, $\mathrm{r}_{\mathrm{s}}=.861, N=28, \mathrm{p}<.01$. 
Research Question 4: Is there a relationship between the number of successful entrepreneurial initiatives and the following factors:

The number of years the president/chancellor has been in current position?

A Kruskal-Wallis test was conducted to evaluate the differences among the five lengths of service categories for the number of years the president/chancellor has been in current position on median change in the level of successful entrepreneurial initiatives using the New Initiatives Success Score. With alpha set at .05, the test was not significant, $\chi^{2}(4, N=28)=6.665, p>.05$. The critical value was 9.49. This suggests that there is no significant relationship between the time in office of the president/chancellor and the level of successful entrepreneurial initiatives at the institution as measured by the New Initiatives Score.

A Kruskal-Wallis test was conducted to evaluate the differences among the five lengths of service categories on median change in the level of successful entrepreneurial initiatives using the Traditionally Used Successful Initiatives Score. With alpha set at .05 , the test was not significant, $\chi^{2}(4, N=28)=3.812, p>.05$. The critical value was 9.49 .

A Kruskal-Wallis test was conducted to evaluate the differences among the five lengths of service categories on median change in the level of successful entrepreneurial initiatives using the Composite Success Score. With alpha set at .05, the test was not significant, $\chi^{2}(4, N=28)=4.735, p>.05$. The critical value was 9.49 .

The analysis failed to reveal any significant relationship between the number of years the president/chancellor has been in current position and the level of successful 
entrepreneurial initiatives as measured by the New Initiatives Success Score, The Traditionally Used Initiatives Success Score, and the Composite Success Score. The field of study or discipline of the president/chancellor?

A Kruskal-Wallis test was conducted to evaluate differences among the various fields of study or disciplines of the president/chancellor on median change in the level of successful entrepreneurial initiatives as measured by the New Initiatives Success Score. With alpha set at .05 , the test was not significant, $\chi^{2}(9, N=28)=10.687, p>.05$. The critical value was 16.919. This suggests that there is no significant relationship between the various fields of study or disciplines of the president/chancellor and the level of successful entrepreneurial initiatives at the institution as measured by the New Initiatives Success Score.

A Kruskal-Wallis test was conducted to evaluate the differences among the various fields of study or disciplines of the president/chancellor on median change in the level of successful entrepreneurial initiatives using the Traditionally Used Successful Initiatives Score. With alpha set at .05 , the test was not significant, $\chi^{2}(9, N=28)=7.748$, $p>.05$. The critical value was 16.919 .

A Kruskal-Wallis test was conducted to evaluate the differences among the various fields of study or disciplines of the president/chancellor on median change in the level of successful entrepreneurial initiatives using the Composite Success Score. With alpha set at .05 , the test was not significant, $\chi^{2}(9, N=28)=9.811, p>.05$. The critical value was 16.919 .

The analysis failed to reveal any significant relationship between the various fields of study or disciplines of the president/chancellor and the level of successful 
entrepreneurial initiatives as measured by the New Initiatives Success Score, The Traditionally Used Initiatives Success Score, and the Composite Success Score. The business/industry experience of the institution's president/chancellor?

As stated earlier, the data revealed that all of the presidents/chancellors for the respondent institutions $(N=28)$ came to their current positions through academic positions, reflecting no business/industry experience offering no basis for further assessment.

The institution's enrollment?

Statistical tests were conducted using the Kruskal-Wallis test to evaluate differences among the various levels of enrollment at the institutions on median change in successful entrepreneurial initiatives as measured by the New Initiatives Success Score. These tests were done for full-time undergraduate, part-time undergraduate and part-time graduate enrollments. No further assessment was made for full-time graduate enrollments since all $(N=28)$ institutions reported the same enrollment level of $<1,000$.

A Kruskal-Wallis test was conducted for the full-time undergraduate enrollments. With alpha set at .05 , the test was not significant, $\chi^{2}(2, N=28)=4.947, p>.05$. The critical value was 5.99 .

A Kruskal-Wallis test was conducted for the part-time undergraduate enrollments. With alpha set at .05 , the test was not significant, $\chi^{2}(1, N=28)=1.916, p>.05$. The critical value was 3.84 .

A Kruskal-Wallis test was conducted for the part-time graduate enrollments. With alpha set at .05 , the test was not significant, $\chi^{2}(1, N=28)=2.839, p>.05$. The critical value was 3.84 . 
Statistical tests were conducted using the Kruskal-Wallis test to evaluate differences among the various levels of enrollment at the institutions on median change in successful entrepreneurial initiatives as measured by the Traditionally Used Initiatives Success Score. These tests were done for full-time undergraduate, part-time undergraduate and part-time graduate enrollments. Again, no further assessment was made for full-time graduate enrollments since all $(N=28)$ institutions reported the same enrollment level of $<1,000$.

A Kruskal-Wallis test was conducted for the full-time undergraduate enrollments. With alpha set at .05 , the test was not significant, $\chi^{2}(2, N=28)=.896, p>.05$. The critical value was 5.99.

A Kruskal-Wallis test was conducted for the part-time undergraduate enrollments. With alpha set at .05 , the test was not significant, $\chi^{2}(1, N=28)=.010, p>.05$. The critical value was 3.84 .

A Kruskal-Wallis test was conducted for the part-time graduate enrollments. With alpha set at .05 , the test was not significant, $\chi^{2}(1, N=28)=1.387, p>.05$. The critical value was 3.84 .

Statistical tests were conducted to evaluate differences among the various levels of enrollment at the institutions on median change in successful entrepreneurial initiatives as measured by the Composite Success Score. These tests were done for full-time undergraduate, part-time undergraduate and part-time graduate enrollments. Once again, no further assessment was made for full-time graduate enrollments since all $(N=28)$ institutions reported the same enrollment level of $<1,000$. 
A Kruskal-Wallis test was conducted for the full-time undergraduate enrollments. With alpha set at .05 , the test was not significant, $\chi^{2}(2, N=28)=2.165, p>.05$. The critical value was 5.99 .

A Kruskal-Wallis test was conducted for the part-time undergraduate enrollments. With alpha set at .05 , the test was not significant, $\chi^{2}(1, N=28)=2.335, p>.05$. The critical value was 3.84 .

A Kruskal-Wallis test was conducted for the part-time graduate enrollments. With alpha set at .05 , the test was not significant, $\chi^{2}(1, N=28)=2.802, p>.05$. The critical value was 3.84 .

The analysis failed to reveal any significant relationship between enrollments and the level of successful entrepreneurial initiatives as measured by the New Initiatives Success Score, the Traditionally Used Success Initiatives Success Score, and the Composite Success Score.

An increase or decrease in enrollment from the previous year?

Enrollments for the respondent institutions $(N=28)$ decreased for nine institutions (32.1\%) and increased for the other nineteen institutions (67.9\%). To test for a relationship between a change in enrollment and the level of successful entrepreneurial initiatives, Mann-Whitney tests were conducted to assess whether an increase or decrease in enrollment affects the level of successful entrepreneurial initiatives as measured first by the New Initiatives Success Score, second by the Traditionally Used Initiatives Success Score, and third by the Composite Success Score.

With alpha set at .05 , the Mann-Whitney $(U=79)$ test yielded no significant finding when testing the relationship of decreased or increased enrollments to the level of 
successful entrepreneurial initiatives as measured by the New Initiatives Success Score, $z$ $=-.348, p>.05$.

With alpha set at .05 , the Mann-Whitney $(U=80.5)$ test yielded no significant finding when testing the relationship of decreased or increased enrollments to the level of successful entrepreneurial initiatives as measured by the Traditionally Used Initiatives Success Score, $z=-.246, p>.05$.

With alpha set at .05 , the Mann-Whitney $(U=85.5)$ test yielded no significant finding when testing the relationship of decreased or increased enrollments to the level of successful entrepreneurial initiatives as measured by the Composite Success Score, $z$ $=.000, p>.05$.

The analysis failed to reveal any significant relationship between decreased or increased enrollments and the level of successful entrepreneurial initiatives as measured by the New Initiatives Success Score, the Traditionally Used Initiatives Success Score, and the Composite Success Score.

The institution's tuition, both in-state and out-of-state?

Kruskal-Wallis statistical tests were conducted to evaluate differences among the various levels of tuition at the institutions, in-state and out-of-state, on median change in successful entrepreneurial initiatives as measured by the New Initiatives Success Score, the Traditionally Used Initiatives Success Score, and the Composite Success Score.

A Kruskal-Wallis test was conducted to evaluate differences among the various levels of in-state tuition on median change in successful entrepreneurial initiatives as measured by the New Initiatives Success Score. With alpha set at .05, the test was not significant, $\chi^{2}(4, N=28)=6.107 p>.05$. The critical value was 9.49 . 
A Kruskal-Wallis test was conducted to evaluate differences among the various levels of in-state tuition on median change in successful entrepreneurial initiatives as measured by the Traditionally Used Initiatives Success Score. With alpha set at .05, the test was not significant, $\chi^{2}(4, N=28)=4.992, p>.05$. The critical value was 9.49 .

A Kruskal-Wallis test was conducted to evaluate differences among the various levels of in-state tuition on median change in successful entrepreneurial initiatives as measured by the Composite Success Score. With alpha set at .05, the test was not significant, $\chi^{2}(4, N=28)=1.456, p>.05$. The critical value was 9.49 .

A Kruskal-Wallis test was conducted to evaluate differences among the various levels of out-of-state tuition on median change in successful entrepreneurial initiatives as measured by the New Initiatives Success Score. With alpha set at .05, the test was not significant, $\chi^{2}(3, N=28)=3.621, p>.05$. The critical value was 7.82 .

A Kruskal-Wallis test was conducted to evaluate differences among the various levels of out-of-state tuition on median change in successful entrepreneurial initiatives as measured by the Traditionally Used Initiatives Success Score. With alpha set at .05, the test was not significant, $\chi^{2}(3, N=28)=5.187, p>.05$. The critical value was 7.82 .

A Kruskal-Wallis test was conducted to evaluate differences among the various levels of out-of-state tuition on median change in successful entrepreneurial initiatives as measured by the Composite Success Score. With alpha set at .05, the test was not significant, $\chi^{2}(3, N=28)=1.498, p>.05$. The critical value was 7.82

The analysis failed to reveal any significant relationship between the levels of instate and out-of-state tuition and the level of successful entrepreneurial initiatives as 
measured by the New Initiatives Success Score, the Traditionally Used Initiatives

Success Score, and the Composite Success Score.

An increase or decrease in tuition from previous year?

A Kruskal-Wallis test was conducted to evaluate differences among the various levels of the frequency distribution of changes in in-state tuition on median change in successful entrepreneurial initiatives as measured by the New Initiatives Success Score. With alpha set at .05 , the test was not significant, $\chi^{2}(6, N=28)=9.997, p>.05$. The critical value was 12.59 .

A Kruskal-Wallis test was conducted to evaluate differences among the various levels of the frequency distribution of changes in in-state tuition on median change in successful entrepreneurial initiatives as measured by the Traditionally Used Initiatives Success Score. With alpha set at .05 , the test was not significant, $\chi^{2}(6, N=28)=7.124, p$ $>.05$. The critical value was 12.59 .

A Kruskal-Wallis test was conducted to evaluate differences among the various levels of the frequency distribution of changes in in-state tuition on median change in successful entrepreneurial initiatives as measured by the Composite Success Score. With alpha set at .05 , the test was not significant, $\chi^{2}(6, N=28)=5.435, p>.05$. The critical value was 12.59 .

A Kruskal-Wallis test was conducted to evaluate differences among the various levels of the frequency distribution of changes in out-of-state tuition on median change in successful entrepreneurial initiatives as measured by the New Initiatives Success Score. With alpha set at .05 , the test was not significant, $\chi^{2}(5, N=28)=4.125, p>.05$. The critical value was 11.07 . 
A Kruskal-Wallis test was conducted to evaluate differences among the various levels of the frequency distribution of changes in out-of-state tuition on median change in successful entrepreneurial initiatives as measured by the Traditionally Used Initiatives Success Score. With alpha set at .05 , the test was not significant, $\chi^{2}(5, N=28)=8.881, p$ $>$.05. The critical value was 11.07. However, the Spearman's rank correlation coefficient was significant at the .05 level, $\mathrm{r}_{\mathrm{s}}=.447, N=28, \mathrm{p}<.05$, indicating a possible relationship between changes in out-of-state tuition and changes in successful entrepreneurial initiatives as measured by the Traditionally Used Initiatives Success Score.

A Kruskal-Wallis test was conducted to evaluate differences among the various levels of the frequency distribution of changes in out-of-state tuition on median change in successful entrepreneurial initiatives as measured by the Composite Success Score. With alpha set at .05 , the test was significant, $\chi^{2}(5, N=28)=14.666, p<.05$. The critical value was 11.07 .

Follow-up tests were conducted to evaluate pair wise differences among the six out-of-state categories, controlling for Type I error across tests using Holm's sequential Bonferroni approach. The results of these tests indicated no significant difference.

The analysis failed to reveal any significant relationship between the changes in in-state and out-of-state tuition and the level of successful entrepreneurial initiatives as measured by the New Initiatives Success Score, the Traditionally Used Initiatives Success Score, and the Composite Success Score. The analysis did reveal a significant relationship between the changes in out-of-state tuition and the level of successful entrepreneurial initiatives as measured by the Traditionally Used Initiatives Success 
Score, suggesting that successful entrepreneurial initiatives tend to move in the same direction as out-of-state tuition.

The number of faculty, both full-time and part-time?

A Kruskal-Wallis test was conducted to evaluate the differences in total full-time faculty on median change in the level of successful entrepreneurial initiatives using the New Initiatives Success Score. With alpha set at .05 , the test was not significant, $\chi^{2}(4, N$ $=28)=8.722, p>.05$. The critical value was 9.49. However, the Spearman's rank correlation coefficient was significant at the .05 level, $\mathrm{r}_{\mathrm{s}}=.516, N=28, \mathrm{p}<.01$, indicating a possible relationship between changes in total full-time faculty and changes in successful entrepreneurial initiatives as measured by the New Initiatives Success Score.

Successful entrepreneurial initiatives were also assessed by the Traditionally Used Initiatives Success Score. Again, a Kruskal-Wallis test was conducted to evaluate the differences in total full-time faculty on median change in the level of successful entrepreneurial initiatives. With alpha set at .05 , the test was not significant, $\chi^{2}(4, N=28)$ $=2.941, p>.05$. The critical value was 9.49 .

Successful entrepreneurial initiatives were further assessed by the Composite Success Score. A Kruskal-Wallis test was conducted to evaluate the differences in total full-time faculty on median change in the level of successful entrepreneurial initiatives. With alpha set at .05 , the test was not significant, $\chi^{2}(4, N=28)=7.269, p>.05$. The critical value was 9.49 .

This suggests that there is no significant relationship between the total full-time faculty and the level of successful entrepreneurial initiatives at the institution as measured 
by the Traditionally Used Initiatives Success Score or the Composite Success Score. The analysis did reveal a significant relationship between the total full-time faculty and the level of successful entrepreneurial initiatives as measured by the New Initiatives Success Score, suggesting that successful entrepreneurial initiatives tend to move in the same direction as total full-time faculty.

A Kruskal-Wallis test was conducted to evaluate the differences in total part-time faculty on median change in the level of successful entrepreneurial initiatives using the New Initiatives Success Score. With alpha set at .05, the test was not significant, $\chi^{2}(4, N$ $=28)=7.757, p>.05$. The critical value was 9.49 .

A Kruskal-Wallis test was also conducted to evaluate the differences in total parttime faculty on median change in the level of successful entrepreneurial initiatives using the Traditionally Used Initiatives Success Score. With alpha set at .05, the test was not significant, $\chi^{2}(4, N=28)=3.646, p>.05$. The critical value was 9.49 .

Finally, a Kruskal-Wallis test was also conducted to evaluate the differences in total part-time faculty on median change in the level of successful entrepreneurial initiatives using the Composite Success Score. With alpha set at .05, the test was not significant, $\chi^{2}(4, N=28)=3.957, p>.05$. The critical value was 9.49 .

There appears to be no significant relationship between the total part-time faculty and the level of successful entrepreneurial initiatives at the institution as measured by the New Initiatives Success Score, the Traditionally Used Initiatives Success Score, and the Composite Success Score. 
The number of tenure track and non-tenure track faculty?

A Kruskal-Wallis test was conducted to evaluate the differences in total full-time tenure track faculty on median change in the level of successful entrepreneurial initiatives using the New Initiatives Success Score. With alpha set at .05, the test was not significant, $\chi^{2}(4, N=28)=5.956, p>.05$. The critical value was 9.49. However, the Spearman's rank correlation coefficient indicated a significant relationship between total full-time tenure track faculty and successful entrepreneurial initiatives, $r_{s}=.426, N=28$, $\mathrm{p}<.05$.

Using the Traditionally Used Initiatives Success Score as the measure of the level of successful entrepreneurial initiatives, with alpha set at .05, the Kruskal-Wallis test of median difference was not significant, $\chi^{2}(4, N=28)=6.919, p>.05$. The critical value was 9.49. However, the Spearman's rank correlation coefficient indicated a significant relationship between total full-time tenure track faculty and successful entrepreneurial initiatives, $r_{s}=-.514, N=28, \mathrm{p}<.01$.

Using the Composite Success Score as the measure of the level of successful entrepreneurial initiatives, with alpha set at .05 , the Kruskal-Wallis test of median difference was not significant, $\chi^{2}(4, N=28)=5.323, p>.05$. The critical value was 9.49.

There appears to be no significant relationship between the total full-time tenure track faculty and the level of successful entrepreneurial initiatives at the institutions as measured by the Composite Success Score. There does appear to be a significant relationship using the New Initiatives Success Score and Traditionally Used Initiatives Success Score. 
A Kruskal-Wallis test was also conducted to evaluate the differences in total fulltime non-tenure track faculty on median change in the level of successful entrepreneurial initiatives using the New Initiatives Success Score. With alpha set at .05, the test was not significant, $\chi^{2}(1, N=28)=.191, p>.05$. The critical value was 3.84 .

A Kruskal-Wallis test was conducted to evaluate the differences in total full-time non-tenure track faculty on median change in the level of successful entrepreneurial initiatives using the Traditionally Used Initiatives Success Score. With alpha set at .05, the test was not significant, $\chi^{2}(1, N=28)=1.149, p>.05$. The critical value was 3.84 .

Finally, a Kruskal-Wallis test was conducted to evaluate the differences in total full-time non-tenure track faculty on median change in the level of successful entrepreneurial initiatives using the Composite Success Score. With alpha set at .05, the test was not significant, $\chi^{2}(1, N=28)=.000, p>.05$. The critical value was 3.84 .

There appears to be no significant relationship between the total full-time nontenure track faculty and the level of successful entrepreneurial initiatives.

An increase or decrease in full-time faculty, both tenure track and non-tenure track, from the previous year?

A Kruskal-Wallis test was used to assess the median change in the level of successful entrepreneurial initiatives using the New Initiatives Success Score, based on an increase, decrease, or no change in full-time faculty from the previous year. With alpha set at .05 , the test was not significant, $\chi^{2}(2, N=28)=.733, p>.05$. The critical value was 5.99. 
Using the Traditionally Used Initiatives Success Score to measure successful entrepreneurial initiatives, the results were still not significant, $\chi^{2}(2, N=28)=2.611, p>$ .05 . The critical value was 5.99 .

Once again, using the Composite Success Score to measure successful entrepreneurial initiatives, the results were not significant, $\chi^{2}(2, N=28)=1.653, p>.05$. The critical value was 5.99 .

No significant relationship was found between the changes in full-time faculty and the level of successful entrepreneurial initiatives. An increase or decrease in full-time tenure track faculty from the previous year.

A Kruskal-Wallis test was used to assess the median change in the level of successful entrepreneurial initiatives using the New Initiatives Success Score, based on an increase, decrease, or no change in full-time tenure track faculty from the previous year. With alpha set at .05 , the test was not significant, $\chi^{2}(2, N=28)=.152, p>.05$. The critical value was 5.99 .

Using the Traditionally Used Initiatives Success Score to measure successful entrepreneurial initiatives, the results were still not significant, $\chi^{2}(2, N=28)=1.131, p>$ .05 . The critical value was 5.99 .

Once again, using the Composite Success Score to measure successful entrepreneurial initiatives, the results were not significant, $\chi^{2}(2, N=28)=2.987, p>.05$. The critical value was 5.99 .

No significant relationship was found between the changes in full-time tenure track faculty and the level of successful entrepreneurial initiatives. 
An increase or decrease in part-time faculty from the previous year?

A Kruskal-Wallis test was used to assess the median change in the level of successful entrepreneurial initiatives using the New Initiatives Success Score, based on an increase, decrease, or no change in part-time faculty from the previous year. With alpha set at .05 , the test was not significant, $\chi^{2}(2, N=28)=.552, p>.05$. The critical value was 5.99.

Using the Traditionally Used Initiatives Success Score to measure successful entrepreneurial initiatives, the results were still not significant, $\chi^{2}(2, N=28)=1.835, p>$ .05 . The critical value was 5.99 .

Once again, using the Composite Success Score to measure successful entrepreneurial initiatives, the results were not significant, $\chi^{2}(2, N=28)=.966, p>.05$. The critical value was 5.99 .

No significant relationship was found between the changes in part-time faculty and the level of successful entrepreneurial initiatives.

The highest degree offered at the institution?

A Mann-Whitney $(U=88.5)$ test was conducted to evaluate whether institutions offering the masters degree as their highest degree have a higher number of successful entrepreneurial initiatives, as measured by the New Initiatives Success Score, than institutions that only offer the baccalaureate degree as their highest degree. The results were not significant, $z=-.379, p>.05$.

The test was conducted again, first using the Traditionally Used Initiatives Success Score as the measure of successful entrepreneurial initiatives and second, the 
Composite Success Score. Both tests found nothing significant, $U=75, z=-.976, p>$ $.05, U=82, z=-.651, \mathrm{p}>.05$.

The addition or elimination of programs for teaching, research, and service since the previous year?

The Kruskal-Wallis test was used to assess the median change in the number of successful entrepreneurial initiatives using the New Initiatives Success Score, based on the teaching programs added or eliminated since the previous year. With alpha set at .05, the test was not significant, $\chi^{2}(2, N=28)=.822, p>.05$. The critical value was 5.99 .

Using the Traditionally Used Initiatives Success Score to measure the number of successful entrepreneurial initiatives, the results were still not significant, $\chi^{2}(2, N=28)=$ $3.406, p>.05$. The critical value was 5.99 .

Once again, using the Composite Success Score to measure number of successful entrepreneurial initiatives, the results were not significant, $\chi^{2}(2, N=28)=2.462, p>.05$. The critical value was 5.99 .

The Kruskal-Wallis test was used to assess the median change in the number of successful entrepreneurial initiatives using the New Initiatives Success Score, based on the research programs added or eliminated since the previous year. With alpha set at .05, the test was not significant, $\chi^{2}(2, N=28)=.409, p>.05$. The critical value was 5.99 .

Using the Traditionally Used Initiatives Success Score to measure the number of successful entrepreneurial initiatives, the results were still not significant, $\chi^{2}(2, N=28)=$ $3.202, p>.05$. The critical value was 5.99 . 
Once again, using the Composite Success Score to measure the number of successful entrepreneurial initiatives, the results were not significant, $\chi^{2}(2, N=28)=$ $2.424, p>.05$. The critical value was 5.99 .

The Kruskal-Wallis test was used to assess the median change in the number of successful entrepreneurial initiatives using the New Initiatives Success Score, based on the service programs added or eliminated since the previous year. With alpha set at .05 , the test was not significant, $\chi^{2}(2, N=28)=.254, p>.05$. The critical value was 5.99 .

Using the Traditionally Used Initiatives Success Score to measure the number of successful entrepreneurial initiatives, the results were still not significant, $\chi^{2}(2, N=28)=$ 2.833, $p>.05$. The critical value was 5.99 .

Finally, using the Composite Success Score to measure the number of successful entrepreneurial initiatives, the Kruskal-Wallis test results were not significant, $\chi^{2}(2, N=$ $28)=2.699, p>.05$. The critical value was 5.99 .

An increase or decrease in state appropriations from the previous year?

A Kruskal-Wallis test was conducted to evaluate the differences in state appropriations (increase, decrease, or no change) on median change in the number of successful entrepreneurial initiatives using the New Initiatives Success Score, the Traditionally Used Initiatives Success Score, and the Composite Success Score. Using the New Initiatives Success Score as the measure of the number of successful entrepreneurial initiatives, with alpha set at .05 , the test was not significant, $\chi^{2}(2, N=28)$ $=5.719, p>.05$. The critical value was 5.99. However, the Spearman's rank correlation coefficient indicated a significant relationship between the differences in state appropriations and number of successful entrepreneurial initiatives, $r_{s}=-.460, N=28, \mathrm{p}$ 
$<.05$, indicating that the number of successful entrepreneurial initiatives increases as state appropriations increase. See Figure 15.

Figure 15. Box Plot Comparing New Initiatives Success Score with the Level of State Appropriations

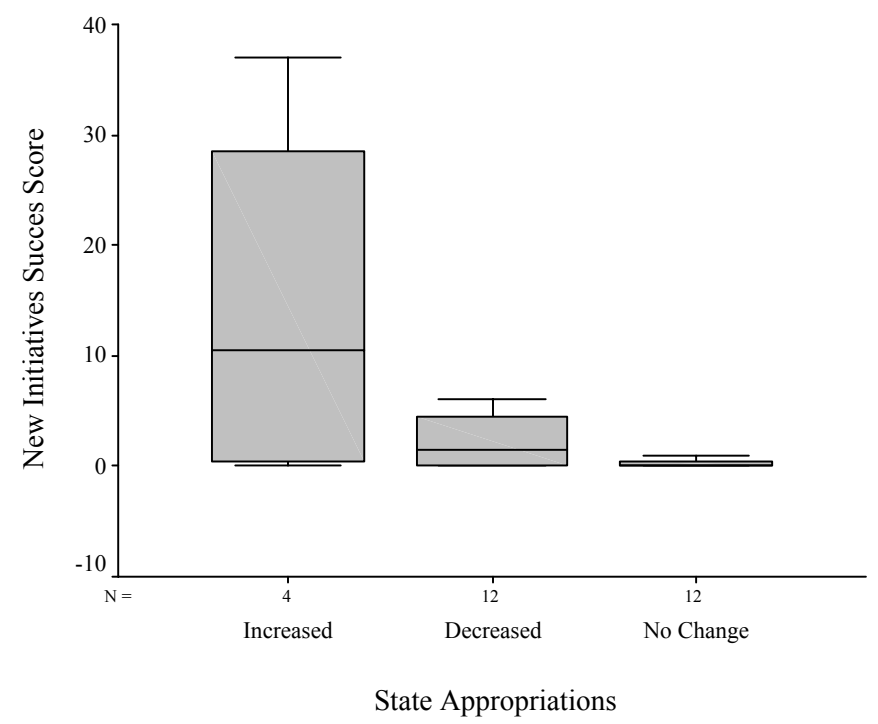

Using the Traditionally Used Initiatives Success Score to measure the number of successful entrepreneurial initiatives, the results were still not significant, $\chi^{2}(2, N=28)=$ $.072, p>.05$. The critical value was 5.99 .

Using the Composite Success Score to measure the number of successful entrepreneurial initiatives, the results were not significant, $\chi^{2}(2, N=28)=2.806, p>.05$. The critical value was 5.99 .

Statistical analysis revealed no significant relationship between the level of state appropriations and the number of successful entrepreneurial initiatives as measured by the Traditionally Used Initiatives Success Score and the Composite Success Score. A significant relationship was found between the level of state appropriations and the number of successful entrepreneurial initiatives as measured by the New Initiatives Success Score. 
Whether the governing board encourages or discourages entrepreneurial activities to generate revenue?

Statistical analysis using the Kruskal-Wallis independent-samples test revealed no significant relationship between the level of governing board support for entrepreneurial activities and three measures of the number of successful entrepreneurial initiatives using the New Initiatives Success Score, the Traditionally Used Initiatives Success Score, and the Composite Success Score.

Using the New Initiatives Success Score as the measure of the number of successful entrepreneurial initiatives, with alpha set at .05, the Kruskal-Wallis test was not significant, $\chi^{2}(2, N=26)=3.742, p>.05$. The critical value was 5.99 .

Using the Traditionally Used Initiatives Success Score to measure the number of successful entrepreneurial initiatives, the results were still not significant, $\chi^{2}(2, N=26)=$ $2.784, p>.05$. The critical value was 5.99 .

Using the Composite Success Score to measure the number of successful entrepreneurial initiatives, the results were not significant, $\chi^{2}(2, N=26)=4.007, p>.05$. The critical value was 5.99 . The number of programs supported by generating their own revenue?

Statistical analysis revealed no significant relationship between the number of programs responsible for a portion of their own revenue and the number of successful entrepreneurial initiatives. A Kruskal-Wallis test was conducted to evaluate the differences in the number of at least partially self-supported programs on median change in the number of successful entrepreneurial initiatives using the New Initiatives Success 
Score. With alpha set at .05 , the test was not significant, $\chi^{2}(2, N=28)=.633, p>.05$. The critical value was 5.99 .

Using the Traditionally Used Initiatives Success Score to measure the number of successful entrepreneurial initiatives, the results were still not significant, $\chi^{2}(2, N=28)=$ $1.412, p>.05$. The critical value was 5.99 .

Using the Composite Success Score to measure the number of successful entrepreneurial initiatives, the results were not significant, $\chi^{2}(2, N=28)=3.025, p>.05$. The critical value was 5.99 .

Administrative and/or organizational changes during the president's/chancellor's tenure?

A Kruskal-Wallis test was conducted to evaluate the differences in the various levels of administrative and/or organizational change (from no changes through and including changes in all three categories) on median change in the number of successful entrepreneurial initiatives using the New Initiatives Success Score. With alpha set at .05, the test was not significant, $\chi^{2}(5, N=28)=2.377, p>.05$. The critical value was 11.07.

Using the Traditionally Used Initiatives Success Score to measure the number of successful entrepreneurial initiatives, the results were still not significant, $\chi^{2}(5, N=28)=$ $4.611, p>.05$. The critical value was 11.07 .

Using the Composite Success Score to measure the number of successful entrepreneurial initiatives, the results were not significant, $\chi^{2}(5, N=28)=5.421, p>.05$. The critical value was 11.07 .

Statistical analysis was also conducted for each separate category of administrative and/or organizational change. Mann-Whitney tests were conducted to 
assess whether administrative and/or organizational restructuring affects the number of successful entrepreneurial initiatives as measured first by the New Initiatives Success Score, second by the Traditionally Used Initiatives Success Score, and third by the Composite Success Score.

With alpha set at .05 , the Mann-Whitney $(U=70)$ test yielded no significant finding when testing the relationship of administrative and/or organizational restructuring to the number of successful entrepreneurial initiatives as measured by the New Initiatives Success Score, $z=-.554, p>.05$.

With alpha set at .05 , the Mann-Whitney $(U=45.5)$ test yielded no significant finding when testing the relationship of administrative and/or organizational restructuring to the number of successful entrepreneurial initiatives as measured by the Traditionally Used Initiatives Success Score, $z=-1.757, p>.05$.

With alpha set at .05 , the Mann-Whitney $(U=54.5)$ test yielded no significant finding when testing the relationship of administrative and/or organizational restructuring to the number of successful entrepreneurial initiatives as measured by the Composite Success Score, $z=-1.299, p>.05$.

Mann-Whitney tests were conducted to assess whether changes in decisionmaking authority patterns affects the number of successful entrepreneurial initiatives as measured first by the New Initiatives Success Score, second by the Traditionally Used Initiatives Success Score, and third by the Composite Success Score.

With alpha set at .05 , the Mann-Whitney $(U=66.5)$ test yielded no significant finding when testing the relationship of changes in decision-making authority patterns to 
the number of successful entrepreneurial initiatives as measured by the New Initiatives Success Score, $z=-.748, p>.05$.

With alpha set at .05 , the Mann-Whitney $(U=61)$ test yielded no significant finding when testing the relationship of changes in decision-making authority patterns to the number of successful entrepreneurial initiatives as measured by the Traditionally Used Initiatives Success Score, $z=-.968, p>.05$.

With alpha set at .05, the Mann-Whitney $(U=73)$ test yielded no significant finding when testing the relationship of changes in decision-making authority patterns to the number of successful entrepreneurial initiatives as measured by the Composite Success Score, $z=-.357, p>.05$.

Mann-Whitney tests were conducted to assess whether creation of new positions in central administration affects the number of successful entrepreneurial initiatives as measured first by the New Initiatives Success Score, second by the Traditionally Used Initiatives Success Score, and third by the Composite Success Score.

With alpha set at .05 , the Mann-Whitney $(U=63)$ test yielded no significant finding when testing the relationship of creation of new positions in central administration to the number of successful entrepreneurial initiatives as measured by the New Initiatives Success Score, $z=-1.410, p>.05$.

With alpha set at .05 , the Mann-Whitney $(U=83)$ test yielded no significant finding when testing the relationship of creation of new positions in central administration to the number of successful entrepreneurial initiatives as measured by the Traditionally Used Initiatives Success Score, $z=-.336, p>.05$. 
With alpha set at .05 , the Mann-Whitney $(U=75)$ test yielded no significant finding when testing the relationship of creation of new positions in central administration to the number of successful entrepreneurial initiatives as measured by the Composite Success Score, $z=-.720, p>.05$.

There appears to be no significant relationship between the reported types of administrative and/or organizational change and the number of successful entrepreneurial initiatives at the institution as measured by the New Initiatives Success Score, second by the Traditionally Used Initiatives Success Score, and third by the Composite Success Score.

Whether faculty are formally encouraged to pursue innovative and entrepreneurial activities?

A Kruskal-Wallis test was used to assess the median change in the number of successful entrepreneurial initiatives using the New Initiatives Success Score, based on the level of institutional support for faculty entrepreneurial activities. With alpha set at .05 , the test was not significant, $\chi^{2}(2, N=28)=1.904, p>.05$. The critical value was 5.99 .

Using the Traditionally Used Initiatives Success Score to measure the number of successful entrepreneurial initiatives, the results were still not significant, $\chi^{2}(2, N=28)=$ $1.184, p>.05$. The critical value was 5.99 .

Once again, using the Composite Success Score to measure the number of successful entrepreneurial initiatives, the results were not significant, $\chi^{2}(2, N=28)=$ 4.432, $p>.05$. The critical value was 5.99. However, the Spearman's rank correlation coefficient indicated a significant relationship between the level of institutional support 
for faculty entrepreneurial activities and number of successful entrepreneurial initiatives, $r_{s}=-.397, N=28, \mathrm{p}<.05$, indicating that the number of successful entrepreneurial initiatives increases as the level of institutional support for faculty entrepreneurial activities increase. See Figure 16.

Figure 16. Box Plot Comparing Composite Success Score with the Level of Institutional Support for Faculty Entrepreneurial Activities

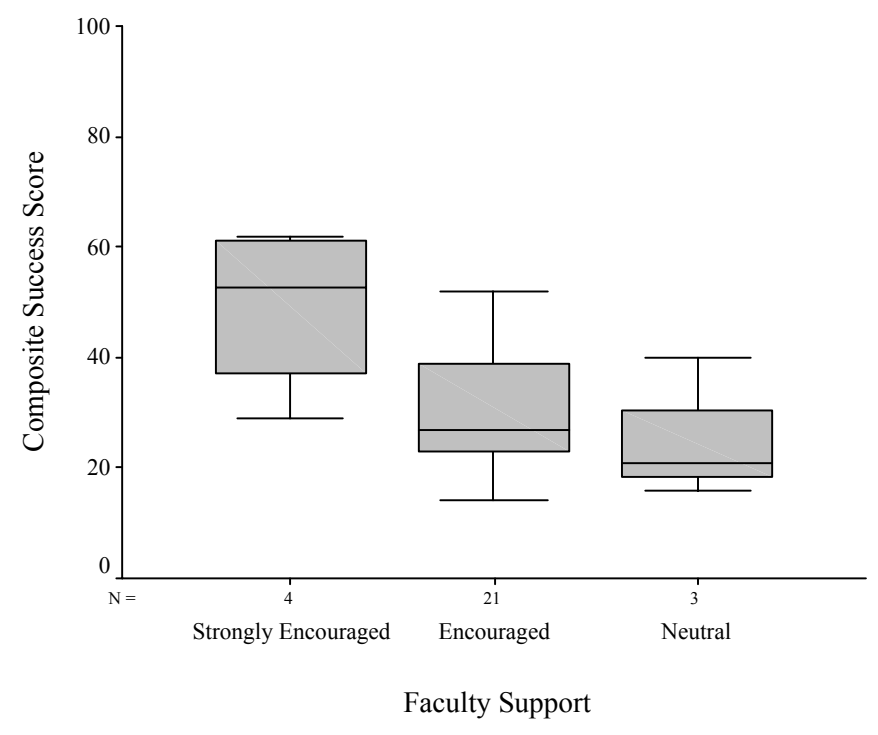

No significant relationship was found between the level of institutional support for faculty entrepreneurial activities and the number of successful entrepreneurial initiatives at the institution as measured by the New Initiatives Success Score and the Traditionally Used Initiatives Success Score. A significant relationship was found between the level of institutional support for faculty entrepreneurial activities and the number of successful entrepreneurial initiatives at the institution as measured by the Composite Success Score. 
Whether merit pay or other reward systems are used to encourage faculty to pursue innovative and entrepreneurial activities?

A Kruskal-Wallis test was used to assess the median change in the number of successful entrepreneurial initiatives using the New Initiatives Success Score, based on the reward system used to encourage faculty entrepreneurial activities. With alpha set at .05 , the test was not significant, $\chi^{2}(2, N=28)=5.435, p>.05$. The critical value was 5.99 .

Using the Traditionally Used Initiatives Success Score to measure the number of successful entrepreneurial initiatives, the results were not significant at the .05 alpha level, $\chi^{2}(2, N=28)=1.601, p>.05$. The critical value was 5.99 .

Finally, using the Composite Success Score to measure the number of successful entrepreneurial initiatives, the results were not significant, $\chi^{2}(2, N=28)=1.417, p>.05$. The critical value was 5.99.

No significant relationship was found between the reward system used to encourage faculty entrepreneurial activities and the number of successful entrepreneurial initiatives at the institution.

Whether the institution's purpose and/or mission has been changed to reflect greater emphasis on entrepreneurial activities?

Mann-Whitney tests were conducted to assess whether changes in the institution's purpose or mission affects the number of successful entrepreneurial initiatives as measured first by the New Initiatives Success Score, second by the Traditionally Used Initiatives Success Score, and third by the Composite Success Score. 
With alpha set at .05 , the Mann-Whitney $(U=42.5)$ test yielded no significant relationship between the change in the institution's purpose or mission and the number of successful entrepreneurial initiatives as measured by the New Initiatives Success Score, z $=-.114, p>.05$.

With alpha set at .05 , the Mann-Whitney $(U=40)$ test yielded no significant finding when testing the relationship between the change in the institution's purpose or mission and the number of successful entrepreneurial initiatives as measured by the Traditionally Used Initiatives Success Score, $z=-.285, p>.05$.

With alpha set at .05 , the Mann-Whitney $(U=32)$ test yielded no significant finding when testing the relationship between the change in the institution's purpose or mission and the number of successful entrepreneurial initiatives as measured by the Composite Success Score, $z=-.854, p>.05$.

There appears to be no significant relationship between the change in the institution's purpose or mission and the number of successful entrepreneurial initiatives at the institution.

\section{Whether faculty or staff are represented by union?}

Ten $(35.7 \%)$ institutions indicated that their faculty are represented by a union and eleven (39.3\%) institutions indicated that their staff are represented by a union.

Mann-Whitney tests were conducted to assess whether faculty representation by a union affects the number of successful entrepreneurial initiatives as measured first by the New Initiatives Success Score, second by the Traditionally Used Initiatives Success Score, and third by the Composite Success Score. 
With alpha set at .05 , the Mann-Whitney $(U=78.5)$ test yielded no significant relationship between whether faculty are represented by a union and the number of successful entrepreneurial initiatives as measured by the New Initiatives Success Score, z $=-.086, p>.05$.

With alpha set at .05 , the Mann-Whitney $(U=71)$ test yielded no significant finding when testing the relationship between whether faculty are represented by a union and the number of successful entrepreneurial initiatives as measured by the Traditionally Used Initiatives Success Score, $z=-.475, p>.05$.

With alpha set at .05 , the Mann-Whitney $(U=76.5)$ test yielded no significant finding when testing the relationship between whether faculty are represented by a union and the number of successful entrepreneurial initiatives as measured by the Composite Success Score, $z=-.185, p>.05$.

Mann-Whitney tests were conducted to assess whether staff representation by a union affects the number of successful entrepreneurial initiatives as measured first by the New Initiatives Success Score, second by the Traditionally Used Initiatives Success Score, and third by the Composite Success Score.

With alpha set at .05 , the Mann-Whitney $(U=60)$ test yielded no significant relationship between whether staff are represented by a union and the number of successful entrepreneurial initiatives as measured by the New Initiatives Success Score, z $=-1.492, p>.05$.

With alpha set at .05 , the Mann-Whitney $(U=86.5)$ test yielded no significant finding when testing the relationship between whether staff are represented by a union 
and the number of successful entrepreneurial initiatives as measured by the Traditionally Used Initiatives Success Score, $z=-.074, p>.05$.

With alpha set at .05 , the Mann-Whitney $(U=86.5)$ test yielded no significant finding when testing the relationship between whether staff are represented by a union and the number of successful entrepreneurial initiatives as measured by the Composite Success Score, $z=-.074, p>.05$.

There appears to be no significant relationship regarding whether faculty or staff are represented by a union and the number of successful entrepreneurial initiatives at the institution.

Question 4 Summary

Question 4 focused on whether or not there is a relationship between the number of successful entrepreneurial initiatives and twenty-two institutional factors. Table 35 summarizes the results of the data analysis indicating which factors were found to have a significant relationship and which ones were found to have no significant relationship with the number of successful entrepreneurial initiatives.

Table 35.

Relationship between the Number of Successful Entrepreneurial Initiatives and 22 Institutional Factors Institutional Factor Results*

The number of years the president/chancellor has been in current position.

Not Significant

The field of study or discipline of the president/chancellor.

Not Significant

The business/industry experience of the institution's president

Not Significant chancellor. 
The institution's enrollment.

Not Significant

An increase or decrease in enrollment from the previous year.

Not Significant

The institution's tuition, both in-state and out-of-state.

Not Significant

An increase or decrease in tuition from the previous year:

In-state tuition

Out-of-state tuition

Not Significant

Significant

The number of faculty, both full-time and part-time:

Full-time faculty

Part-time faculty

Significant

Not Significant

The number of tenure track and non-tenure track faculty:

Tenure track faculty

Non-tenure track faculty

Significant

Not Significant

An increase or decrease in full-time faculty, both tenure track and non-

Not Significant

tenure track, from the previous year.

An increase or decrease in full-time tenure track faculty from the previous year.

An increase or decrease in part-time faculty from the previous year.

Not Significant

The highest degree offered at the institution.

Not Significant

The addition or elimination of programs for teaching, research, and service since the previous year:

Teaching programs added

Teaching programs eliminated

Research programs added

Research programs eliminated

Service programs added

Service programs eliminated

Not Significant

An increase or decrease in state appropriations

Not Significant

Not Significant

Not Significant

Not Significant

Not Significant

Not Significant

Significant

Whether the governing board encourages or discourages entrepreneurial activities to generate revenue.

Not Significant

The number of programs supported by generating their own revenue.

Not Significant 
Institutional Factor

Results*

Administrative and/or organizational changes during the

Not Significant president's/chancellor's tenure.

Whether faculty are formally encouraged to pursue innovative and

Significant entrepreneurial activities.

Whether merit pay or other reward systems are used to encourage faculty to pursue innovative and entrepreneurial activities.

Not Significant

Whether the institution's purpose and/or mission has been changed to reflect greater emphasis on entrepreneurial activities.

Not Significant

Whether faculty or staff are represented by a union.

Not Significant

* An alpha level of .05 was used as the criterion to establish significance.

Research Question 5: What impact have entrepreneurial initiatives had on institutional mission, purpose and academic integrity?

As indicated earlier, four institutions (14.3\%) indicated that their institutional purpose and/or mission had changed to reflect a greater emphasis on entrepreneurial activities. Twenty-two (78.6\%) institutions indicated that there had been no change to the institution's purpose or mission. Two (7.1\%) did not respond to this question.

Of the four institutions with changes to their purpose and/or mission, three of these respondents provided comments. One indicated that its purpose or mission had changed to better serve two-year college graduates. Another respondent indicated that the old mission reflected a focus on traditional program offerings and that the new mission focused on expected benefits to students, the region, and to society. They further indicated that their new vision now focused on the institution's impact on the region. The third respondent commented that the purpose or mission changed to optimize 
entrepreneurial opportunities and to think in terms of investment and fundraising opportunities.

The respondents were also asked if there were any downsides to entrepreneurial programs or activities. Table 36 summarizes their responses.

Table 36

Downsides to Entrepreneurial Programs or Activities

\begin{tabular}{ccc}
\hline Downsides to Entrepreneurial Programs & Frequency & Percent \\
\hline Yes & 7 & 25.0 \\
No & 19 & 67.9 \\
\hline Total & 26 & 92.9 \\
\hline NR & 2 & 7.1 \\
\hline N & 28 & 100.0 \\
\hline
\end{tabular}

Seven $(25 \%)$ institutions indicated that there are downsides to entrepreneurial programs or activities, making the following comments:

- Risk of mission dilution.

- Not all work as planned - culture is uncomfortable with failure.

- Creates an environment that some see as chaotic, which can drag them and the institution down.

- Some programs are not fiscally viable.

- Potential exists for conflicting/competing forces for influence in terms of future direction.

- More private money means more "noses under the tent."

- Lack of funding for start-up.

- As a state agency, entrepreneurial opportunities are limited. 
- It is not easy to convince all faculty members of its importance.

- In a public institution there is a heavy reliance on legislative revenues, which decrease each year.

- Entrepreneurial activities require a cultural change in the institution, which is always a struggle.

- The benefits to the institution will not be seen immediately, making it increasingly difficult to promote.

- Tax implications since revenue may be considered unrelated business income and we are a non profit institution.

Research Question 6: Does the institution's governing board/body encourage or discourage entrepreneurial initiatives to generate revenue?

Twenty-three (82.1\%) of the responding institutions indicated that the governing board strongly encouraged (25.0\%) or encouraged (57.1\%) entrepreneurial activities to generate revenue. Of the remaining five institutions, three (10.7\%) indicated that the governing board was neutral, and two (7.1\%) did not respond to the question. None of the institutions indicated that the governing board discouraged or strongly discouraged entrepreneurial activity to generate revenue.

One institution made the observation that "there is a huge difference between verbal and actual encouragement", going on to say that their state board is "gung ho" verbally, but very reluctant to approve innovative changes. 
Comparison of Institutional Data for the Population with Institutional Data for the Respondent Institutions

In order to assess whether or not the findings regarding the respondent institutions can be reasonably generalized to the population, institutional data was compiled for all institutions in the population on key factors, including enrollment, tuition, faculty, and the highest degree offered at the institution. This data was then compared to the same data compiled for the respondent institutions.

Enrollment Data

Table 37 summarizes the enrollment data for full-time and part-time undergraduate and graduate enrollments for the population of seventy-five institutions.

Table 37

Enrollments for Full-Time and Part-time Undergraduate Students and Full-Time and Part-Time Graduate Students for Population

Full-Time Undergraduate Students Part-Time Undergraduate Students

\begin{tabular}{|c|c|c|c|c|c|}
\hline Enrollments & Frequency & Percent & Enrollments & Frequency & Percent \\
\hline$<1,000$ & 12 & 16.0 & $<1,000$ & 55 & 73.3 \\
\hline $1,000-5,000$ & 60 & 80.0 & $1,000-5,000$ & 18 & 24.0 \\
\hline $5,001-10,000$ & 2 & 2.7 & $5,001-10,000$ & 2 & 2.7 \\
\hline$>10,000$ & 1 & 1.3 & $>10,000$ & 0 & 0 \\
\hline Total & 75 & 100.0 & Total & 75 & 100.0 \\
\hline
\end{tabular}


Full-Time Graduate Students

\begin{tabular}{lcc}
\hline Enrollments & Frequency & Percent \\
\hline$<1,000$ & 75 & 100.0 \\
$1,000-5,000$ & 0 & 0 \\
$5,001-10,000$ & 0 & 0 \\
$>10,000$ & 0 & 0 \\
\hline Total & 75 & 100.0 \\
\hline
\end{tabular}

Part-Time Graduate Students

\begin{tabular}{lcc}
\hline Enrollments & Frequency & Percent \\
\hline$<1,000$ & 74 & 98.7
\end{tabular}

$1,000-5,000 \quad 1 \quad 1.3$

$5,001-10,000 \quad 0 \quad 0$

$>10,000 \quad 0 \quad 0$

Total $\quad 75 \quad 100.0$

The majority of institutions in the population have full-time undergraduate enrollments in the category of 1,000 to $5,000(60,80 \%)$. The data regarding the respondent institutions also reflected the majority of institutions in the 1,000 to 5,000 category $(21,75 \%)$. The largest number of institutions in the population fell into the $<$ 1,000 category for part-time undergraduate enrollments $(55,73.3 \%)$, as did the respondent institutions $(20,71.4 \%)$ Since the institutions in the population are baccalaureate institutions, it was expected that graduate enrollments would be small. The data support this observation. All of the institutions in the population and the respondent institutions reported full-time graduate student enrollments in the $<1,000$ category (population, 75, 100\%; respondents, 28, 100\%), and all but one institution reported parttime graduate student enrollments in the $<1,000$ category (population, $74,98.7 \%$; respondents, $27,96.4 \%$ ). The respondent institutions fairly reflect the enrollments found within the population.

\section{Tuition Data}

Table 38 summarizes the in-state and out-of-state data for the population of seventy-five institutions. One institution did not publish tuition data and is not reported. 
Table 38

In-State and Out-of-State Tuition for Population

In-State Tuition

\begin{tabular}{lcc}
\hline Tuition & Frequency & Percent \\
\hline Less Than $\$ 2,000$ & 4 & 5.4 \\
$\$ 2,001-\$ 4,000$ & 32 & 43.2 \\
$\$ 4,001-\$ 6,000$ & 25 & 33.8 \\
$\$ 6,001-\$ 8,000$ & 6 & 8.1 \\
More Than $\$ 8,000$ & 7 & 9.5 \\
\hline Total & 74 & 100.0 \\
\hline Out-Of-State Tuition & & \\
\hline Tuition & Frequency & Percent \\
\hline Less Than $\$ 5,000$ & 7 & 9.5 \\
\$5,001 - \$10,000 & 33 & 44.6 \\
\$10,001 - \$15,000 & 27 & 36.5 \\
More Than $\$ 15,000$ & 7 & 9.5 \\
\hline Total & 74 & 100.0 \\
\hline
\end{tabular}

The majority of institutions in the population have in-state tuition ranging from $\$ 2,000$ to $\$ 6,000(57,77 \%)$. The data regarding the respondent institutions also reflected the majority of institutions in the $\$ 2,000$ to $\$ 6,000$ range $(22,78.5 \%)$. The majority of institutions in the population report out-of-state tuition ranging from $\$ 5,000$ to $\$ 15,000$ $(60,81.1 \%)$. The largest number of the respondent institutions reported out-of-state tuition in this range $(24,85.7 \%)$. The respondent institutions fairly represent in-state and out-of-state tuitions found within the population. 


\section{Faculty Data}

Table 39 summarizes the total full-time faculty data for the population of seventyfive institutions.

Table 39

Total Full-Time Faculty for the Population

\begin{tabular}{lcc}
\hline Total Full-Time Faculty & Frequency & Percent \\
\hline$<50$ & 9 & 12.0 \\
$51-100$ & 22 & 29.3 \\
$101-150$ & 15 & 20.0 \\
$151-200$ & 20 & 26.7 \\
$>200$ & 9 & 12.0 \\
\hline Total & 75 & 100.0 \\
\hline
\end{tabular}

The majority of institutions in the population report total full-time faculty from 51 to 200 members $(57,76 \%)$. The data regarding the respondent institutions also reflected the majority of institutions in the same range $(21,75 \%)$.

Table 40 summarizes the total full-time faculty data for the population.

Table 40

Total Part-Time Faculty for Population

\begin{tabular}{lcc}
\hline Total Part-Time Faculty & Frequency & Percent \\
\hline$<50$ & 39 & 52.0 \\
$51-100$ & 19 & 25.3 \\
$101-150$ & 6 & 8.0 \\
$151-200$ & 6 & 8.0 \\
$>200$ & 5 & 6.7 \\
\hline Total & 75 & 100.0 \\
\hline
\end{tabular}


The majority of institutions in the population report total part-time faculty from zero to 100 members $(58,77.3 \%)$. The data regarding the respondent institutions also reflected the majority of institutions in the same range $(22,78.5 \%)$.

Table 41 summarizes the total full-time faculty data for the population of seventyfive institutions.

Table 41

Total Full-Time Tenure Track Faculty for Population

\begin{tabular}{lcc}
\hline $\begin{array}{l}\text { Total Full-Time } \\
\text { Tenure Track Faculty }\end{array}$ & Frequency & Percent \\
\hline$<50$ & 19 & 25.3 \\
$51-100$ & 26 & 34.7 \\
$101-150$ & 17 & 22.7 \\
$151-200$ & 8 & 10.7 \\
$>200$ & 5 & 6.7 \\
\hline Total & 75 & 100.0 \\
\hline
\end{tabular}

The majority of institutions in the population report total full-time tenure track faculty from zero to 150 members $(62,82.7 \%)$. The data regarding the respondent institutions also reflected the majority of institutions in the same range $(24,85.7 \%)$.

Table 42 summarizes the total full-time faculty data for the population of seventyfive institutions. 
Table 42

Total Full-Time Non-Tenure Track Faculty for Population

\begin{tabular}{lcc}
\hline $\begin{array}{l}\text { Total Full-Time Non- } \\
\text { Tenure Track Faculty }\end{array}$ & Frequency & Percent \\
\hline$<50$ & 62 & 82.7 \\
$51-100$ & 8 & 10.7 \\
$101-150$ & 2 & 2.7 \\
$151-200$ & 2 & 2.7 \\
$>200$ & 1 & 1.3 \\
\hline Total & 75 & 100.0 \\
\hline
\end{tabular}

The majority of institutions in the population report total full-time non-tenure track faculty as less than fifty members $(62,82.7 \%)$. The data regarding the respondent institutions also reflected the majority of institutions in the same range $(26,92.9 \%)$.

The faculty data from the respondent institutions fairly represent the data for the population.

\section{Highest Degree Offered Data}

The highest degree offered at any institution within the population was the masters degree. Of the seventy-five institutions in the population, thirty-nine $(52 \%)$ offer the baccalaureate degree as their highest degree. The remaining thirty-six institutions (48\%) offer the masters. Of the respondents institutions, sixteen $(57.1 \%)$ offer the baccalaureate degree as their highest degree with the remaining twelve institutions $(42.9 \%)$ offering the masters. The respondent institutions fairly represent the population regarding the highest degree offered. 


\section{CHAPTER V \\ DISCUSSION \\ Introduction}

This chapter summarizes and discusses the major findings for each of the research questions that guided this study. It also includes recommendations for practice and recommendations for further study.

\section{Interpretation of Findings}

In order to summarize the findings and better reveal associations and relationships, research questions one and three, relating to the number of entrepreneurial initiatives utilized by the respondent institutions (Question 1) and the success of those initiatives (Question 3), will be discussed together. For the same reason, questions two and four, and the relationship factors tested for each of these questions (which are identical), will also be discussed together. Questions five and six will be discussed separately.

\section{Questions 1 \& 3}

To what extent do these institutions generate revenue through entrepreneurial initiatives and what entrepreneurial institutional initiatives are proving successful in terms of generating revenue for these institutions?

This study focused on baccalaureate institutions identified as Public Liberal Arts and General Baccalaureate institutions according to the Carnegie Classification (The Carnegie Foundation for the Advancement of Teaching, 2000). Forty-three potential institutional initiatives were identified on the survey instrument that represented initiatives discussed throughout the literature on community colleges and large 
universities. The respondents were asked to identify new institutional initiatives, initiatives that have been traditionally used, and initiatives that they are planning to use in the future. Additionally, the respondents were asked to identify the level of success (very successful, moderately successful, minimally successful, or not effective) they have experienced for each new initiative or traditionally used initiative identified.

The findings indicate a large variation in the number of new initiatives attempted, ranging from a low of zero new initiatives (13 institutions, 46.4\%) up to a high of thirteen new initiatives ( 1 institution, 3.6\%). The variation is even greater with traditionally used initiatives, ranging from a low of zero traditionally used initiatives ( 1 institution, 3.6\%) to a high of 30 traditionally used initiatives ( 1 institution, 3.6\%). Another observation that seems to speak volumes are the findings on new initiatives planned for the future, which ranged from a low of zero ( 8 institutions, $28.6 \%$ ) to a high of twelve (1 institution, 3.6\%). It was unexpected to find that over twenty-five percent of the institutions have no plans for new initiatives in the future.

The respondent institutions reported increasing tuition and fees, college/university foundations, and distance-learning within the existing organizational structure as having the highest levels of success, with 82.1 percent of the respondents using these initiatives. It was also found that technology transfer centers, spin-off companies, distance-learning programs in partnership with private sector enterprise, and distance-learning programs as for-profit subsidiaries had the lowest levels of success, with only 3.6 percent of the respondents using these initiatives.

Fifty percent or more of the institutions reported using the following initiatives:

- Increasing student laboratory, supplies, and other service fees (75\%) 
- Degree completion programs $(71.4 \%)$

- Profit-sharing with food service, bookstore, and other auxiliary services (71.4\%)

- Increasing residence fees $(67.9 \%)$

- Alumni associations (64.3\%)

- Increasing cost of campus food services $(60.7 \%)$

- Evening degree completion programs (60.7\%)

- Lease/rent institutional facilities and/or equipment (57.1\%)

- Develop or expand endowments (57.1\%)

- Debt financing $(57.1 \%)$

- Research contracts with government agencies (57.1\%)

- Certificate programs $(53.6 \%)$

- Contract-training programs with business/industry (50\%)

These initiatives were generally reported as the most successful initiatives as well. Other equally successful initiatives were weekend degree offering programs, capital campaigns, catering food services, and specialized training programs and certificate programs for business/industry.

There also appears to be a strong, positive correlation between the number of initiatives and the level of success, indicating that institutions that have used a high number of initiatives tend to also have higher levels of success.

There appears to be a reliance on rather conventional types of initiatives for generating revenue. In fact, increasing tuition and fees and the reliance on foundation giving, which are the top two initiatives in terms of the number of institutions using them $(82.1 \%)$ and in terms of success, are hardly entrepreneurial in nature. These more 
conventional types of activities may not be representative of entrepreneurial activity, but were included in this study to identify all initiatives being used or considered at these institutions, whether new initiatives, traditionally used, or planned for the future. As a result it was discovered that 7.1 percent of the respondents indicated that increasing tuition and fees and reliance on their foundation to generate revenue were new initiatives rather than traditionally used initiatives.

The entrepreneurial initiatives being used most frequently and most successfully at baccalaureate institutions seem to be more closely aligned to the types of initiatives reported in the literature as being utilized by community colleges than to the large research universities. For example, the more traditional revenue sources for community colleges have been state appropriations, tuition, local tax levies, and direct fees (Catanzaro \& Arnold, 1989; Hebel, 2003; Maradian, 1989). Also, because of their traditional role in job training, community colleges have been successful with both government and industry in preparing workers for jobs (Kozeracki, 1998). And community colleges have been very effective in utilizing distance-learning models (Rosenfeld \& Liston, 2000). This study revealed that many of the highest utilized and most successful initiatives at the baccalaureate institutions mirror many of these community college initiatives, such as increasing tuition and fees, distance-learning programs within the existing organizational structure, increasing student laboratory, supplies, and other service fees, degree completion programs, increasing residence fees, certificate programs, and contract-training programs with business/industry.

This study revealed that the more commercial, market-oriented and corporate venturing types of initiatives are much less utilized and experiencing less success in 
generating revenue. The literature reveals that these types of initiatives are more aligned with large research universities. Universities, while they still use many of the conventional means to generate revenue, generally focus on research collaborations with government and industry (Kozeracki, 1998). Dill (1995) conducted a national survey of large universities to determine the extent of technology transfer. Dill states, "universities which grant the doctorate and specialized institutions engaged in engineering and healthrelated work account for the vast majority of federally and privately sponsored research conducted in American academic institutions" (p. 371). While 57.1 percent of the institutions participating in this study indicated that they are using research contracts with government agencies, only 3.6 percent of the respondents indicated that they are using technology transfer centers, spin-off companies, and distance-learning programs in partnership with private sector enterprise or as for-profit subsidiaries.

\section{Questions 2 \& 4}

Is there a relationship between the number of entrepreneurial initiatives and the number of successful entrepreneurial initiatives and the following factors:

Information on twenty-one institutional factors was compiled to assess whether or not there is a relationship between these factors and the number of entrepreneurial initiatives used and the number of successful entrepreneurial initiatives. The following discussion will summarize the findings for each factor. Number of years the president/chancellor has been in current position?

The majority of presidents/chancellors have been in their current position five or fewer years $(64.3 \%)$. This is fairly consistent with the demographic findings of Corrigan's survey (2002) of the presidents of all American higher education institutions 
by Carnegie Classification, which indicated that the average length of service was 6.6 years.

Of the fifteen institutions with low entrepreneurial scores $(\leq 37)$, ten $(66.7 \%)$ of the presidents/chancellors have been in their current positions five or fewer years. Of the thirteen institutions with high entrepreneurial scores ( $>37)$, eight $(61.5 \%)$ have been in their current positions five or fewer years.

When using the entrepreneurial score as the measure of the level of entrepreneurial activity in evaluating the differences among the five length of service categories, nothing significant was found. However, when using the number of new initiatives as the measure of entrepreneurial activity, a significant difference was found. The median number of new initiatives was higher for the eleven to fifteen years of service group than for the five or fewer years of service group, offering support that the length of service of the president/chancellor does affect entrepreneurial activity, at least in terms of new initiatives.

An expected finding would be that each sequentially longer length of service category show an increase in the number of new initiatives. Why the difference is only between the zero to five year category and the eleven to fifteen year category is not clear. However, the proportion of variability $\left(\eta^{2}=.37\right)$ in the number of new initiatives accounted for by the president's/chancellor's years of service in current position indicates a fairly strong relationship, and warrants additional research. This particular finding may be an artifact of one or more other intervening variables, such as a closer, more trusting relationship with the faculty and/or governing board, greater understanding of the culture 
of the institution, stronger affiliation with the institution with so many years of service, or accepted and respected presidential leadership by the institutions constituencies.

The analysis failed to reveal any significant relationship between the number of years the president/chancellor has been in current position and the level of successful entrepreneurial initiatives.

The field of study or discipline of the president/chancellor?

According to the survey by Corrigan (2002), the president's top three fields of study were education (43.8\%), humanities (14.3\%), and social sciences (13.5\%). This study found the largest representation in the fields of education (35.7\%) and social sciences $(28.6 \%)$. The humanities and the physical/natural sciences were each represented by 7.1 percent. Only one president/chancellor (3.6\%) indicated a field of study in business.

The statistical analysis failed to reveal any significant relationship between the president's/chancellor's field of study or discipline and the level of entrepreneurial activity or the level of successful entrepreneurial initiatives.

The business/industry experience of the institution's president/chancellor?

There were no statistically significant findings regarding the business/industry experience of the president/chancellor and level of entrepreneurial activity or level of successful entrepreneurial initiatives. The data revealed that all of the presidents/chancellors came to their current position through academic positions, reflecting no business/industry experience. However, this may still be an important finding since it does not reflect current trends. According to the survey by Corrigan (2002), an increasing number of presidents have experience from outside higher education. In 2001, nearly fifteen percent of presidents' immediate prior positions were 
from outside higher education, up from ten percent in 1986, and more than sixty percent of presidents have some experience outside higher education (Corrigan, 2002). Goral (2003) states, "with an apparent growing need to operate a university as a business, it would seem to make sense to draw talent from the corporate world" (para. 17). Posner (as cited in Goral, 2003) vice-president at Educational Management Network, states, "because of the economic challenges that some institutions are facing, there is an increasing movement to at least take a look at people who are not from the traditional, up-through-the-ranks world, people who are from the development world or finance" (para. 18). However, despite this growing trend, it is still most common for the president to come from an academic background. Corrigan's (2002) survey indicates that the most common prior positions of the presidents are, (1) other senior campus executive (32.7\%), (2) chief academic officer or provost (27.8\% or, (3) president or chief executive officer $(20.4 \%)$.

\section{The institution's enrollment?}

This study failed to reveal any significant relationship between enrollments and the level of entrepreneurial activity or the level of successful entrepreneurial initiatives. The majority of institutions had full-time undergraduate enrollments in the 1,000 to 5,000 category (75\%) and part-time undergraduate enrollments of less than 1,000 (71.4\%). Since, by definition, the institutions surveyed were baccalaureate institutions, it was expected that graduate enrollments would be small. The data support this observation, with all institutions reporting full-time graduate enrollments less than 1,000 and all but one institution reporting part-time graduate enrollments less than 1,000. 
An increase or decrease in enrollment from the previous year?

Brenneman (2002) states, "the economic difficulties today's institutions must now grapple with are especially burdensome because higher education now faces an enrollment surge similar to that experienced during the baby boom" (p. 3). According to a 1999 report published by the Western Interstate Commission for Higher Education and the College Board (as cited in Brenneman, 2002):

The number of high-school graduates began to increase in the 1990s and will continue through 2008, when the nation will graduate the largest public high-school class in its history -3.2 million students - exceeding the class of 1979, the peak year of the baby boom, by more than 60,000 graduates. (p. 3)

This study revealed that 67.9 percent of the institutions realized increasing enrollments from the previous year while the remaining 32.1 percent saw enrollment decreases. Statistical analysis failed to reveal any significant relationship between the change in enrollments from the previous year and the level of entrepreneurial activity or the level of successful entrepreneurial initiatives.

The institution's tuition, both in-state and out-of-state?

This study found that 32.1 percent reported in-state tuition ranging from $\$ 2,001$ $\$ 4,000$, with 46.4 percent of the institutions reporting in-state tuition ranging from $\$ 4,001$ - $\$ 6,000$. Three (10.7\%) institutions reported in-state tuition between $\$ 6,001$ - $\$ 8,000$. Only two (7.1\%) institutions reported tuition less than $\$ 2,000$, and only one (3.6\%) institution reported in-state tuition greater than $\$ 8,000$.

The majority of institutions reported out-of-state tuition in two categories, $\$ 5,001$ - $\$ 10,000(50 \%)$ and $\$ 10,001-\$ 15,000(35.7 \%)$. Only two institutions reported out-of- 
state tuition at less than $\$ 5,000(7.1 \%)$ and two (7.1\%) reported out-of-state tuition in excess of $\$ 15,000$.

When assessing the distributions of in-state and out-of-state tuition, there were no statistically significant relationships with the level of entrepreneurial activity or the level of successful entrepreneurial initiatives.

An increase or decrease in tuition from previous year?

Yudof (2002) reports that, ' ... as state support for higher education has declined relative to other public services, the value of education to students has increased substantially" (para. 8). Yudof goes on to say that, "After adjusting for inflation, a male college graduate today makes an average of $\$ 32,000$ more each year than a high school graduate, compared with a $\$ 15,000$ gap in $1975 \ldots$. With the wage premium rising, education is increasingly seen as a private, rather than a public good" (para. 8). Federal and state policy makers often encourage tuition increases, then favor giving direct aid to students in the form of scholarships and tax benefits (Yudof, 2002) However, the Rand Corporation's Council for Aid to Education estimated that increasing college costs, when combined with declining real wages and growing immigration rates, will create a class for whom college is out of reach (Hammonds, Jackson, DeGeorge, \& Morris, 1997).

Yet there are limits to how far institutions can go with tuition increases. In a College Board report (as cited in Farrell, 2003), tuition in 2003-2004 at public four-year institutions surged at its highest rate in three decades, rising 14 percent over the previous year. The College Board report goes on to say that the average cost of tuition, room and board was equal to seventy percent of family income for families earning up to $\$ 25,207$, an increase of more than ten percent in the previous three years. 
In this study, survey respondents were asked to identify whether tuition, both instate and out-of-state, had increased, decreased, or not changed from the previous year. Twenty-two (78.5\%) institutions reported increases in in-state tuition ranging from 3.8 percent to 27 percent, and twenty (75\%) institutions reported increases in out-of-state tuition ranging from 4 percent to 18 percent. For in-state and out-of state tuition, 35.7 percent of the institutions raised tuition by $5.1 \%-10.0 \%$. Only one institution indicated a decrease in both in-state and out-of-state tuition. Five (17.9\%) institutions reported no change in in-state tuition, and six (21.4\%) institutions reported no change in out-of-state tuition.

Analysis failed to reveal any significant relationship between changes in in-state tuition and the level of entrepreneurial activity or the level of successful entrepreneurial initiatives.

Analysis revealed a statistically significant relationship between changes in outof-state tuition and the level of entrepreneurial activity as measured by the Entrepreneurial Score, $r_{\mathrm{s}}=.415, N=28, \mathrm{p}<.05$. However, analysis failed to reveal a statistically significant relationship between changes in out-of-state tuition and the level of entrepreneurial activity as measured by the number of new initiatives and the number of new initiatives planned for the future. Since the Entrepreneurial Score was calculated using weights assigned to all categories of initiatives, it likely provides the best overall assessment of the level of entrepreneurial activity. It is also likely that the significant relationship found was a result of the weight assigned to the traditionally used initiatives. This is supported by the findings in regard to the level of successful initiatives. While no significant relationship was found between changes in out-of-state tuition and the New 
Initiatives Success Score, a significant relationship was found between the changes in out-of-state tuition and the Traditionally Used Success Score, $r_{s}=.447, N=28, \mathrm{p}<.05$. Furthermore, analysis initially revealed a statistically significant difference among the various levels of changes in out-of-state tuition on median change in successful entrepreneurial initiatives as measured by the Composite Success Score, $\chi^{2}(5, \mathrm{~N}=28)=$ $14.666, \mathrm{p}<.05$, where the critical value is 11.07 . However, follow-up analysis with pair wise tests of the six out-of-state categories indicated no significant finding. While the findings are rather inconclusive, they warrant further investigation.

The number of faculty, both full-time and part-time?

Respondents in this study reported full-time faculty with a minimum of thirty-two to a maximum of $588(M=123.04, S D=104.88)$. Fifteen institutions $(53.6 \%)$ had 100 or fewer full-time faculty. Eleven (39.3\%) had between 101 and 200 full-time faculty. Only two (7.1\%) reported full-time faculty in excess of 200.

Part-time faculty ranged from zero to $328(M=79.25, S D=81.00)$. Twenty-two (78.5\%) institutions reported part-time faculty numbers 100 or less. Three (10.7\%) institutions reported between 101 to 200 part-time faculty, and three (10.7\%) reported more than 200 part-time faculty.

This study found no significant relationship between the total full-time faculty and the level of entrepreneurial activity as measured by the Entrepreneurial Score or the number of new initiatives planned for the future. The study did reveal a significant relationship between the total full-time faculty and the level of entrepreneurial activity as measured by the number of new initiatives, $r_{s}=.334, N=28, \mathrm{p}<.05$, suggesting that entrepreneurial activity, through new initiatives, tends to move in the same direction as total full-time faculty. This finding is supported by a significant relationship between the 
total full-time faculty and the level of successful initiatives as measured by the New Initiatives Success Score, $r_{s}=.516, N=28, \mathrm{p}<.01$, suggesting that the level of successful entrepreneurial initiatives tends to move in the same direction as total full-time faculty. The Traditionally Used Initiatives Success Score or the Composite Success Score found no significant relationship between the total full-time faculty and the level of successful initiatives.

There appears to be no significant relationship between total part-time faculty and the level of entrepreneurial activity and the level of successful entrepreneurial initiatives by any of the measures used in this study.

The number of tenure track and non-tenure track faculty?

The number of full-time tenure track faculty ranged from a minimum of twentyseven to a maximum of $515(M=101.50, S D=94.99)$. Twenty-four $(85.7 \%)$ of the institutions reported the number of full-time tenure track faculty at 150 or less.

Full-time non-tenure track numbers ranged a low of zero to seventy-three $(M=$ $21.54, S D=17.79)$. Twenty-six $(92.9 \%)$ reported less than 50 full-time non-tenure track faculty.

This study found no significant relationship between the total full-time tenure track faculty and the level of entrepreneurial activity as measured by the Entrepreneurial Score or the number of new initiatives planned for the future. The study did reveal a significant relationship between the total full-time tenure track faculty and the level of entrepreneurial activity as measured by the number of new initiatives, $r_{s}=.511, N=28, \mathrm{p}$ $<.01$, suggesting that entrepreneurial activity through new initiatives, tends to move in the same direction as total full-time tenure track faculty. This finding is supported by a significant relationship between the total full-time tenure track faculty and the level of 
successful initiatives as measured by the New Initiatives Success Score, $r_{s}=.426, N=28$, $\mathrm{p}<.05$, and the Traditionally Used Initiatives Success Score, $r_{s}=.514, N=28, \mathrm{p}<.01$, suggesting that the level of successful entrepreneurial initiatives tends to move in the same direction as total full-time tenure track faculty. The Composite Success Score found no significant relationship between the total full-time tenure track faculty and the level of successful initiatives.

There appears to be no significant relationship between total full-time non-tenure faculty and the level of entrepreneurial activity and the level of successful entrepreneurial initiatives by any of the measures used in this study.

An increase or decrease in full-time faculty, both tenure track and non-tenure track, from the previous year?

Thirteen institutions (46.4\%) reported total full-time had decreased from the previous year, while twelve (42.9\%) reported increases. Only three (10.7\%) reported no change in total full-time faculty.

No significant relationship was found between changes in total full-time faculty and the level of entrepreneurial activity and the level of successful entrepreneurial initiatives by any of the measures used in this study. An increase or decrease in full-time tenure track faculty from the previous year?

Thirteen (46.4\%) institutions reported increases in full-time tenure track faculty and thirteen (46.4\%) reported decreases. The remaining two (7.1\%) institutions reported no change in full-time tenure track faculty.

No significant relationship was found between changes in full-time tenure track faculty and the level of entrepreneurial activity and the level of successful entrepreneurial initiatives by any of the measures used in this study. 
An increase or decrease in part-time faculty from the previous year?

Nine (32.1\%) institutions reported increases in part-time faculty and twelve (42.9\%) indicated that part-time faculty had decreased from the previous year. Seven $(25.0 \%)$ indicated no change in part-time faculty from the previous year.

No significant relationship was found between changes in part-time faculty and the level of entrepreneurial activity and the level of successful entrepreneurial initiatives by any of the measures used in this study.

The findings in this study regarding changes in total full time faculty, full-time tenure track faculty, and part-time faculty are not consistent with claims made in the literature. Lieberwitz (2002) indicates that between 1971 and 1986 the employment of part-time faculty increased by 133 percent, while full-time faculty only increased by 22 percent. Lieberwitz sees this as a change in values and norms, with attempts to remove the faculty tenure process and to increase the numbers of part-time and adjunct faculty. Lieberwitz states that the growth of part-time, adjunct, and contingent faculty lowers costs and increases administrative control. This tendency away from a tenure track system and toward a greater utilization of part-time faculty was not represented in this study.

\section{The highest degree offered at the institution?}

No significant relationship was found between the highest degree offered at the institution and the level of entrepreneurial activity and the level of successful entrepreneurial initiatives by any of the measures used in this study. This finding is not surprising in that the study focused on baccalaureate degree institutions and most of the institutions indicated graduate enrollments of less than 1000. Sixteen (57.1\%) offer the 
baccalaureate degree as their highest degree. The remaining twelve $(42.9 \%)$ offer masters degree programs.

The addition or elimination of programs for teaching, research, and service since the previous year?

Fifteen (53.6\%) of the institutions added teaching programs since the previous year. Twelve (42.9\%) indicated no change. Only one (3.6\%) institution indicated the elimination of teaching programs. Statistical analysis revealed no significant findings, either with the level of entrepreneurial activity or the number of successful initiatives.

Five (17.9\%) institutions indicated that they added research programs. Twentytwo (78.6\%) indicated no change. Again, only one (3.6\%) indicated the elimination of programs. There were no statistically significant findings regarding the addition or elimination of research programs for either the level of entrepreneurial activity or the number of successful entrepreneurial initiatives.

Eight (28.6\%) institutions reported adding service programs. Nineteen (67.9\%) indicated no change, and one (3.6\%) institution eliminated service programs. Statistical analysis found nothing significant between the level of entrepreneurial activity, as measured by the Entrepreneurial Score and the number of new initiatives planned for the future, and the addition or elimination of service programs. However, a significant relationship was found using the number of new initiatives as the measure of entrepreneurial activity. Further statistical analysis revealed that the significant relationship was specifically between the entrepreneurial activity as measured by the number of new initiatives and the number of service programs added, $r_{s}=.399, N=28, p$ $<.05$. This findings suggests that as the number of service programs increase, the number of new initiatives increase as well. Nothing significant was found in relationship 
to the number of programs eliminated. Furthermore, no significant relationship was found between the number of service programs added or eliminated and the number of successful entrepreneurial initiatives.

Slaughter and Leslie (1997) indicate that declining state support has forced higher education to find ways to cut costs, operate more efficiently, find alternative sources of revenue, and has led to organizational restructuring. Program elimination is one obvious way to cut costs and, perhaps, operate more efficiently. However, this study reflects more program additions than eliminations. Particularly noteworthy is the increase in service programs and the significant positive relationship with the number of new initiatives. Yudof (2002) states that “...especially at land-grant institutions, students and parents may question using tuition dollars to pay for extension services and other outreach activities that don't directly improve students' education" (para. 14). Yudof goes on to say that they may have to begin charging fees for traditionally free services. This study does not indicate the reasons for the service program additions, nor whether the additions generated additional revenues. This is an area that deserves additional attention in the research.

An increase or decrease in state appropriations from the previous year?

Levine (1997) reports that government support for higher education has been in decline since the 1980s, both politically and financially, primarily because of increasing and competing demands for less money. Levine indicates that prisons, health care, and highways compete for limited dollars, and, even within education, schools get preference over colleges. Theo Yu (as cited in Selingo, 2003), the higher education budget assistant to Washington's governor, stated “...higher education is the single largest chunk of discretionary spending in the state budget" (para. 24). 
State appropriations identified in this study generally follow the trend of decreasing or stagnant state support. Twenty-four (85.8\%) of the institutions indicated either no change $(42.9 \%)$ or a decrease $(42.9 \%)$ in state appropriations, with only four institutions (14.3\%) receiving an increase. The reported decreases ranged from two percent to seventeen percent. The four institutions reported increased appropriations ranged from 0.98 percent to eleven percent.

It is interesting to note that, when comparing changes in state appropriations with a median split of the Entrepreneurial Score, a greater number of institutions with decreased appropriations had low entrepreneurial scores (66.7\%) and a greater number of institutions with increased appropriations had high entrepreneurial scores (75.0\%). This is the opposite of what would be expected if shrinking state appropriations lead to seeking alternative sources of revenue.

Statistical analysis failed to reveal any significant relationship between the level of entrepreneurial activity and the changes in state appropriations. Similarly, nothing significant was revealed from the analysis between the changes in state appropriations and the number of successful entrepreneurial initiatives as measured by the Traditionally Used Initiatives Success Score and the Composite Success Score. However, a statistically significant relationship was found between the changes in state appropriations and the New Initiatives Success Score, indicating that as state appropriations increase the number of new initiative successes increase as well. This may indicate that new initiatives have a better chance of being successful when budgetary conditions are able to support the new initiative. When budgets are tight and state 
appropriations constant or decreasing, it may be difficult to launch new initiatives successfully. This warrants further investigation.

Whether the governing board encourages or discourages entrepreneurial activities to generate revenue?

Twenty-three (82.1\%) of the institutions indicated that the governing board either strongly encouraged (25.0\%) or encouraged (57.1\%) entrepreneurial activities to generate revenue. None of the institutions reported that the governing board discouraged entrepreneurial activity. However, the analysis failed to reveal any significant relationship between level of governing board support and the level of entrepreneurial activity or the number of successful entrepreneurial initiatives.

The number of programs supported by generating their own revenue?

Slaughter and Leslie (1997) indicate that organizational “...restructuring often put resources at the disposal of units and departments close to the market; that is, those relatively able to generate external grants and contracts or other sources of revenue" (p. 8). Aronowitz and Giroux (2000) point out, “...those areas of study that do not translate into substantial profits get marginalized, underfunded, or eliminated" (p. 1).

In this study, nineteen $(67.9 \%)$ of the institutions indicated that they had no programs supported by generating their own revenue. Six (21.4\%) reported one program responsible for generating some portion of its own revenue, and three (10.7\%) reported two programs. The percentage of support that these programs must provide for themselves ranged from two percent to 100 percent. The programs identified that were totally self-supporting were:

- Professional Development and Continuing Education

- Coastal Research Center 
- Special Education Teacher Training

- Education and Training Partnership

- Education Leadership Masters

This study found no significant relationship between the number of programs responsible for a portion of their own revenue and the level of entrepreneurial activity or the number of successful entrepreneurial initiatives. Administrative and/or organizational changes during the presidents'/chancellor's tenure?

As our institutions of higher education become more entrepreneurial in generating revenues, this market orientation has led many researchers to indicate that traditional models of shared governance in higher education are no longer responsive (Buchbinder, 1993; Elford \& Hemstreet, 1996; Keast, 1995). Buchbinder says, ...the emergence of the market university will change the ground rules. Cost will be the criterion. The market university will be characterized by less democracy, less collegiality, more privatization, more centralization. (p. 340)

James Carlin (as cited in Aronowitz \& Giroux, 2000), Commissioner on Higher Education in Massachusetts, contends that higher education requires a model of management and leadership that place more power and authority in the hands of the university president.

In this study, all but six (78.6\%) indicated administrative and/or organizational changes in one or more of the three identified categories, (1) administrative and/or organizational restructuring, (2) changes in decision-making authority, and (3) creation of 
new positions in central administration. Twenty (71.4\%) institutions reported administrative and/or organizational restructuring, eight (28.6\%) reported changes in decision-making authority, and ten (35.7\%) reported creation of new positions in central administration.

This study failed to reveal any significant relationship between administrative and/or organizational changes and the level of entrepreneurial activity or the number of successful entrepreneurial initiatives.

Whether faculty are formally encouraged to pursue innovative and entrepreneurial activities?

Bird and Allen (1989) explain that there is often a low level of faculty entrepreneurial activity based on differences in individual values and values for their lifestyles, suggesting:

For the academic, work involves research and teaching in a relatively narrow disciplinary focus and service to the university and other communities. The intrinsic rewards of publishing ideas, research with students, and acceptance in scholarly circles are vastly different from the world of commerce. For the entrepreneur, work involves linking resources and opportunities and requires a myriad of technical, managerial, and interpersonal competencies. In entrepreneurial realms, knowledge is embodied in a finished, marketable product or service with objective success criteria measured by sales and profits and intrinsic rewards of winning the game....Academic activities often take on longer future time horizons for feedback and require patience and persistence; entrepreneurship is in contrast, very here-and-now and action oriented. In 
general, academia is bureaucratic, slow to change and low on stress, at least among faculty; entrepreneurship involves organizational birth, rapid change and growth and considerable stress. (p. 593)

While faculty may intuitively understand that their work has economic consequence, it is through the mechanism of increasing the body of knowledge. Kozeracki (1998) explains that a commitment to tradition and a disdain of commerce, especially for thinking of students as clients, or customers, often dominates the thinking of faculty members. Kozeracki goes on to explain that it is the administration within higher education, facing increasing fiscal constraints, legislative intervention, and charged with institutional planning and survival, that embrace and promote the entrepreneurial process.

Peck $(1984,1985)$ identifies six characteristics of entrepreneurial leadership:

1. Commitment to a mission and a purpose.

2. Opportunity conscious, with continual attention to changes in the environment.

3. Active agents in innovative and creative processes, creating a climate that encourages, supports, and catalyzes change.

4. Decisions are made on the future based on sound judgments and intuition, not simply on data and systematic analysis.

5. Improved intuitive decision making through intelligence gathering.

6. Understanding of the elements of risk and how to measure risk.

This question tried to assess whether the respondent institutions create a climate that encourages and supports entrepreneurial activity and whether or not there is a relationship between this support and encouragement and the level of entrepreneurial 
activity and the number of successful entrepreneurial initiatives. Twenty-five $(89.3 \%)$ of the institutions reported that they either encourage or strongly encourage faculty entrepreneurial activities. None of the institutions reported discouragement of faculty entrepreneurial activities. However, statistical assessment failed to reveal any significant relationship between the level of institutional support for faculty entrepreneurial activities and the level of entrepreneurial activity at the institution.

Statistical analysis did indicate a significant relationship between the level of institutional support for faculty entrepreneurial activity and the number of successful entrepreneurial initiatives as measured by the Composite Success Score, $r_{s}=-.397, N=$ $28, p<.05$, indicating that the number of successful entrepreneurial initiatives increases as the level of institutional support for faculty entrepreneurial activity increases. No significant relationship was found using the New Initiatives Success Score or the Traditionally Used Initiatives Success Score.

Whether merit pay or other reward systems are used to encourage faculty to pursue innovative and entrepreneurial activities?

Sixteen $(57.1 \%)$ of the institutions have no identified reward system for encouraging faculty to pursue entrepreneurial activities. Four (14.3\%) institutions reported using a merit pay system to reward faculty for entrepreneurial activities. Eight $(28.6 \%)$ institutions reported using a variety of other reward systems:

- Support for ideas-to-reality organizational culture.

- Intellectual property.

- Equipment or technology rewards.

- Compensation. 
- Indirect costs split with principal investigator.

- Points for each project developed, which are granted upon requesting promotion.

- Release from class time.

- Percentage of dollars obtained.

Statistical analysis failed to reveal any significant relationship between the reward systems used and the level of entrepreneurial activity as measured by the Entrepreneurial Score and the number of new initiatives planned for the future. Statistical analysis revealed a significant relationship between the reward systems used and the level of entrepreneurial activity as measured by the number of new initiatives, but this result is hard to interpret. Initially, using a Kruskal-Wallis test to assess the median change in the level of entrepreneurial activity as measured by the number of new initiatives, based on the reward systems used to encourage faculty entrepreneurship, the test was significant at the .05 level, $\chi^{2}(2, \mathrm{~N}=28)=6.307, \mathrm{p}<.05$, critical value of 5.99. Follow-up tests using pair wise comparisons among the three reward system categories failed to support this finding, reporting nothing significant. However, further analysis with the Spearman rank correlation coefficient was significant at the .05 level, $\mathrm{r}_{\mathrm{s}}=-.403, \mathrm{~N}=28, \mathrm{p}<.05$. While it appears there may be some relationship between the reward system used to encourage faculty entrepreneurial activity and the number of new initiatives, the results are difficult to interpret.

This study found no significant relationship between the reward systems used by the institutions to support faculty entrepreneurial activity and the number of successful entrepreneurial initiatives. 
Whether the institution's purpose and/or mission has been changed to reflect greater emphasis on entrepreneurial activities?

Buchbinder (1993) warned of potential problems of a market-orientation approach and its effect on institutional mission and purpose:

Both unions and senates are more and more by-passed, not by conspiracy but rather by the effects of these institutional changes. Policy appears to derive almost solely from budget conditions and the university as an institution must rationalize itself in accord with those constraints. The objectives of higher education which are expressed as the production of knowledge as a social good are replaced by an emphasis on the production of knowledge as a market good, a saleable commodity. Simultaneously, the development of a market-oriented university supersedes academic decision making. This can result in an "efficient", well managed institution in which academics are marginalized, academic institutions are by-passed and social knowledge is diminished as market knowledge achieves greater prominence. (p. 335)

This study attempts to determine if institutions at the baccalaureate level are changing their purpose and/or mission to reflect a greater emphasis on entrepreneurial activities to generate revenue, and further determine if this is having an impact on the level of entrepreneurial activity and the number of successful entrepreneurial initiatives.

Even though only four (14.3\%) of the institutions reported changes in their purpose and/or mission, the results of this study show that changes in purpose and/or mission are taking place at some of the institutions at the baccalaureate level to encourage 
entrepreneurial activity and that it does impact the level of entrepreneurial activity. The findings do not support a relationship between the changes in purpose and/or mission and the number of successful entrepreneurial initiatives.

One institution indicated that its purpose or mission had changed to better serve two-year college graduates. This clearly reflects a change of focus to the needs of a particular market. Another institution indicated that its old mission reflected a focus on traditional program offerings and that the new mission focused on expected benefits to students, the region, and to society. The institution's comments further indicated that their new vision now focused on the institution's impact on the region. Once again, the market approach to meeting customer needs and customer satisfaction seems to drive the change in purpose and mission. Finally, a third comment clearly shows a change to a more opportunistic market-like approach to their purpose and mission. The third respondent commented that the purpose and mission had changed to optimize entrepreneurial opportunities and to think in terms of investment and fundraising opportunities.

Statistical analysis revealed a significant relationship between the changes in the institution's purpose or mission and the level of entrepreneurial activity as measured by the Entrepreneurial Score, $\mathrm{z}-1.992, \mathrm{p}<.05$. The proportion of variability in entrepreneurial activity accounted for by the changes in institutional purpose or mission was $\eta^{2}=.16$, indicating a small, yet significant relationship. A Spearman's rank correlation coefficient was also significant at the .05 level, $\mathrm{r}_{\mathrm{s}}=-.398, \mathrm{~N}=28, \mathrm{p}<.05$.

The analysis failed to reveal any significant relationship between the changes in institutional purpose or mission and the level of entrepreneurial activity as measured by 
the number of new initiatives or the number of new initiatives planned for the future. Furthermore, the analysis failed to reveal any significant relationship between changes in the institution's purpose or mission and the number of successful entrepreneurial initiatives by any of the three measures.

Whether faculty or staff are represented by union?

Buchbinder (1993), reflecting on the potential problems of privatization and a market-oriented approach, indicated that both unions and senates are more frequently bypassed by the effects of institutional change. However, nothing was discovered in the literature that indicated a relationship between employee union representation and the level of entrepreneurial activity or the associated level of success with entrepreneurial activities.

Of the respondent institutions in this study, only ten (35.7\%) indicated that a union represents their faculty, and eleven (39.3\%) indicated that a union represents their staff.

Statistical analysis failed to reveal any significant relationship between union representation of the faculty and staff of the institution and the level of entrepreneurial activity or the number of successful entrepreneurial initiatives.

Research Question 5: What impact have entrepreneurial initiatives had on institutional mission, purpose and academic integrity?

Many researchers investigating the privatization and market-like behaviors in higher education have voiced concerns over the impact a more entrepreneurial approach may have on the overriding purpose and mission of our institutions of higher education (Buchbinder, 1993;Gose, 2002; Yudof, 2002,). 
As indicated earlier, four (14.3\%) institutions reported a change in the purpose and/or mission toward a greater emphasis on entrepreneurial activities to generate revenue. Their accompanying comments were all market related responses. The question asked here is whether the entrepreneurial activities have then impacted the purpose, mission or academic integrity of the institution. This is somewhat like asking which came first, the chicken or the egg. Nevertheless, it is useful to note that while changes in purpose and mission may be necessary to facilitate an environment that supports entrepreneurship, it is equally true that moves toward more entrepreneurial endeavors will, perhaps, without intention, impact the overriding purpose and mission of the institution and further impact academic integrity. For example, Aronowitz and Giroux (2000) comment that as universities adopt the business model, "corporate planning replaces social planning, management becomes a substitute for leadership, and the private domain of individual achievement replaces the discourse of public politics and social responsibility" (p. 2). Lieberwitz (2002) states that this "new corporate university identity" (p. 28) brings values and practices that threaten academic freedom.

The respondents were asked if there were any downsides to entrepreneurial programs or activities. Seven (25.0\%) provided comments. Some of the most pertinent are as follows:

- Risk of mission dilution.

- Not all [entrepreneurial initiatives] work as planned - culture is uncomfortable with failure.

- Creates an environment that some see as chaotic, which can drag them and the institution down. 
- Potential exists for conflicting/competing forces for influence in terms of future direction.

- More private money means more "noses under the tent."

- It is not easy to convince all faculty members of its [entrepreneurial initiatives] importance.

- Entrepreneurial activities require a cultural change in the institution, which is always a struggle.

- The benefits to the institution will not be seen immediately, making it increasingly difficult to promote.

The two comments about influence of private money and conflicting/competing forces is reflected in the literature. Lieberwitz (2002) indicates that private, corporate intervention into public higher education has lead to attacks on academic freedom, attacks on tenure systems, the growth of the contingent workforce of adjunct faculty, increasing use of graduate students to fulfill teaching needs, university patents of faculty research for commercial profit, leading to an emphasis on applied research over basic research, and a limiting effect on the faculty voice in administration.

This study, with only four institutions indicating changes in their purpose and/or mission, nevertheless, by their comments support the concerns over entrepreneurial endeavors impacting the purpose and mission of the institution and on academic integrity.

Research Question 6: Does the institution's governing board/body encourage or discourage entrepreneurial initiatives to generate revenue?

This study did not find any significant relationship between the level of governing board support and the level of entrepreneurial activity or the number of successful 
entrepreneurial initiatives. The majority of the institutions $(23,82.1 \%)$ indicated that the governing board either strongly encouraged $(25.0 \%)$ or encouraged $(57.1 \%)$ entrepreneurial activities, while three $(10.7 \%)$ indicated that the governing board remained neutral on the topic.

One institution made the comment that "there is a huge difference between verbal and actual encouragement", continuing on to say that their state board is "gung ho" verbally, but very reluctant to approve innovative changes.

\section{Recommendations for Practice}

The purpose of this study was to investigate the current patterns of entrepreneurial activities in public liberal arts and general baccalaureate colleges and universities as defined by the Carnegie Classification (The Carnegie Foundation for the Advancement of Teaching, 2000). These institutions are not presented in the literature on academic entrepreneurship, yet face the same fiscal constraints as other public higher education institutions.

This study provided much needed data regarding the types of traditional and entrepreneurial initiatives being used at four-year colleges and universities and which ones are proving successful. Several significant relationships were found between the number of entrepreneurial initiatives and various institutional factors. Significant relationships were also found between the level of success of entrepreneurial activities and various institutional factors. The sample of twenty-eight respondent institutions $(37.3 \%)$ in this study was compared to the population of public liberal arts and general baccalaureate institutions on several key institutional factors, including enrollments, tuition, faculty, and the highest degree offered. This data comparison revealed that the 
respondent institutions fairly represent the population of institutions. The significant findings reported in this study, along with the comparative analysis of the respondent institutions to the population of institutions, are encouraging and suggest some reasonable recommendations for practice

The respondent institutions reported increasing tuition and fees, using college/university foundations, and distance-learning within the existing organizational structure as having the highest levels of success, with over eighty percent of the institutions using these three initiatives to generate revenue. Of equal importance is the finding that the least successful initiatives were technology transfer centers, spin-off companies, distance-learning programs in partnership with private sector enterprise, and distance-learning programs as for-profit subsidiaries, with only 3.6 percent of the respondent institutions using these initiatives.

The following is a list of the most successful initiatives reported by fifty percent or more of the respondent institutions:

- Increasing student laboratory, supplies, and other service fees (75\%)

- Degree completion programs (71.4\%)

- Profit-sharing with food service, bookstore, and other auxiliary services (71.4\%)

- Increasing residence fees $(67.9 \%)$

- Alumni associations (64.3\%)

- Increasing cost of campus food services $(60.7 \%)$

- Evening degree completion programs (60.7\%)

- Lease/rent institutional facilities and/or equipment (57.1\%)

- Develop or expand endowments (57.1\%) 
- Debt financing (57.1\%)

- Research contracts with government agencies (57.1\%)

- Certificate programs $(53.6 \%)$

- Contract-training programs with business/industry (50\%)

Other equally successful initiatives, utilized by less than one-half of the respondents, are weekend degree offering programs, capital campaigns, catering food services, and specialized training programs and certificate programs for business/industry. With more pressure being placed on public higher education to use restraint in raising tuition and fees, it is encouraging to note the many other initiatives that are proving successful.

This study also found that there is a high correlation between the number of initiatives utilized and the level of success, indicating that institutions that are using a high number of initiatives tend to also have high levels of success. This would be an encouragement to institutions to try using as many different ways to generate revenue as seems fiscally prudent.

An interesting finding in this study reflected a direct relationship between the number of full-time faculty and the number and success of entrepreneurial initiatives. This finding would suggest that as full-time faculty numbers increase, the number of successful entrepreneurial initiatives increase. There was no similar finding with parttime faculty. With enrollments expected to continue to increase through 2008 (Brenneman, 2002), even with increasing class sizes, the number of faculty is likely to increase. This finding should encourage institutions to consider full-time faculty rather than part-time faculty. The full-time faculty, although one of the highest cost factors, is 
also one of the greatest resources in our institutions of higher education. With appropriate encouragement and reward systems, the faculty can be a vital resource to generating revenue through entrepreneurial endeavors. This study found that there is a positive and significant relationship between the level of institutional support for faculty entrepreneurial activities and the number of successful entrepreneurial initiatives. It also found a significant relationship between the reward system used and the level of entrepreneurial activity.

State appropriations identified in this study generally follow the trend of decreasing or stagnant state support. Twenty-four (85.8\%) of the institutions indicated either no change $(42.9 \%)$ or a decrease $(42.9 \%)$ in state appropriations, with only four institutions (14.3\%) receiving an increase.

A statistically significant relationship was found between the changes in state appropriations and the New Initiatives Success Score, indicating that as state appropriations increase the number of new initiative successes increase as well. This may indicate that new initiatives have a better chance of being successful when budgetary conditions are able to support the new initiative. When budgets are tight and state appropriations constant or decreasing, it may be difficult to launch new initiatives successfully. This finding should encourage institutions that are receiving increased state support to consider additional revenue generating initiatives while resources are available to support those initiatives.

This study also found a significant relationship between changes in the institution's purpose and/or mission to reflect greater emphasis on entrepreneurial activities and the level of entrepreneurial activity. In other words, the desired impact on 
the level of entrepreneurial activity occurred where changes were made to the institution's purpose and/or mission to encourage entrepreneurship. This finding makes intuitive sense when one considers how the institution's overriding purpose and mission permeates all aspects of the institution's activities. This should offer encouragement to those institutions considering new, entrepreneurial endeavors, to engage in institutionwide reassessment of the institution's purpose and mission. Generally, such reassessment involves all constituencies of the institution, and acceptance at large across and throughout the institution. This "buy-in" is more than likely essential to cultivating a culture and atmosphere conducive to entrepreneurial endeavors.

\section{Recommendations for Further Study}

1. In this study, there was a significant finding between the number of years the president/chancellor has been in current position and the number of new initiatives. This finding was only significant between the service category of five or fewer years and the category eleven to fifteen years, with the later showing the highest number of new initiatives. These findings did not extend to the level of success of these new initiatives. The findings may be an artifact of one or more other intervening variables, such as a closer, more trusting relationship with the faculty and/or governing board through many years of service together, greater understanding of the culture of the institution, stronger affiliation with the institution with so many years of service, accepted and respected presidential leadership by the institutions constituencies, or the leadership style of the president/chancellor, just to name a few possibilities. It is difficult to accept that length of service alone accounts for any significant variation in the number of 
new entrepreneurial initiatives. Recommended additional research would determine what factors or variables affect the length of service in the position of the president/chancellor at the baccalaureate level and determine how these factors effect entrepreneurship at the institution.

2. This study found a significant relationship between changes in out-of-state tuition and the level of entrepreneurial activity as measured by the Entrepreneurial Score. The study also found a significant relationship between out-of-state tuition and the level of success as measured by the Traditionally Used Initiatives Success Score. No significant findings were revealed between changes in in-state tuition and the level of entrepreneurial activity or the number of successful initiatives. This study searched for relationships between various institutional variables, such as changes in tuition and the level of entrepreneurial activity or the number of successful initiatives. Having found the above relationships, additional research is warranted to determine if there are common variables that drive changes in tuition as well as other initiatives to generate revenue.

3. This study found a direct relationship between the number of full-time faculty and the number and success of entrepreneurial initiatives. This study also found that there is a positive and significant relationship between the level of institutional support for faculty entrepreneurial activities and the number of successful entrepreneurial initiatives. Finally, it found a significant relationship between the faculty reward system used and the level of entrepreneurial activity. Additional research could focus on what types of encouragement and rewards that are most effective in promoting faculty entrepreneurial initiatives. 
4. Lieberwitz (2002) indicates that between 1971 and 1986 the employment of parttime faculty increased by 133 percent, while full-time faculty only increased by 22 percent. Lieberwitz sees this as a change in values and norms, with attempts to remove the faculty tenure process and to increase the numbers of part-time and adjunct faculty. The findings in this study regarding changes in total full-time faculty, full-time tenure track faculty, and part-time faculty are not consistent with what Lieberwitz has indicated. A movement away from a tenure track system and toward a greater utilization of part-time faculty was not represented in this study and warrants further investigation.

5. Slaughter and Leslie (1997) indicate that declining state support has forced higher education to find ways to cut costs, operate more efficiently, find alternative sources of revenue, and has led to organizational restructuring. Program elimination is one obvious way to cut costs and, perhaps, operate more efficiently. However, this study reflects more program additions than eliminations.

Particularly noteworthy is the increase in service programs and the significant positive relationship with the number of new initiatives. Additional research into this area is needed to understand the dynamics of cost versus potential for generating new revenues.

6. It is interesting to note that, when comparing changes in state appropriations with a median split of the Entrepreneurial Score, a greater number of institutions with decreased appropriations had low entrepreneurial scores $(66.7 \%)$ and a greater number of institutions with increased appropriations had high entrepreneurial scores $(75.0 \%)$. This is the opposite of what would be expected if shrinking state 
appropriations lead to seeking alternative sources of revenue. This may indicate that new initiatives have a better chance of being successful when budgetary conditions are able to support the new initiative. When budgets are tight and state appropriations are constant or decreasing, it may be difficult to launch new initiatives successfully. Additional research is warranted.

7. Statistical analysis revealed a significant relationship between the changes in the institution's purpose or mission and the level of entrepreneurial activity as measured by the Entrepreneurial Score. The desired impact on the level of entrepreneurial activity occurred where changes were made to the institution's purpose and/or mission to encourage entrepreneurship. Further study is warranted on how an institution's purpose or mission impacts its ability to effectively implement new entrepreneurial initiatives to generate revenue.

8. While the survey instrument used was very effective in gathering data regarding what initiatives are being used at four-year institutions to generate revenue, additional research might incorporate interviews with the presidents/chancellors, and possibly other academic officers of the institutions.

9. Most of the research has focused on entrepreneurial activities at community colleges and large universities. This study focused on baccalaureate institutions. Additional research could compare entrepreneurial activities at all three levels, the community college level, the baccalaureate level, and the large research university level.

10. Additional research could examine the president's leadership style at the baccalaureate level and how it affects entrepreneurial activity at the institution. 
11. Additional research could examine organizational culture at the baccalaureate level and how it affects entrepreneurial activity at the institution.

12. Additional research could examine how public policy impacts entrepreneurial activity at public higher education institutions. 


\section{Bibliography}

Anderson, M. S. (2001). The complex relations between the academy and industry. Journal of Higher Education, 72(2), 226. Retrieved August 22, 2001 from InfoTrac OneFile database, Article A71577268.

Arnone, M. (2002). State spending on colleges increases at lowest rate in a decade. The Chronicle of Higher Education, 49(16). Retrieved on December 2, 2003 from http://chronicle.com/prm/weekly/v49/116/16a02801.htm

Arnone, M., Hebel, S, \& Schmidt, P. (2003). Another bleak budget year. The Chronicle of Higher Education, 49(17). Retrieved on June 3, 2003 from http://chronicle.com/weekly/v49/i17/17a02101.htm

Aronowitz, S. \& Giroux, H. A. (2000). The corporate university and the politics of education. The Educational Forum, 64(4). Retrieved on September 29, 2003 from http://vnweb.hwwilsonweb.com/hww/emailprintsave/emailprintsave_results.jhtml

ASHE-ERIC Higher Education Reports (2000). Higher Education Outside of the Academy 27(7). 1-84. Retrieved March 10, 2003 from http://vnweb.hwwilsonweb.com/emailprintsave/emailprintsave_results.jhtml

Berdahl, R. O., Altbach, P. G. \& Gumport, P. J. (1999). The context of American higher education. In P. G. Altbach, R. O. Berdahl, \& P. J. Gumport (Eds.), American Higher Education in the Twenty-first Century: Social, Political, and Economic Challenges (pp. 1-11). Baltimore, MD: The Johns Hopkins University Press.

Bird, B. J., \& Allen, N. A. (1989). Faculty entrepreneurship in research university environments. Journal of Higher Education, 60(5), 583-596. 
Birnbaum, R. (1999). The dilemma of presidential leadership. In P. G. Altbach, R. O. Berdahl, \& P. J. Gumport (Eds.), American Higher Education in the Twenty-first Century: Social, Political, and Economic Challenges (pp. 323-344). Baltimore, MD: The Johns Hopkins University Press.

Bok, D. (2003). Universities in the Marketplace: The Commercialization of Higher Education. Princeton, NJ: Princeton University Press.

Brawer, F. B. (1998a). Academic entrepreneurship in higher education. Digest, 98(3). Kauffman Center for Entrepreneurial Leadership Clearinghouse on Entrepreneurship Education (CELCEE). Retrieved March 3, 2003, from http://www.celcee.edu/publications/digest/Dig98-3.html

Brawer, F. B. (1998b). The town/gown syndrome in higher education. Digest, 98(6). (ERIC Document Reproduction Service No. ED435341)

Breneman, D. W. (2002). For colleges, this is not just another recession. The Chronicle of Higher Education, 48(40). Retrieved on July 29, 2002 from http://chronicle.com/weekly/v48/i40/40b00701.htm

Buchbinder, H. (1993). The market oriented university and the changing role of knowledge. Higher Education, 26, 331-347.

Burd, S. (2003). Curbing tuition costs will be top priority in renewal of higher education act, key republicans say. The Chronicle of Higher Education. Retrieved on July 28, 2003 from http://chronicle.com/daily/2003/07/2003072301n.htm

Burke, J. M. (Ed.). (2004). 2004 Higher Education Directory. Falls Church, VA: Higher Education Publications, Inc. 
Campbell, T. I. D. \& Slaughter, S. (1999). Faculty and administrators' attitudes toward potential conflicts of interest, commitment, and equity in university-industry relationships. Journal of Higher Education, 70(3) 309. Retrieved on July 14, 2003 from InfoTrac OneFile Plus database, Article A54770349.

Carnegie Foundation for the Advancement of Teaching, The (2000). Carnegie Classification (2000 edition). Retrieved July 17, 2003 from http://www.carnegiefoundation.org/Classification/CIHE2000/defNotes/Definition $\underline{\text { s.htm }}$

Catanzaro, J. L., Ed. \& Arnold, A. D., Ed. (1989). Alternative funding sources, editors' notes. New Directions for Community Colleges, 68, 1-3. (ERIC Document Reproduction Service No. ED 320651)

Corrigan, M. (2002). The American college president, 2002 Edition. Washington, D.C.: American Council on Education.

Crawford, E. (2003). Americans give higher education high marks in all areas except cost, survey finds. The Chronicle of Higher Education. Retrieved on July 28, 2003 from http://chronicle.com/daily/2003/06/2003061906n.htm

Dill, D. D. (1995). University-industry entrepreneurship: the organization and management of American university technology transfer units. Higher Education, 29, 369-384.

Elford, E., \& Hemstreet, B. (1996). Intrapreneurship - a new way of doing business: maintaining academic integrity in the face of the political imperative to make money. In, The Olympics of Leadership: Overcoming Obstacles, Balancing Skills, 
Taking Risks. Proceedings of the Fifth Annual International Conference of the National Community College Chair Academy, (pp. 295-303). Phoenix, AZ.

Farrell, E. F. (2003). Public college tuition rise is largest in 3 decades. The Chronicle of Higher Education, 50(10). Retrieved on December 1, 2003 from http://chronicle.com/weekly/v50/i10/10a00101.htm

Forest, J. \& Kinser, K. (2002). Important events. Higher Education in the United States: An Encyclopedia. New York: ABC-CLIO Publishers.

Gladieux, L. E. \& King, J. E., (1999). The federal government and higher education. In Philip G. Altbach, Robert O. Berdahl, \& Patricia J. Gumport (Eds.), American Higher Education in the Twenty-first Century (pp. 151-182). Baltimore, MD: The John Hopkins University Press.

Goral, T. (February, 2003). Getting behind the salary surge. University Business. Retrieved on December 2, 2003 from http://www.universitybusiness.com/pageprint.cfm?p=137

Gose, B (2002). The fall of the flagships: Do the best state universities need to privatize to thrive?. The Chronicle of Higher Education, 48(43). Retrieved on July 1, 2002 from http://chronicle.com/weekly/v48/i43/43a01901.htm

Hammonds, K. H., Jackson, S., DeGeorge, G., \& Morris, K. (1997, December 22). The new university: a tough market is reshaping colleges. Business Week, 96-102. Retrieved April 9, 2003 from http://palinurus.English.ucsb.edu/BIBLIO-academeand-business+academe-to-corporation.html 
Hebel, S. (2003). Unequal impact: community colleges face disproportionate cuts in state budgets. The Chronicle of Higher Education, 49(38). Retrieved on June 3, 2003 from http://chronicle.com/weekly/v49/i38/38a02101.htm

Keast, D. A. (1995). Entrepreneurship in universities: definitions, practices, and implications. Higher Education Quarterly, 49(3), 248-266.

Klor De Alva, J. (1999). Remaking the academy in the age of information. Issues in Science and Technology, 16(2), 52. Retrieved from InfoTrac OneFile database, Article A59245906.

Kozeracki, C. (1998). Institutional entrepreneurship in higher education. Digest, 98(5). Kauffman Center for Entrepreneurial Leadership Clearinghouse on Entrepreneurship Education (CELCEE). Retrieved March 3, 2003, from http://www.celcee.edu/publications/digest/Dig98-5.html

Levine, A. (1997). Higher education's new status as a mature industry. The Chronicle of Higher Education, A48. Retrieved on July 14, 2003 from http://chronicl.com/che-data/articles.dir/art-43/issue-21/21a04801.htm

Lieberwitz, R. L. (2002). The corporatization of the university: distance learning at the cost of academic freedom?. The Boston Public Interest Law Journal, 12 B.U. Pub. Int. L. J. 73. Retrieved on September 29, 2003 from http://web.lexis.com/universe/printdoc

Low, M. B. (2001). The adolescence of entrepreneurship: specification of purpose. Entrepreneurship Theory and Practice, 25(4), 17-25.

Maradian, S. (1989). Economic development, the community college, and technology training. In J. L. Catanzaro \& A. D. Allen (Eds.), Alternative Funding Sources, 
New Directions for Community Colleges 68, 51-56. (ERIC Document Reproduction Service No. ED320651)

Marcy, M. B. (2003). Why foundations have cut back in higher education. The Chronicle of Higher Education, 49(46). Retrieved on July 28, 2003 from http://chronicle.com/weekly/v49/i46/46b01601.htm

McGuinness, A. C. Jr. (1999). The states and higher education. In Philip G. Altbach, Robert O. Berdahl, \& Patricia J. Gumport (Eds.), American Higher Education in the Twenty-first Century (pp. 183-215). Baltimore, MD: The John Hopkins University Press.

McLennan, F. W. (1996). Entrepreneurial management in the community colleges of Ontario, Canada (Doctoral dissertation, University of Oregon, 1996). Dissertation Abstracts International, 57(09A): 3789.

McWilliam, C. L. (1990). Innovation and entrepreneurship in colleges: an interpretive study of the piloting of innovation centres. The Canadian Journal of Higher Education, 20(3), 85-102.

Miller, S. D. (April, 2003). Yes, we run our college like a business. University Business. Retrieved on December 2, 2003 from http://www.universitybusiness.com/pageprint.cfm?p=237

Peck, R. D. (1984). Entrepreneurship as a significant factor in successful adaptation. Journal of Higher Education, 55(2), 269-285.

Peck, R. D. (1985). Entrepreneurship and small-college leadership. New Directions for Higher Education, 49, 23-29. 
Potter, W. (August, 2003). State lawmakers again cut higher-education spending. The Chronicle of Higher Education, 49(48). Retrieved on December 2, 2003 from http://chronicle.com/weekly/v49/i48/48a02201.htm

Potter, W. (November 14, 2003). Senates Democrats weigh in on college-cost debate. The Chronicle of Higher Education, 50(12). Retrieved on December 1, 2003 from http://chronicle.com/weekly/v50/i12/12a02201.htm

Potter, W. (November 19, 2003). House Democrats propose plan that would penalize states that cut spending on colleges. The Chronicle of Higher Education. Retrieved on December 1, 2003 from http://chronicle.com/daily/2003/2003111901.htm

Powers, J. B. (2002, April). Critical resource effects on america's universities: what's behind the growing entrepreneurial orientation?. Paper presented at the Annual Meeting of the American Education Research Association (New Orleans, LA, April 1-5, 2002). (ERIC Reproduction Service No. ED465332.

Rosenfeld, S. A. \& Liston, C. D. (2000). Engines of growth: rural community colleges. Forum for Applied Research and Public Policy, 15(1), 101. Retrieved from InfoTrac OneFile database, Article A64457786.

Schmidt, P. (1996). Higher education gets largest increase from states since 1990. The Chronicle of Higher Education, 43(10). Retrieved on December 2, 2003 from http://chronicle.com/prm/che-data/articles.dir/art-43.dir/issue-10/10a03101.htm

Schmidt, P. (1999). As economy chugs along, states pour money into higher education. The Chronicle of Higher Education, 46(17). Retrieved on December 2, 2003 from http://chronicle.com/prm/weekly/v46/i17/17a02801.htm 
Schmidt, P. (2000). State higher-education funds rise over all, but growth slows in much of the nation. The Chronicle of Higher Education, 47(16). Retrieved on December 2, 2003 from http://chronicle.com/prm/weekly/v47/i16/16a03401.htm

Schmidt, P. (2002). State spending on higher education grows by smallest rate in 5 years: funds increased by $4.6 \%$, but 13 states failed to keep pace with inflation. The Chronicle of Higher Education, 48(19). Retrieved on January 16, 2002 from http://chronicle.com/weekly/v48/i19/19a02001.htm

Selingo, J. (2003). The disappearing state in public higher education. The Chronicle of Higher Education 49(25). Retrieved on December 2, 2003 from $\underline{\text { http://chronicle.com/weekly/v49/i25/25a02201.htm }}$

Slaughter, S., \& Leslie, L. L. (1997). Academic Capitalism: Politics, Policies, and the Entrepreneurial University. Baltimore, MD: The John Hopkins University Press.

Trombley, W. (2003). The rising price of higher education. National Center for Public Policy and Higher Education: College Affordability in Jeopardy, A Special Supplement to National Crosstalk, Winter. Retrieved on February 12, 2003 from http://highereducation.org/reports/affordability_supplement/affordability 1. shtml

Ucbasaran, D., Westhead, P., \& Wright, M. (2001). The focus of entrepreneurial research: contextual and process issues. Entrepreneurship Theory and Practice, 25(4), 57- 80 .

Upcraft, M. L. \& Schuh, J. H. (1996). Assessment in Student Affairs: A Guide for Practitioners. San Francisco: Jossey-Bass. 
Yudof, M. G. (2002). Is the public research university dead?. The Chronicle of Higher Education, 48(18). Retrieved on July 1, 2002 from http://chronicle.com/weekly/v48/i18/18b02401.htm

Zusman, Ami (1999). Issues facing higher education in the twenty-first century. In P. G. Altbach, R. O. Berdahl, \& P. J. Gumport (Eds.), American Higher Education in the Twenty-first Century: Social, Political, and Economic Challenges (pp. 109148). Baltimore, MD: The Johns Hopkins University Press. 


\begin{abstract}
APPENDIX A
Carnegie Classification of Institutions of Higher Education
\end{abstract}

Baccalaureate Colleges - Liberal Arts

Public Institutions, by State.

California California State University-Monterey Bay

Colorado Fort Lewis College

Mesa State College

Western State College

Connecticut Charter Oak State College

Florida New College of the University of South Florida

Hawaii University of Hawaii at Hilo

University of Hawaii West Oahu

Maine University of Maine at Presque Isle

Maryland $\quad$ St. Mary's College of Maryland

Massachusetts Massachusetts College of Liberal Arts

Minnesota University of Minnesota-Morris

New Hampshire College for Lifelong Learning

New Jersey Richard Stockton College of New Jersey, The

North Carolina University of North Carolina at Asheville

Ohio Shawnee State University

Pennsylvania University of Pittsburgh at Bradford

University of Pittsburgh Greensburg Campus

Puerto Rico University of Puerto Rico-Cayey University College

South Carolina Coastal Carolina University

Texas Texas A\&M University - Galveston 
Virginia Christopher Newport University University of Virginia's College at Wise, The Virginia Military Institute

Washington Evergreen State College, The

Baccalaureate Colleges - General

Public Institutions, by State.

\begin{tabular}{|c|c|}
\hline Alabama & Athens State University \\
\hline \multirow[t]{2}{*}{ Arkansas } & University of Arkansas at Monticello \\
\hline & University of Arkansas at Pine Bluff \\
\hline Colorado & Metropolitan State College of Denver \\
\hline Idaho & Lewis-Clark State College \\
\hline \multirow[t]{2}{*}{ Indiana } & Indiana University East \\
\hline & Indiana University Kokomo \\
\hline \multirow[t]{3}{*}{ Maine } & University of Maine at Farmington \\
\hline & University of Maine at Fort Kent \\
\hline & University of Maine at Machias \\
\hline \multirow[t]{2}{*}{ Minnesota } & Southwest State University \\
\hline & University of Minnesota-Crookston \\
\hline Mississippi & Mississippi Valley State University \\
\hline \multirow[t]{2}{*}{ Missouri } & Missouri Southern State College \\
\hline & Missouri Western State College \\
\hline Montana & Western Montana College \\
\hline New Hampshire & University of New Hampshire at Manchester \\
\hline New Jersey & Ramapo College of New Jersey \\
\hline \multirow[t]{3}{*}{ New York } & City University of New York Medgar Evers College \\
\hline & City University of New York York College \\
\hline & State University of New York College at Old Westbury \\
\hline \multirow[t]{2}{*}{ North Carolina } & Elizabeth City State University \\
\hline & Winston-Salem State University \\
\hline
\end{tabular}




\begin{tabular}{|c|c|}
\hline North Dakota & $\begin{array}{l}\text { Dickinson State University } \\
\text { Mayville State University } \\
\text { Valley City State University }\end{array}$ \\
\hline Ohio & Central State University \\
\hline Oklahoma & $\begin{array}{l}\text { Langston University } \\
\text { Oklahoma Panhandle State University } \\
\text { University of Science and Arts of Oklahoma }\end{array}$ \\
\hline Pennsylvania & University of Pittsburgh Johnstown Campus \\
\hline Puerto Rico & $\begin{array}{l}\text { University of Puerto Rico-Aguadilla University College } \\
\text { University of Puerto Rico-Arecibo University College } \\
\text { University of Puerto Rico-Bayamon University College } \\
\text { University of Puerto Rico-Humacao University College } \\
\text { University of Puerto Rico-Ponce University College }\end{array}$ \\
\hline South Carolina & $\begin{array}{l}\text { University of South Carolina - Aiken } \\
\text { University of South Carolina Upstate }\end{array}$ \\
\hline South Dakota & $\begin{array}{l}\text { Black Hills State University } \\
\text { Dakota State University }\end{array}$ \\
\hline Texas & University of Houston - Downtown \\
\hline Vermont & Lyndon State College \\
\hline West Virginia & $\begin{array}{l}\text { Bluefield State College } \\
\text { Concord University } \\
\text { Fairmont State University } \\
\text { Glenville State College } \\
\text { Shepherd University } \\
\text { West Liberty State College } \\
\text { West Virginia State University } \\
\text { West Virginia University Institute of Technology }\end{array}$ \\
\hline
\end{tabular}


1. Job Title:

2. Number of years in current position, including this year:

**Please attach a copy of your vita with the survey? This will provide information regarding your academic credentials and your academic \& business experience. Thank you.

3. Have state appropriations increased or decreased from the previous academic year? By what percent?
Increased
$\% \quad$ Decreased
$\%$
No Change

4 Does your institution's governing board/body encourage or discourage entrepreneurial activities to generate revenue?
1
2
3
Strongly Encouraged
Encouraged Neutral
4
5
Discouraged Strongly Discouraged

5. Does your institution formally encourage or discourage faculty/staff initiatives in innovative and entrepreneurial activities?
Strongly Encouraged
2
3
4
5

If strongly encouraged or encouraged, does your institution use merit pay or other reward systems? Merit Pay

Other Reward Systems Please explain:

6. What administrative and/or organizational changes have been implemented over the last academic year?

Administrative and/or organizational restructuring.

Changes in decision-making authority patterns.

Creation of new positions in central administration.

Comments or other changes:

7. Please indicate whether any teaching, research, or service programs been added or eliminated since the previous academic year.

$\begin{array}{llcc}\text { Teaching programs } & \text { Number Added } & \text { Number Eliminated } & \text { No Change }(\checkmark) \\ \text { Research programs } & \\ \text { Service programs } & & & \\ \end{array}$

8. If applicable, please list any academic units that are supported by generating all or a portion of their own revenue for their programs and activities. If not applicable, indicate "None".

Name of Academic Unit

$\overline{ } \overline{ } \longrightarrow$

Percentage of Support Generated by Academic Unit

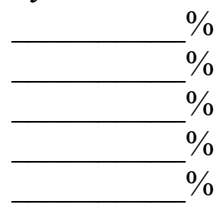

9. Are your employees represented by a union? Faculty?

Staff?

$\longrightarrow$ Yes $\longleftarrow$ No


10. Entrepreneurial Initiatives

For purposes of this study, entrepreneurship is defined as a market-oriented approach to managing institutions of higher education manifested through the creation of new ventures and new programs, along with innovative ways of performing traditional roles and responsibilities, with the objective of generating revenue for the institution.

This section identifies many potential institutional initiatives. For each initiative identified, please check $(\checkmark)$ the appropriate box indicating its use. Also, please check $(\checkmark)$ the level of success (in generating revenue) for each current new initiative, or traditionally used initiative at your institution.

\section{INITIATIVE}

1. Innovation/Entrepreneurship Center.

2. Small Business Development Center.

3. Incubation of start-up companies.

4. Product development services to business/industry.

5. Technical services to business/industry.

6. Personnel exchanges with business/industry.

7. Personnel exchanges with government agencies

8. Contract-training programs with business/industry.

9. Contract-training programs for government agencies.

10. Executive training programs for business/industry.

11. Specialized training programs and certificate programs for business/industry.

12. Research contracts with government agencies.

13. Research contracts with private sector enterprises.

14. Joint ventures or partnerships with private sector enterprises.

15. Technology transfer centers to patent, license and/or commercialize research outcomes.

16. Spin-off companies from research outcomes.

17. Distance-learning programs within existing organizational structure.

18. Distance-learning programs in partnership with private sector enterprises.

19. Distance-learning programs as for-profit subsidiaries.

20. Distance-learning programs funded through venture capital.

21. Evening degree offering programs.

22. Weekend degree offering programs.

23. Degree completion program.

24. Certificate programs.

25. Fast Track programs.

26. Executive programs.

27. College/university foundation to raise funds to support programs and services.

28. Alumni association to raise funds to support programs and services.

29. Initiated a capital campaign.

30. Sale of products and services from educational endeavors (e.g., logos and sports paraphernalia).

31. Licensing of products and services from educational endeavors (e.g., logos and sports paraphernalia).

32. Profit-sharing with food service, bookstores, and other auxiliary services.

33. Develop real estate ventures.

34. Debt financing, such as revenue bonds.

35. Develop or expand endowments.
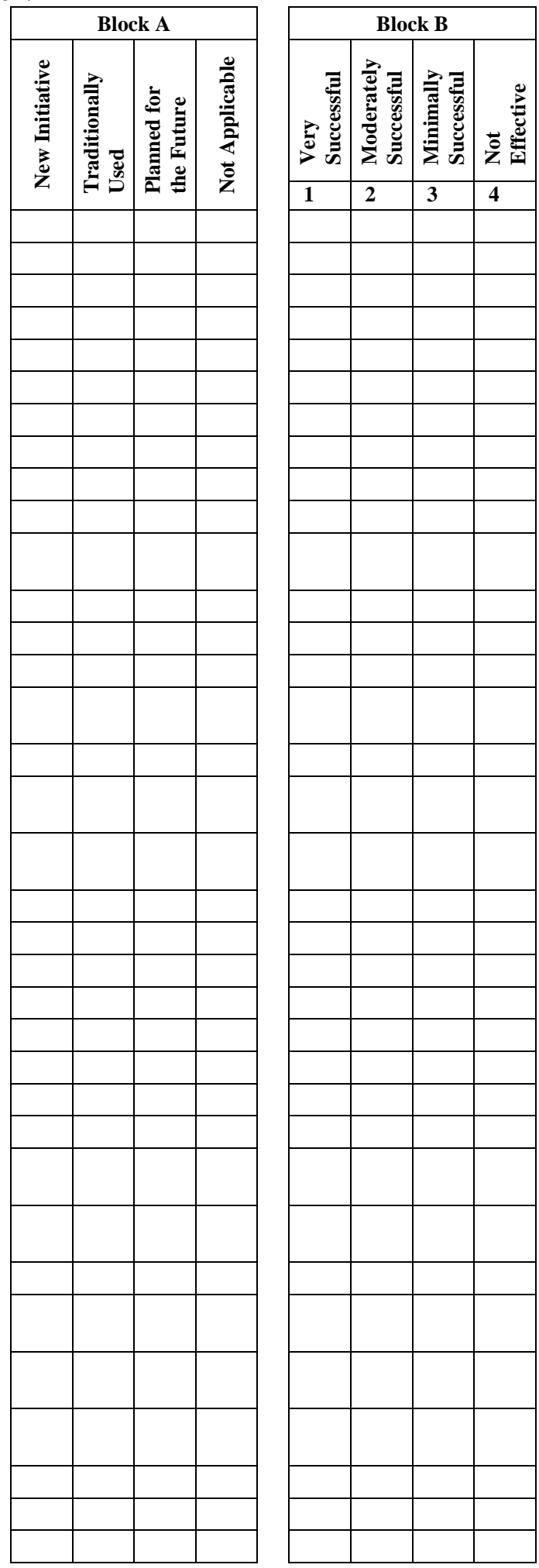


\begin{tabular}{|l|}
\hline INITIATIVE \\
\hline 36. Develop new revenues from sports/athletic events and activities. \\
\hline 37. Lease/rent institutional facilities and/or equipment. \\
\hline $\begin{array}{l}\text { 38. Retail sales of institutional resources, such as computer time and } \\
\text { internet access. }\end{array}$ \\
\hline 39. Catering food services. \\
\hline 40. Increasing tuition and fees. \\
\hline 41. Increasing residence fees. \\
\hline 42. Increasing cost of campus food services. \\
\hline 43. Increasing student laboratory, supplies, and other service fees. \\
\hline 44. Other: Please specify. \\
\hline 45. Other: Please specify. \\
\hline 46. Other: Please specify. \\
\hline 47. Other: Please specify. \\
\hline 48. Other: Please specify. \\
\hline
\end{tabular}
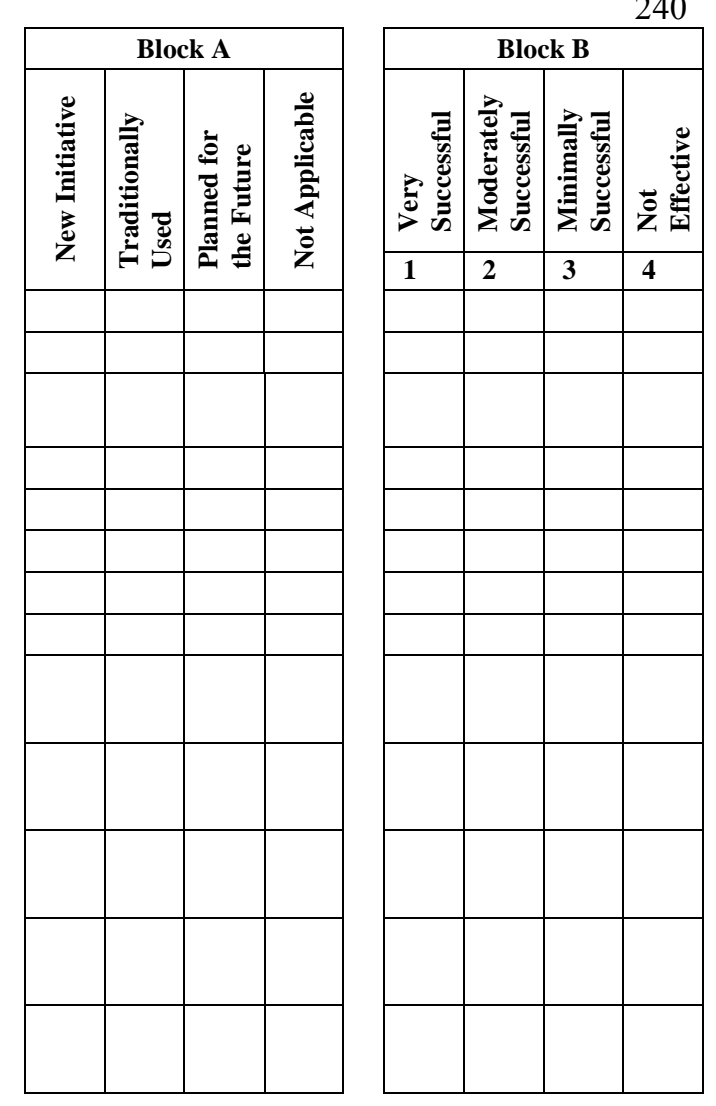

11. How many entrepreneurial activities have been initiated during your tenure?
0 to 4
5 to 9
10 to 14

15 or more

12. Has your institution's purpose and/or mission been changed or revised to reflect a greater emphasis on entrepreneurial activities?
If Yes, please explain
Yes
No

13. Are there any downsides to your institution's entrepreneurial programs or activities that you can identify?
If Yes, please explain
Yes No

14. Please provide any additional comments that you would consider important to understanding entrepreneurial activities or initiatives at your institution or at public liberals arts and public general baccalaureate institutions in general:

Thank you for taking the time to complete this survey. Again, please attach a copy of your vita?

Please be assured that all responses provided on this survey will remain confidential. Presentation of the statistical results from this survey will be in aggregate with no individual or institution identified. 


\title{
APPENDIX C
}

\author{
Initial Letter
}

[Date]

[West Virginia University Letterhead]

[Name]

[Address]

Dear :

As part of my doctoral degree in higher education administration, I am conducting a research study to investigate the current patterns of entrepreneurial activities in public liberal arts and general baccalaureate colleges as defined by the Carnegie Classification of Institutions of Higher Education.

For the purposes of this study, entrepreneurship will be defined as a market-oriented approach to managing institutions of higher education manifested through the creation of new ventures and new programs, along with innovative ways of performing traditional roles and responsibilities, with the objective of generating revenue for the institution.

With increasing and competing demands for government support and with legislative mandates calling for greater accountability in public higher education, institutions at all levels will need to become more creative, innovative, and entrepreneurial in finding ways to generate revenues. The implications for policy decisions, institutional planning, and institutional principles could be immense.

The literature has been primarily on community colleges and large research universities. Public liberal arts and general baccalaureate colleges are not presented in the literature on academic entrepreneurship. Nevertheless, these institutions are under the same government and economic pressure to be more entrepreneurial or market-oriented in order to generate financial support for continued viability.

Within the next two weeks, you will receive a survey "Entrepreneurial Roles and Expectations". This survey will ask you to comment on the present status of entrepreneurial activities at your institution. The data obtained from this survey will be used as part of my doctoral dissertation at West Virginia University in Morgantown, West Virginia.

Your participation in this study is voluntary and you do not have to respond to every item. Please be assured that all responses provided on this survey will remain confidential. A self-addressed stamped envelope will be provided for your convenience in returning the survey. Presentation of the statistical results from the survey will be in aggregate with no individual institution identifiable. appreciated.

Your thoughtful consideration in completing the survey you will be receiving is greatly

Sincerely,

Jack R. Kirby

Assistant Professor Business Administration

Fairmont State University 


\section{APPENDIX D \\ Cover Letter for Survey Instrument}

[Date]

[West Virginia University Letterhead]

[Name]

[Address]

Dear :

Within the last two weeks, you received a letter from me regarding a research study I am conducting as part of my doctoral degree in higher education administration. The purpose of this study is to investigate the current patterns of entrepreneurial activities in public liberal arts and general baccalaureate colleges as defined by the Carnegie Classification of Institutions of Higher Education.

For the purposes of this study, entrepreneurship will be defined as a market-oriented approach to managing institutions of higher education manifested through the creation of new ventures and new programs, along with innovative ways of performing traditional roles and responsibilities, with the objective of generating revenue for the institution.

Enclosed is the survey "Entrepreneurial Initiatives Survey", which asks you to comment on the present status of entrepreneurial activities at your institution. The data obtained from this survey will be used as part of my doctoral dissertation at West Virginia University in Morgantown, West Virginia.

Your participation in this study is voluntary and you do not have to respond to every item. Please be assured that all responses provided on this survey will remain confidential. A self-addressed stamped envelope will be provided for your convenience in returning the survey. Presentation of the statistical results from the survey will be in aggregate with no individual institution identifiable.

The survey should not take more than 20 minutes to complete. Your response is important in assessing how public liberal arts and general baccalaureate institutions are responding to increasing pressures to find alternative sources of funding in light of increasing and competing demands for government support.

Please complete and return this survey within 10 days of receipt. If you have any questions, or would like additional information regarding the purpose or procedure of this study, please feel free to contact me by phone at (304) 367-4223 or by e-mail at jkirby@fairmontstate.edu.

Following completion of this study, I will be forwarding an executive summary of the highlights of the findings, as well as conclusions relevant to the research project, to the individuals that participated. Thank you for your consideration and response to this survey and assisting me in completing this research.

Sincerely,

Jack R. Kirby

Assistant Professor Business Administration

Fairmont State University 


\section{APPENDIX E}

Follow-up Letter

[Date]

[West Virginia University Letterhead]

[Name]

[Address $\}$

Dear :

Recently you should have received a survey instrument "Entrepreneurial Initiatives Survey" to complete. This instrument was designed to obtain information regarding the current patterns of entrepreneurial activities in public liberal arts and general baccalaureate colleges as defined by the Carnegie Classification of Institutions of Higher Education.

The data obtained from this research study will be used as part of my doctoral dissertation at West Virginia University in Morgantown, West Virginia.

To date, I have not received your completed survey. If you have completed and mailed your survey, please disregard this request. Your contribution to this study is important to provide the best representation from all segments of the targeted population.

I would greatly appreciate receiving your completed survey at your earliest convenience. If for some reason you did not receive the survey or have misplaced the original, I am enclosing another survey to assist you. Please feel free to contact me at Fairmont State University (304) 367-4223, or by e-mail at jkirby@fairmontstate.edu, if you have any questions regarding the research or the survey.

Your participation in this study is voluntary and you do not have to respond to every item. Please be assured that all responses provided on this survey will remain confidential. A self-addressed stamped envelope will be provided for your convenience in returning the survey. Presentation of the statistical results from the survey will be in aggregate with no individual institution identifiable.

I recognize that there are many demands on your time. It is my hope that this research will provide useful and meaningful results that can be helpful in meeting today's challenges in our institutions of higher education.

Thank you for your cooperation in completing and returning this survey.

Sincerely,

Jack R. Kirby

Assistant Professor Business Administration

Fairmont State University 


\title{
APPENDIX F
}

Contact Information for Survey Recipients

Source: 2004 Higher Education Directory

\author{
Dr. Peter Smith \\ President \\ California State University - Monterey Bay \\ 100 Campus Center \\ Seaside, CA 93955-8000 \\ Dr. Robert Dolphin, Jr. \\ Interim President \\ Fort Lewis College \\ 1000 Rim Drive \\ Durango, CO 81301-3999 \\ Dr. Samuel B. Gingerich \\ Interim President \\ Mesa State College \\ 1100 North Avenue \\ Grand Junction, CO 81501-3122 \\ Dr. Jay Helman \\ President \\ Western State College \\ Gunnison, CO 81231-0001 \\ Dr. Merle Harris \\ President \\ Charter Oak State College \\ 55 Paul Manafort Drive \\ New Britain, CT 06053-2142 \\ Dr. Gordon Michalson, Jr. \\ President \\ New College of Florida \\ 5700 North Tamiami Trail \\ Sarasota, FL 34243-2197 \\ Dr. Rose Tseng \\ Chancellor \\ University of Hawaii at Hilo \\ 200 West Kawili Street \\ Hilo, HI 96720-4091
}


Dr. William Pearman

Chancellor

University of Hawaii West Oahu

96-129 Ala Ike

Pearl City, HI 96782-3699

Dr. Nancy Hensel

President

University of Maine at Presque Isle

181 Main Street

Presque Isle, ME 04769-2888

Dr. Jane O'Brien

President

St. Mary's College of Maryland

18952 E. Fisher Road

Saint Mary's City, MD 20686-3001

Dr. Mary Grant

President

Massachusetts College of Liberal Arts

375 Church Street

North Adams, MA 01247-4100

Dr. Samuel Schuman

Chancellor

University of Minnesota - Morris

600 East $4^{\text {th }}$ Street

Morris, MN 56267-2134

Dr. Thomas Rocco

President

College of Lifelong Learning

125 N. State Street

Concord, NH 03301-6400

Dr. Herman Saatkamp, Jr.

President

The Richard Stockton College of New Jersey

PO Box 195

Pomona, NJ 08240-0195 
Dr. James Mullen

Chancellor

University of North Carolina at Asheville

1 University Heights

Asheville, NC 28804-8503

Dr. Rita Morris

President

Shawnee State University

940 Second Street

Portsmouth, $\mathrm{OH}$ 45662-4344

Dr. William Shields

Interim President

University of Pittsburgh at Bradford

300 Campus Drive

Bradford, PA 16701-2812

Dr. Frank Cassell

President

University of Pittsburgh Greensburg Campus

1150 Mt. Pleasant Road

Greensburg, PA 15601-5860

Dr. Ronald Ingle

President

Coastal Carolina University

PO Box 261954, 755 Hwy 544

Conway, SC 29528-6054

Dr. W. Michael Kemp

Vice President \& CEO

Texas A \& M University at Galveston

PO Box 1675

Galveston, TX 77553-1675

Sen. Paul Trible

President

Christopher Newport University

1 University Place

Newport News, VA 23606-2998 
Dr. Steven Kaplan

Chancellor

The University of Virginia's College at Wise

1 College Avenue

Wise, VA 24293-4412

Gen. J. H. Benford

Superintendent

Virginia Military Institute

Lexington, VA 24450-0304

Dr. Thomas Purce

President

The Evergreen State College

2700 Evergreen Parkway NW

Olympia, WA 98505-0005

Dr. Rafael Aragunde

Chancellor

University of Puerto Rico - Cayey University College

Ave. Antonio R Barcelo

Cayey, PR 00736

Dr. Jerry Bartlett

President

Athens State University

300 North Beaty Street

Athens, AL 35611-1902

Dr. Fred Taylor

Chancellor

University of Arkansas at Monticello

Monticello, AR 71656-3596

Dr. Lawrence Davis

Chancellor

University of Arkansas at Pine Bluff

1200 North University Drive

Pine Bluff, AR 71601-2799

Dr. Raymond Kieft

Interim President

Metropolitan State College of Denver

PO Box 173362

Denver, CO 80217-3362 
Dr. Dene Thomas

President

Lewis-Clark State College

500 8th Avenue

Lewiston, ID 83501-2698

Dr. David Fulton

Chancellor

Indiana University East

2325 Chester Boulevard

Richmond, IN 47374-1289

Dr. Ruth Person

Chancellor

Indiana University Kokomo

2300 S. Washington, Box 9003

Kokomo, IN 46904-9003

Dr. Theodora Kalikow

President

University of Maine at Farmington

224 Main Street

Farmington, ME 04938-1911

Dr. Richard Cost

President

University of Maine at Fort Kent

23 University Drive

Fort Kent, ME 04743-1292

Dr. Sue Ann Huseman

Interim President

University of Maine at Machias

9 O'Brien Avenue

Machias, ME 04654-1397

Dr. David Danahar

President

Southwest Minnesota State University

1501 State Street

Marshall, MN 56258-1598 


\author{
Dr. Velmer Burton \\ Chancellor \\ University of Minnesota - Crookston \\ 2900 University Avenue \\ Crookston, MN 56716-5001 \\ Dr. Lester Newman \\ President \\ Mississippi Valley State University \\ 14000 Highway 82 West \\ Itta Bena, MS 38941-1400 \\ Dr. Julio Leon \\ President \\ Missouri Southern State University-Joplin \\ 3950 East Newman Road \\ Joplin, MO 64801-1595 \\ Dr. James Scanlon \\ President \\ Missouri Western State College \\ 4525 Downs Drive \\ Saint Joseph, MO 64507-2294 \\ Dr. Karl Ulrich \\ Interim Chancellor \\ The University of Montana - Western \\ Dillon, MT 59725-3598 \\ Dr. Karol Lacroix \\ Dean \\ University of New Hampshire at Manchester \\ 400 Commercial Street \\ Manchester, NH 03101-1113 \\ Dr. Rodney Smith \\ President \\ Ramapo College of New Jersey \\ 505 Ramapo Valley Road \\ Mahwah, NJ 07430-1680
}


Dr. Edison Jackson

President

City University of New York Medgar Evers College

1650 Bedford Avenue

Brooklyn, NY 11225-2010

Dr. Russell Holtzer

President

City University of New York York College

94-20 Guy Brewer Boulevard

Jamaica, NY 11451-0001

Dr. Calvin Butts, III

President

State University of New York College at Old Westbury

Box 210, 223 Store Hill Road

Old Westbury, NY 11568-0210

Dr. Mickey Burnim

Chancellor

Elizabeth City State University

1704 Weeksville Road

Elizabeth City, NC 27909-7806

Dr. Harold Martin

Chancellor

Winston-Salem State University

601 MLK Jr. Drive, Campus Box 19535

Winston-Salem, NC 27110-0001

Dr. Lee Vickers

President

Dickinson State University

Dickinson, ND 58601-4896

Dr. Pamela Balch

President

Mayville State University

330 3rd Street, NE

Mayville, ND 58257-1299

Dr. Ellen Chaffee

President

Valley City State University

101 College Street SW

Valley City, ND 58072-4098 


\author{
Mr. John Garland \\ President \\ Central State University \\ PO Box 1004, 1400 Brush Row Road \\ Wilberforce, $\mathrm{OH}$ 45384-9999 \\ Dr. Ernest Holloway \\ President \\ Langston University \\ PO Box 907 \\ Langston, OK 73050-0907 \\ Dr. David Bryant \\ President \\ Oklahoma Panhandle State University \\ Box 430 \\ Goodwell, OK 73939-0430 \\ Dr. John Feaver \\ President \\ University of Science and Arts of Oklahoma \\ 1727 West Alabama \\ Chickasha, OK 73018-5322 \\ Dr. Albert Etheridge \\ President \\ University of Pittsburgh Johnstown Campus \\ 450 Schoolhouse Road \\ Johnstown, PA 15904-2990 \\ Dr. Thomas Hallman \\ Chancellor \\ University of South Carolina - Aiken \\ 471 University Parkway \\ Aiken, SC 29801-6399 \\ Dr. John Stockwell \\ Chancellor \\ University of South Carolina Upstate \\ 800 University Way \\ Spartanburg, SC 29303-4996
}


Dr. Thomas Flickema

President

Black Hills State University

1200 University Street

Spearfish, SD 57783-1743

Dr. Jerald Tunheim

President

Dakota State University

820 North Washington

Madison, SD 57042-1799

Dr. Max Castillo

President

University of Houston - Downtown

1 Main Street

Houston, TX 77022-1014

Dr. Carol Moore

President

Lyndon State College

1001 College Road, PO Box 0919

Lyndonville, VT 05851-0919

Dr. Albert Walker

President

Bluefield State College

219 Rock Street

Bluefield, WV 24701-2198

Dr. Jerry Beasley

President

Concord University

PO Box 1000

Athens, WV 24712-1000

Dr. Daniel Bradley

President

Fairmont State University

1201 Locust Avenue

Fairmont, WV 26554-2470 
Dr. Robert Freeman

Interim President

Glenville State College

200 High Street

Glenville, WV 26351-1292

Dr. David Dunlop

President

Shepherd University

PO Box 3210

Shepherdstown, WV 25443-3210

Dr. Richard Owens

President

West Liberty State College

PO Box 295

West Liberty, WV 26074-0295

Dr. Hazo Carter, Jr.

President

West Virginia State University

PO Box 1000

Institute, WV 25112-1000

Dr. Karen Laroe

President

West Virginia University Institute of Technology

Montgomery, WV 25136

Prof. Pablo Rodriguez

Chancellor

University of Puerto Rico - Aguadilla

PO Box 250160

Aguadilla, PR 00604-0160

Prof. Edwin Hernandez

Chancellor

University of Puerto Rico - Arecibo University College

Box 4010

Arecibo, PR 00614-4010

Dr. Andres Rodriguez-Rubio

Chancellor

University of Puerto Rico - Bayamon University College

Carretera Num. 174, Km. 2.8

Bayamon, PR 00959-1919 
Dra. Hilda Colon

Chancellor

University of Puerto Rico - Humacao University College

Bo. Tejas Estacion Postal CUH

Humacao, PR 00791

Prof. Jaime Marrero

Chancellor

University of Puerto Rico at Ponce

PO Box 7186

Ponce, PR 00732-7186 